Florida International University FIU Digital Commons

\title{
The attribution of motives to organizational citizenship behaviors : the influence of personality, gender and ethnicity
}

Alexander Alonso

Florida International University

DOI: $10.25148 /$ etd.FI13101601

Follow this and additional works at: https://digitalcommons.fiu.edu/etd

Part of the Psychology Commons

\section{Recommended Citation}

Alonso, Alexander, "The attribution of motives to organizational citizenship behaviors : the influence of personality, gender and ethnicity" (2003). FIU Electronic Theses and Dissertations. 1108.

https://digitalcommons.fiu.edu/etd/1108 
FLORIDA INTERNATIONAL UNIVERSITY

Miami, Florida

THE ATTRIBUTION OF MOTIVES TO ORGANIZATIONAL

CITIZENSHIP BEHAVIORS: THE INFLUENCE OF

PERSONALITY, GENDER AND ETHNICITY

A dissertation submitted in partial fulfillment of the

requirements for the degree of

DOCTOR OF PHILOSOPHY

in

PSYCHOLOGY

by

Alexander Alonso 
To: Dean Arthur W. Herriott

College of Arts and Sciences

This dissertation, written by Alexander Alonso, and entitled The Attribution of Motives to Organizational Citizenship Behaviors: The Influence of Personality, Gender and Ethnicity, having been approved in respect to style and intellectual content, is referred to you for judgment.

We have read this dissertation and recommend that it be approved.

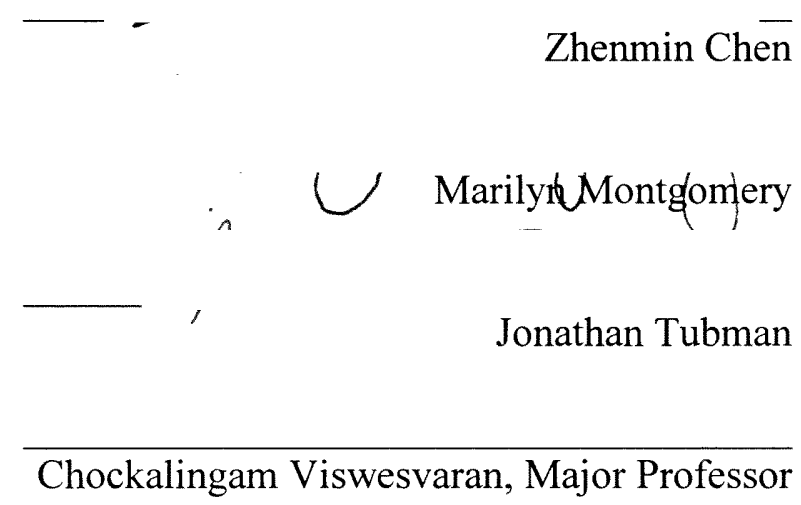

Date of Defense: March 18, 2003

The dissertation of Alexander Alonso is approved.

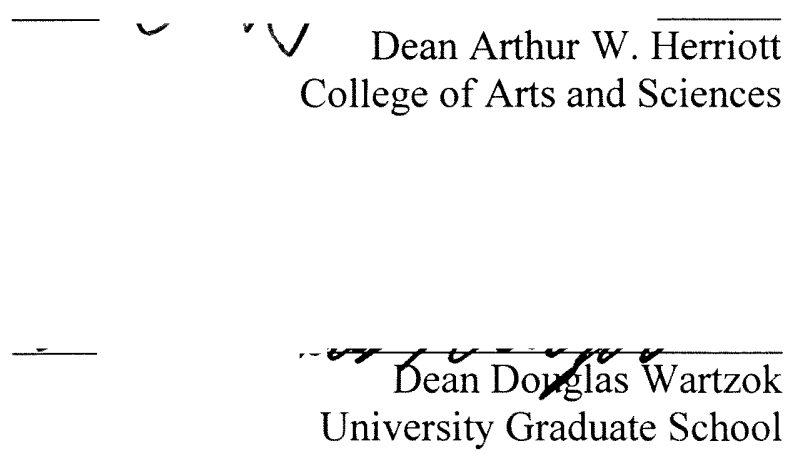

Florida International University, 2003 
(C) Copyright 2003 by Alexander Alonso

All rights reserved. 


\section{DEDICATION}

To my wife, Susie, who has put up with me for this long. I hope she puts up with me forever. 


\section{ACKNOWLEDGMENTS}

I sincerely thank my committee members: Jonathan G. Tubman, Marilyn Montgomery, and Zhenmin Chen for their guidance and support in seeing me through this process. I would also like to acknowledge the kindness of other professors and students who allowed me to come their classes and collect data. These individuals include Robert Beneckson, Ryann Haw, Tara Mitchell, Armando Pina, Lissette SaavedraRodriguez, Melissa Russano, Kevin W. Brown, Leslie A. DeChurch, and Fred Panzer. Without their help I could not have gained access to the sample in this dissertation.

I would also like to acknowledge all those whose efforts have helped my education at Florida International University in an indirect manner. Dr. Michelle Marks, for all your kindness and willingness to force me to learn, I thank you. Dr. Juan I. Sanchez, for your sense of humor and uncanny ability to drive home a point, I thank you. Leslie DeChurch, for your ability to make me feel as though I have learned something but not necessarily enough, I thank you. Fred Panzer, without your ability to come up with a new "panzerism" graduate school would have been endless. Thank you. Julio Fernandez de Cueto, for your ability to listen and for being the one student who knew me better than any other, thank you. Mark J. Sabella, for being the classiest individual I have ever come across, thank you. Jackie Royer, for helping understand the mammoth logistic effort that goes with a thesis or dissertation, thank you. All these individuals invested time and effort in me and I thank them for it.

I would like to acknowledge David Van Rooy whom I failed to notice toward the beginning of his graduate career. However, as time progressed David became an exceptional student, a consummate collaborator, and a true friend. David and I have 
worked on more than four studies in the past year. You are my favorite colleague and I thank you for it.

Finally, I would like to acknowledge my major professor, Dr. Chockalingam Viswesvaran, who has an uncanny ability to make something from what seems to be nothing. No one person has devoted more time and effort to my education than Vish. $\mathrm{He}$ is truly the most intelligent and savvy person with whom I have ever come in contact. For all of his qualities that I have listed and those I have not, I admire him. Thank you for letting me to be your student. 


\section{ABSTRACT OF THE DISSERTATION \\ THE ATTRIBUTION OF MOTIVES TO ORGANIZATIONAL \\ CITIZENSHIP BEHAVIORS: THE INFLUENCE OF \\ PERSONALITY, GENDER AND ETHNICITY \\ by}

Alexander Alonso

Florida International University, 2003

Miami, Florida

Professor Chockalingam Viswesvaran, Major Professor

A major area of research in the realm of Industrial/Organizational Psychology is the exploration of specific job performance behaviors such as organizational citizenship behaviors (OCBs). However, there is a dearth of research examining how peers react to OCBs and the performers of such behaviors. Bolino noted that determining how people attribute motives to these OCBs is an important yet unanswered question in industrial/organizational psychology. The present study attempted to provide insight on what observer (or rater) traits affect the motives attributed to organizational citizenship behaviors. In particular, the effects of personality traits such as the Big Five personality factors, self-monitoring, individualism-collectivism, negative affectivity and identity factors such as cultural mistrust, ethnic orientation, and perceived similarity were examined. A within-subjects survey design was used to collect data on six hypothetical organizational citizenship behaviors from a sample of 369 participants. The gender and ethnicity of the individuals performing the hypothetical organizational citizenship 
behaviors were manipulated (i.e., male or female; African-American, Hispanic, or White).

Results indicated that both similarity $(\mathrm{t}(368)=5.13 ; \mathrm{p} .01)$ and personality factors $\left(\mathrm{R}^{2}=\right.$ .06 for genuine motives and $\mathrm{R}^{2}=.05$ for self-serving motives) had an effect on which motive (genuine or self-serving) was attributed to organizational citizenship behaviors. Support was found for an interaction between similarity and the observer's personality trait of conscientiousness when attributing genuine motives to organizational citizenship behaviors. Finally, specific organizational citizenship behaviors such as altruism were linked to genuine motives while OCBs like conscientiousness, sportsmanship, and civic virtue were associated with self-serving motives. 


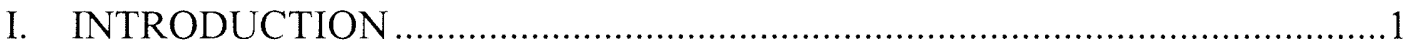

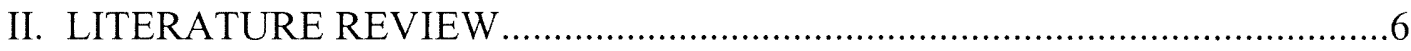

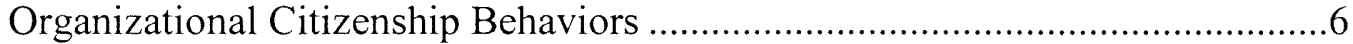

Motives and Organizational Citizenship Behavior ............................................11

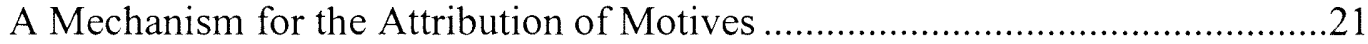

A New General Framework for the Attribution of Motives ...............................26

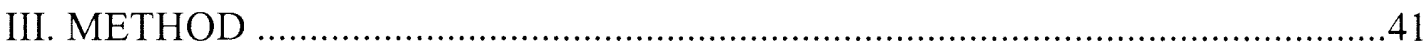

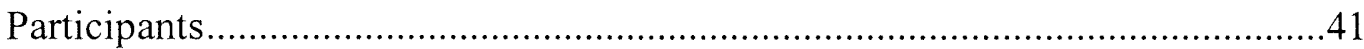

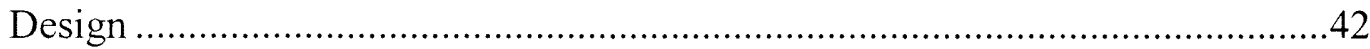

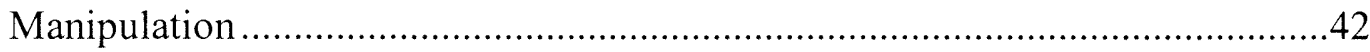

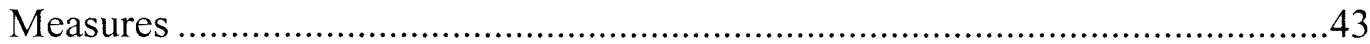

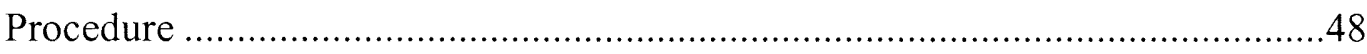

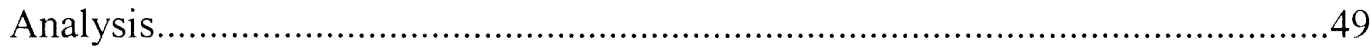

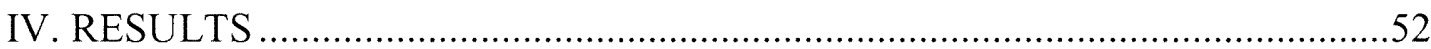

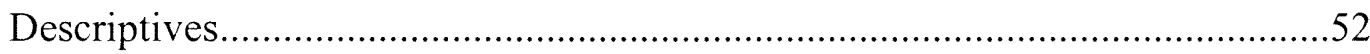

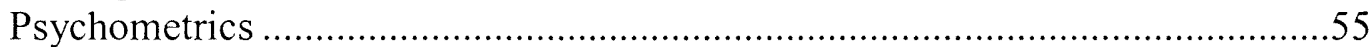

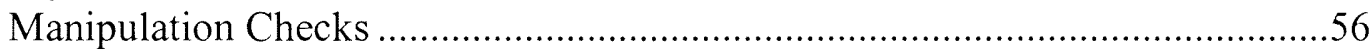

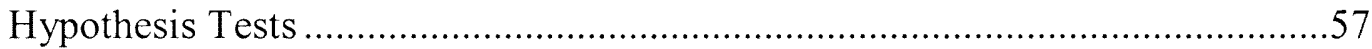

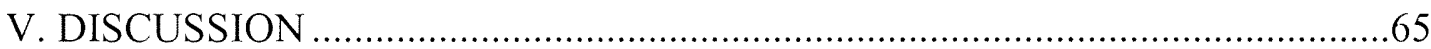

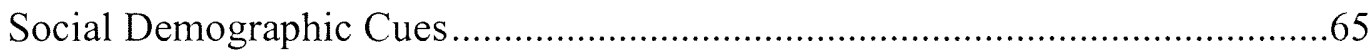

Genuine versus Self-Serving Motives and OCBs ...........................................67

Personality, Similarity, and Potential Interactions............................................ 71

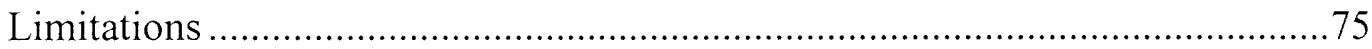

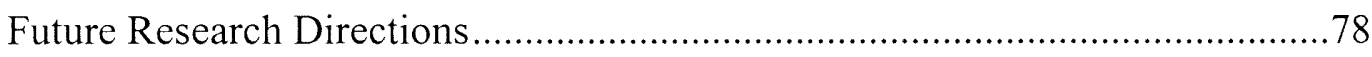

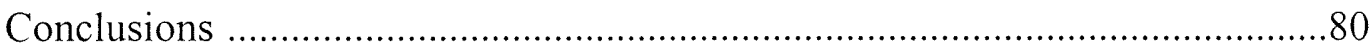

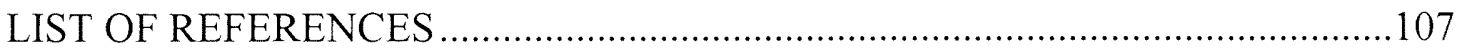

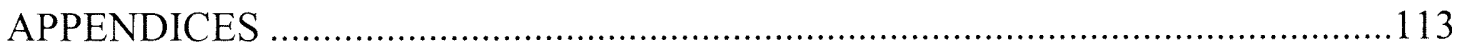

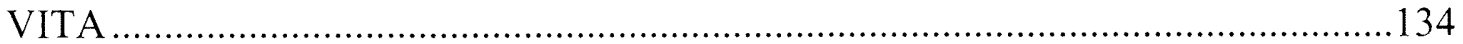


1. Multiple Definitions of Organizational Citizenship Behaviors and Constructs ..81

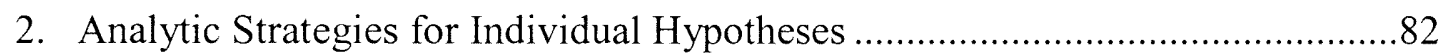

3. Descriptive Statistics for Key Study Variables................................................83

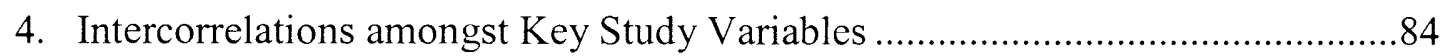

5. Mean Differences between Similar and Dissimilar Individuals (Test of Hypothesis 1 \& 2)

6. Hierarchical Regression Analysis for Key Study Variables Predicting the Attribution of Genuine Motives.

7. Hierarchical Regression Analysis for Key Study Variables Predicting the Attribution of Self-Serving Motives

8. Correlations between Genuine Motives, Self-Serving Motives, and Key Personality Variables for Similar Individuals.

9. Correlations between Genuine Motives, Self-Serving Motives, and Key Personality Variables for Dissimilar Individuals

10. Comparison between Personality Correlations for Similar versus Dissimilar Individuals

11. Analysis of Variance Table for Moderating Effects of Similarity on the Relationship between Conscientiousness and Genuine Motives

12. Analysis of Variance Table for Moderating Effects of Similarity on the Relationship between Ethnic Orientation and Self-Serving Motives

13. Intercorrelations among Genuine Motives, Self-Serving Motives, and Organizational Citizenship Behavior Dimensions ....

14. Mean Comparisons of the Attribution of Genuine versus Self-Serving Motives for Specific Organizational Citizenship Behavior Dimensions .94

15. Summary of Findings .95 


\section{LIST OF FIGURES}

FIGURE

PAGE

1. Organ and Ryan's (1995) Model of Organizational Citizenship Behaviors.......96

2. Borman and Motowidlo's $(1993 ;$ 1997) Model of Contextual Performance.......97

3. Leary and Kowalski's (1990) Model of Impression Management....................98

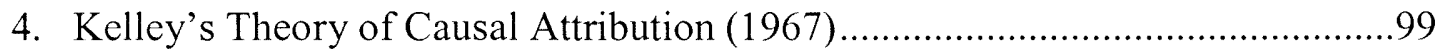

5. Turner's Model of Social Categorization Theory (1987) ............................100

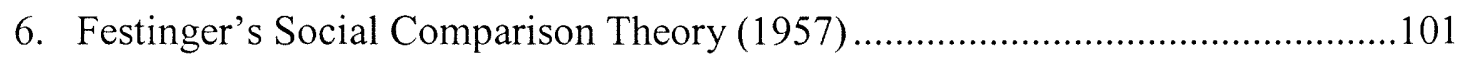

7. A New Integrated Framework for the Attribution of Motives.........................102

8. Plot of the Interaction between Conscientiousness and Similarity (C X S) When Predicting the Attribution of Genuine Motives.

9. Plot of the Interaction between Ethnic Orientation and Similarity (EO X S)

When Predicting the Attribution of Self-Serving Motives. 103 
The primary focus of many researchers in industrial/organizational psychology has been criteria like job performance (Austin \& Villanova, 1992; Borman \& Motowidlo, 1993; Organ, 1990). However, researchers (Bateman and Organ, 1983; Borman and Motowidlo, 1993; Organ, 1988; 1990) have narrowed the focus on performance to specific types or dimensions of job performance such as contextual performance, organizational citizenship behaviors (OCBs), and prosocial behaviors. In essence, these researchers have focused on performance behaviors that are "above and beyond the call of duty set by the organization" (Van Scotter \& Motowidlo, p.525, 1996). Although these behaviors are different to some degree, they are all above and beyond the call of duty, unlike task performance, which is considered the "minimum performance required to do the job" (Borman, White, \& Dorsey, p. 169, 1995). Researchers who have looked at contextual performance, OCBs, and prosocial behaviors have made efforts to understand how to best predict these behaviors (Borman \& Motowidlo, 1993; Organ, 1988; 1990; Organ \& Ryan, 1995; Podsakoff, MacKenzie, Moorman, \& Fetter, 1990; Van Scotter \& Motowidlo, 1996). The predominant focus of researchers in this area has been on the traditional antecedents (e.g., cognitive ability, conscientiousness, extroversion, leadership) of these behaviors; researchers have also investigated how these behaviors influence performance evaluations (Borman, White, \& Dorsey, 1995; Findley, Giles, \& Mossholder, 2000; Kiker \& Motowidlo, 1999) and have attempted to relate these behaviors to other outcome variables such as organizational effectiveness (Bolino, 1999; Griffin, Neal, \& Neale, 2000; Wright, George, Farnsworth, \& McMahan, 1993). 
Recently, however, some researchers (e.g., Bolino, 1999; Leary \& Kowalski 1990) have called into question the emphasis on predicting OCBs using traditional variables like cognitive ability or dispositional factors (e.g., affect) or personality variables such as the Big Five personality factors (Barrick \& Mount, 1991). This call is based on a contention that these behaviors (OCBs) are driven by motives that are selfserving in nature. Bolino (1999) has asked if OCBs are driven by a desire to "do good" or to "look good". In other words, are these performers good soldiers (Organ, 1990) or good actors (Eastman, 1994; Leary and Kowalski, 1990)? This contention is founded on the tenets of self-monitoring (Snyder, 1974), ingratiatory tactics (Jones, 1964), and impression management (Kumar \& Beyerlein, 1991). The reasoning stems from the hypothesis that OCBs can be motivated by a desire to be evaluated as a better performer and that this desire is driven by a need to manage one's impression on others and monitor one's self image; this is also achieved by using OCBs as ingratiatory tactics (Jones \& Pittman, 1982; Wayne \& Ferris, 1990). OCBs are often used to make one look better to performance evaluators in organizational settings (i.e., self-serving motives) (Bolino, 1999) to obtain rewards, promotions (or careerism), increased trust, and positive interviewee impressions (Jones, 1964; Wayne \& Liden, 1995). However, inferences from this research are limited because of the possibility that OCBs may be driven by motives that are genuine and not self-serving in nature (Bolino, 1999; Jones \& Pittman, 1982; Tedeschi \& Melburg, 1984). Moreover, the focus is primarily on OCBs intended to be observed by those who exert power over desirable outcomes, (e.g., rewards, promotions, feedback (Bolino, 1999). 
Although understanding the motives of OCB is still an important topic, I believe that this topic has been examined too narrowly. Previous researchers such as Wayne and Ferris (1992) and Eastman (1994) have examined motives for citizenship behaviors from the performer's and the performance evaluator's points of view. In other words, motives have been measured using the impressions of the person doing the evaluation of performance as well as the self-reported motives of the performers themselves. Both present several problems. First, it is likely that social desirability (Paulhus, 1984) will influence the responses when performers are asked to indicate whether they are performing these citizenship behaviors to serve themselves or to earnestly help others and their organization. Second, those who appraise performance cannot possibly observe all behaviors performed by all performers. Third, it is possible that different motives can drive citizenship behaviors when the performers know that those behaviors are being observed by performance evaluators as compared to when the performers are unaware of being observed. For instance, it is possible that when being observed by performance evaluators, OCBs might be motivated by self-serving motives. However, when other audiences are involved (e.g., co-workers) self-serving motives may not be the motivation behind OCBs. Finally, when dealing with OCBs, it is possible that not all citizenship behaviors are geared towards directly aiding organizations. Essentially, some behaviors such as helping others with their work tasks (Organ, 1990) are more likely directed towards helping individuals and only indirectly helping the organization. When this direct effect on others is combined with the fact that performance evaluators cannot witness all OCBs, it becomes apparent that the impression made on other audiences such as peers and, more specifically, recipients of OCBs (who may be other than performance 
appraisers) is an important factor in understanding the interpretation of motives for citizenship behaviors (Bolino, 1999). In other words, in order to understand the distinction between self-serving motives and genuine motives, one should also examine the perceptions of the recipients as well as audiences other than performance appraisers. These perceptions are important for a variety of reasons such as the increasing use of teams in organizations and the existence of employee conflicts (DeChurch \& Marks, 2001; Simons \& Peterson, 2000). For example, conflict within teams will be approached differently if coworkers interpret actions as self-serving instead of genuine in nature (Sternberg \& Dobson, 1987).

The purpose of the proposed study is to examine the motives behind OCBs as interpreted by audiences such as secondary performance evaluators (e.g., coworkers). The goal is to see if these secondary performance evaluators (with the primary observer being the performance evaluator) will interpret motives as either self-serving or genuinely altruistic in nature. A secondary goal of this study is to determine whether or not these interpretations can be explained by interpreter characteristics such as affect, self-monitoring, individualism-collectivism, locus of control, conscientiousness, agreeableness, extroversion, emotional stability, and openness to experience. Finally, a tertiary goal is to determine whether or not these interpretations can be predicted by similarity or homogeneity in ethnicity and/or gender with the performer and the observer of the citizenship behaviors. This will provide insight into whether interpretations of motives behind citizenship behaviors can be predicted by both compositional factors such as gender and ethnicity similarity as well as by dispositional factors of the observer such as the Big Five personality factors, locus of control, self-monitoring, individualism- 
collectivism, and positive-negative affectivity. As stated earlier, this question is important because of the implications associated with conflict and other organizational issues. In order to address this issue, it is important to first provide understanding of the OCB framework advanced by researchers such as Borman and Motowidlo (1993) and Bateman and Organ (1982). It is also necessary to discuss the relationship between these behaviors and two differing motives: 1) self-serving motives and 2) genuine motives. Moreover, it is important to review the mechanisms by which these motives are derived and attributed (i.e., self-monitoring, impression management, attribution theory, and social comparison process). Finally, an integrated framework of compositional and dispositional factors, and the relationship between them, and attribution of motives will be discussed and tested. 


\section{CHAPTER 2: Literature Review}

To understand the attribution of motives to organizational citizenship behaviors $(\mathrm{OCBs})$, it is necessary to review the extant literature in a few topic areas such as organizational citizenship behaviors and similar constructs (e.g., contextual performance, impression management, and attribution processes). I begin by reviewing the literature on organizational citizenship behaviors before proceeding to discuss the relationship between motives and OCBs. Next, I discuss the process for the attribution of motives as it relates OCB. Finally, I provide a general framework by which motives such as selfserving and/or genuine are attributed based on compositional (i.e., gender and ethnicity) and dispositional factors (i.e., Big Five personality factors, locus of control, selfmonitoring, individualism-collectivism, and positive-negative affectivity).

\section{Organizational Citizenship Behaviors (OCBs)}

For years the focus of studies with performance as a dependent variable or criterion was fixed on task performance (Borman \& Motowidlo, 1993). Austin and Villanova (1992) conducted a review of how job performance has been conceptualized as a criterion since 1917 . One proposition made by these researchers is that the criterion domain may not be the same for all jobs and for all organizations. Moreover, they noted that there are prescribed and non-prescribed behaviors that fall into the criterion domain. This proposition has been evaluated by a variety of researchers who have developed constructs to provide a better understanding of non-prescribed behaviors of job performance (Bateman \& Organ, 1983; Borman \& Motowidlo, 1993; Organ, 1990). The works of these researchers is examined next. 
There are behaviors performed on the job that are not prescribed by the organization as job performance (Organ, 1990); in order to understand what behaviors fall under this category, one must examine the different constructs (i.e., organizational citizenship behaviors, contextual performance, prosocial behaviors, and extra-role behaviors) that have been advanced for this very purpose. To understand each of these constructs, and how they relate to one another, is vital to understand which behaviors are not prescribed by the organization but may be conducive to organizational performance over time. It is also important to determine the overlap between these constructs and assess which of these can be considered the most comprehensive (Alonso, Viswesvaran, \& Sanchez, 2001; Conway, 1999). This would guide an informed choice of what construct to focus in this dissertation.

Bateman and Organ (1983) were the first to explicitly discuss organizational citizenship behaviors (OCBs). They defined OCBs as actions that are "discretionary, not directly, or explicitly recognized by the formal reward system, and that in the aggregate promotes the effective functioning of the organization" (Bateman \& Organ, 1983, p. 588; Organ, 1988) (See Table 1). Furthermore, discretionary infers that the "behavior is not an enforceable requirement of the role or the job description, that is, the clearly specifiable terms of the person's employment contract with the organization; the behavior is rather a matter of personal choice, such that its omission is not generally understood as punishable (p. 590)." Behavior such as staying late at work, offering to help a supervisor (or co-worker) with their workload and taking on extra work during the absence of a coworker represent various forms of OCBs. Morrison (1994) identified two general dimensions of OCBs: altruism and compliance. Altruism refers to behaviors that are 
directed towards others (i.e., peers, subordinates, and supervisors) in an effort to aid or help the individual. Compliance behaviors are those directed towards improving the well being of the organization. Later, Organ (1990) revised this two-dimension framework into a five dimensions: 1) altruism, 2) conscientiousness, 3) courtesy, 4) sportsmanship, and 5) civic virtue. Altruism refers to helping others, conscientiousness describes behaviors that surpass enforceable standards of the organizations, courtesy depicts situations where "touching base" with others occurs before taking actions or making decisions (Bolino, 1999), sportsmanship covers those actions that entail tolerating nuisances on the job, and civic virtue entails taking an active participation in company affairs (e.g., company dinners). This framework has been subsequently backed by more evidence (e.g., MacKenzie, Podsakoff, and Fetter, 1991).

Borman and Motowidlo (1993) took a different approach to these kinds of behaviors. They termed these behaviors "contextual performance" or behaviors that go "above and beyond the call of duty and are not prescribed by the organization as task performance" (Borman \& Motowidlo, 1993; Motowidlo \& Van Scotter, 1994, p. 475). They noted that individuals contribute to organizational effectiveness by performing in ways that benefit the organization and that are not main task functions, but still help shape the organizational landscape and the social "context" that supports prescribed tasks (Organ \& Ryan, 1995). Like OCBs, contextual performance includes contributions such as volunteering for extra-job activities, aiding troubled workers, and upholding the standards of the organizations regardless of whether they inconvenience one's self. Van Scotter and Motowidlo (1996) assessed the construct of contextual performance and found support for two dimensions that comprise the construct (a part of overall 
performance when taken into account with task performance). These dimensions were termed interpersonal facilitation and job dedication. Interpersonal facilitation, like Organ's altruism, refers to actions performed to help others. Job dedication captures the remaining dimensions of OCB as derived by Organ (1990). In other words, job dedication covers behaviors similar to conscientiousness, sportsmanship, courtesy, and civic virtue. Job dedication also captures a notion of organizational commitment that can explain why certain acts of contextual performance are directed towards the organization. This finding is not unlike that found by Organ (1988). The framework of performance developed by Borman and Motowidlo (1993), and later refined by Motowidlo and Van Scotter (1996), has been empirically supported by the works of Borman, White, and Dorsey (1995), Conway (1999), and Goodman (1998).

Other researchers have looked into similar constructs including extra-role behaviors (George \& Brief, 1992), Brief and Motowidlo (1986, p.711) proposed the concept of prosocial organizational behavior (POB), which is defined as "behavior performed with the intention of promoting the welfare of individuals or groups to whom that behavior is directed." This behavior consists of actions that are not prescribed as essential to job performance. In other words, the behaviors are not considered part of task-oriented performance (Borman \& Motowidlo, 1997). Another similar construct, extra-role behavior, has since been described by George and Brief (1992). These behaviors are similar to POB in that they focus on helping others and the organization. However, $\mathrm{POB}$ and extra-role behaviors are not as exhaustive as OCB. For example, POB does not explicitly account for behaviors such as volunteering to carry out task activities that are not formally part of their own job; extra-role behaviors do not explicitly 
account for behaviors such as helping or cooperating with others. However, it is important to note that neither contextual performance, prosocial organizational behavior, nor extra-role behaviors address compliance or adherence to company policies (Borman \& Motowidlo, 1997; Organ and Ryan, 1995).

Furthermore, these constructs share a great deal of conceptual overlap, but do exhibit some minor differences, particularly in terms of antecedents (Bolino, 1999; Borman \& Motowidlo, 1997; Organ \& Ryan, 1995). A host of researchers have examined antecedents for both OCBs and contextual performance (Borman \& Motowidlo, 1993; Conway, 1999; Motowidlo \& Van Scotter, 1994; Organ, 1988; 1990; Organ \& Ryan, 1995; Orr, Sackett, \& Mercer, 1995; Sinclair \& Lyne, 1999). Researchers have predominantly attempted to determine what factors (dispositional or otherwise) best predict an individual performing behaviors that fall under the umbrella of organizational citizenship behaviors and contextual performance. For instance, Conway (1999) found a relationship between the Big Five personality factors and interpersonal facilitation using a sample of managers. Similarly, Borman and Motowidlo (1993) postulate that contextual performance is best predicted by personality factors such as conscientiousness while task performance is best predicted by cognitive ability. Organ and colleagues while agreeing with these antecedents, however, argue that OCBs and/or contextual performance are not necessarily a sole function of dispositional factors such as agreeableness or conscientiousness. They contend that these factors are complimented by attitudinal factors such as job satisfaction, perceived fairness, leader supportiveness, and organizational commitment. 
In essence, there is much conceptual overlap between organizational citizenship behaviors, contextual performance, prosocial organizational behaviors, and extra-role behaviors (Borman \& Motowidlo, 1993; Organ \& Ryan, 1995). Nonetheless, for the purposes of this study, I was forced to choose one to represent the whole of the construct domain. Thus, organizational citizenship behavior (OCB) was chosen since they are most representative of behaviors that go above and beyond the call of duty. Furthermore, this construct has a well-defined factor structure (Organ, 1990; Organ \& Ryan, 1995), an extensive history in the extant literature, and a wider range of antecedents than the other constructs involved. Although the results are framed in terms of OCBs, the findings are equally applicable to other similar constructs such as contextual performance and prosocial organizational behavior.

\section{$\underline{\text { Motives and Organizational Citizenship Behavior }}$}

One of the more interesting questions regarding organizational citizenship behaviors is the underlying motive behind the performance of these behaviors (Bolino, 1999; Rioux \& Penner, 2001). Several researchers have attempted to answer this question by examining predictors of organizational citizenship behaviors (Borman \& Motowidlo, 1993; 1997; Borman, White, \& Dorsey, 1995; Brief \& Motowidlo, 1986; Conway, 1996; 1999; George \& Brief, 1992; Goodman, 1996; Motowidlo \& Van Scotter, 1994; Organ, 1988; 1990; Organ \& Ryan, 1995; Van Scotter \& Motowidlo, 1996). These researchers have looked specifically at dispositional predictors of OCBs (e.g., the Big Five personality factor structure) in an attempt to explain who will perform these behaviors. 
Other researchers (Bolino, 1999; Rioux \& Penner, 2001) argue that it is imperative to study motives guiding OCBs. They have looked at tactics used in impression management and ingratiation and have observed that organizational citizenship behaviors can be used for these. Bolino (1999) went so far as to ask, "Are individuals good soldiers or good actors?" Depending upon the answer to this question, there are important implications for organizational functions such as performance evaluation, teamwork cohesion, and interpersonal conflict resolution. The research is designed to determine if the attribution of these motives can be affected by certain individual differences of the observer. However, before delving into this question, I will first discuss three different frameworks provided to explain the performance of OCBs: 1) traditional models of OCB where type of motives is not of paramount interest, 2) Leary \& Kowalski (1990) framework of impression management emphasizing self-serving motives for explaining OCBs, and 3) frameworks based on volunteerism that stress genuine motives for explaining OCBs).

Traditional Models of $O C B$

Organ and Ryan (1995) conducted a meta-analysis intended to address a variety of issues concerning organizational citizenship behaviors. One of their suppositions suggested that organizational citizenship behaviors are driven by motives such as attitudinal characteristics and personality factors (e.g., conscientiousness and locus of control). The logic for this suggestion is that altruistic and conscientious behaviors are best predicted by personality factors that tap into a person's altruistic nature or conscientiousness. Moreover, job attitudes have been shown to predict the occurrence of behaviors such as sportsmanship, civic virtue, and courtesy. The model also accounts for 
the prediction of task performance (Borman \& Motowidlo, 1993) by individual characteristics such as knowledge, skills, and abilities as well as by incentives and contractual rewards provided as external motivation by the organization (See Figure 1). This proposition was subsequently supported by the findings of Borman and Motowidlo $(1993 ; 1997)$ and Organ (1988). Furthermore, Organ and Ryan (1995) have found that job satisfaction was significantly correlated with the altruism dimension of OCB $(r=$ .24). In terms of dispositional factors, the altruism dimension of OCB was correlated highly with the personality dimension of conscientiousness (an uncorrected mean correlation of .45). For generalized compliance (the second general factor of organizational citizenship behaviors), correlations between dispositional and attitudinal factors ranged from .18 to .25 . This empirical evidence provided support for the notion that OCBs could be motivated by employees' dispositions and attitudes (Organ \& Ryan, 1995). Thus, the implicit assumption is that when individuals engage in OCBs, they are genuinely attempting to perform OCBs. That is, individuals have genuine motives for performing OCBs. However, this assumption of genuine motives, or the claim that OCBs are beneficial regardless of the underlying motives, was later challenged in the work of Bolino (1999). Bolino (1999) challenged these works because there was a dearth of evidence backing the assumption of genuine motives behind OCBs.

An example would be claiming that OCBs that happen on a frequent basis are beneficial to the organization or other individuals because they are not self-serving in motivational nature but genuine (Organ, 1988). In fact, Organ and colleagues proclaim that organizations are best served to select individuals (who are prone to behave in an other-serving nature) and to promote such genuinely motivated behaviors by individuals, 
as this will promote organizational effectiveness directly. This is a belief held not only by Organ and colleagues but also by Borman and Motowidlo $(1993 ; 1997)$ as well as Brief and Motowidlo (1986). Podsakoff, MacKenzie, and Hut (1993) proclaim that even if organizational citizenship behaviors are driven by motives that are not genuine or selfless, it should be of no importance to the organization because of the potential gain to organizational effectiveness. It is clear that researchers such as Borman, Organ, and others have either not acknowledged the possibility of motives that are not selfless or have chosen to ignore them since all OCBs have utility for organizations (regardless of underlying motive). It is my contention that this stance is problematic.

It is true that the motive of the OCB may or may not have an effect on organizational effectiveness (e.g., OCBs are good for organizational effectiveness regardless of motive), but it is important to understand if motives are genuine or selfless as this has several implications. Some of these implications include problems that can arise (e.g., conflict in the workplace) in the case of peer evaluations based on the interpretation of self-serving motives. Thus, understanding whether the motive for engaging in OCB is self-serving or genuine, and especially how viewers attribute these motives, is an important area of research.

Bolino (1999) argues that the assumption that genuine motives are the sole motive behind organizational citizenship behaviors is unreasonable. I add to this by asserting that it is unreasonable to think of any OCBs as being motivated by anything other than a self-serving motive. Accordingly, it is important to consider the attribution of motives by others because others evaluate and respond to those evaluations. This is why the distinction between helping the organization and other individuals as compared to 
helping oneself is so important. My goal is not to dismiss the selfless motives but merely to distinguish between the two and to determine what causes individuals to attribute certain motives to certain behaviors. Examining what behaviors are attributed to selfless motives and what behaviors are attributed to self-serving motives, has important consequences for interpersonal interactions. Before this can be done, it is necessary to examine the motives or antecedents of organizational citizenship behaviors that would be considered self-serving and other-serving. To do so, I begin by reviewing the literature on impression management (Goffman, 1959) and ingratiatory tactics (Jones, 1964). Both streams of literature suggest how and when self-serving motives predicate OCBs. I then focus on the relationship between volunteerism and OCBs (Penner, Midili, \& Kegelmeyer, 1997). This literature hints at genuine or other-serving motives as determinants of OCBs.

Impression Management, Ingratiatory Tactics and Motives for OCBS

Bolino (1999) suggested that people are probably more likely to be "good actors" than they are "good soldiers". This is because people want to manage the impression they make on supervisors as well as ingratiate themselves with their supervisors and coworkers in order to serve their own ends; this proposition has been supported by empirical research (cf. Rioux \& Penner, 2001). In fact, Rioux and Penner (2001) found that individuals who manage their impressions often perform actions that benefit the organization as long as it is identifiable by their supervisors. Moreover, peers and supervisors rated individuals who manage impressions actively, and who engage in activities that benefit the organization, higher on performance; Wayne and Ferris (1990) reported similar findings. It is clear that impression management can affect ratings of 
performance, however, what is impression management and what is the mechanism by which this motivates behavior?

In 1959, Goffman, a sociologist, wrote a book entitled The Presentation of the Self in Everyday Life, which addresses the notion of managing the impressions one makes on others. He referred to impression management as a "rite of passage used by individuals to smooth and ease the social interactions of everyday life (p. 42)." He went on to say that although these behaviors appear to be innocuous at first, they can indeed be strategic and calculated to put the "actor" in a positive light towards others. Despite the fact that this definition provides a negative connotation, Goffman claimed that all individuals engage in this behavior and that it is natural. In addition, he claimed that the reasons for these behaviors, as well as the consequences, can be described as the easiest way to influence or to elicit specific responses from others based on the information one has about the other person.

Meanwhile researchers such as Jones (1964) examined actions by individuals that could be classified as ingratiatory and provided a typology of ingratiatory tactics. This included tactics like conforming and making others feel good about themselves. The general assumption was that ingratiators engage in behaviors that would make others perceive them positively. Later, Jones and Pittman (1982) suggested that certain work performance behaviors could be viewed as ingratiatory tactics. For instance, staying late at work or arriving at work early can both be seen as a way of ingratiating oneself with their supervisor. Jones and Pittman also provided a typology of ingratiatory tactics. Their typology included the following five categories of behaviors: 1) ingratiation, which addresses behavior geared towards making oneself likable; 2) exemplification, 
which describes people who want to be viewed as dedicated; 3) intimidation, where the goal is to appear dangerous or threatening; 4) self-promotion, where individuals hope to be seen as competent; and 5) supplication, where one seeks to be viewed as needy or in need of the help of others. The impressions derived by these tactics often times can be achieved by performing acts of citizenship. In essence, OCBs may be viewed by others as acts of ingratiation or actions taken to make one look good to others and the organization. In other words, one may perform an OCB such as working extra hours in order to appear dedicated. However, raters may see this as being truly conscientious (an other-serving motive) or as an example of exemplification (a self-serving motive).

More recently, an attempt has been made to integrate the ingratiation construct with the notion of impression management (Riordan, 1989). This researcher refers to impression management as a process by which people attempt to influence the image others have of them. Here, the distinction between ingratiatory tactics and impression management is reconciled since motives and behaviors are both integrated as a process. Similarly, Tedeschi and Melburg (1984) incorporated this process by referring to the combination of both as a "strategy employed by all individuals to affect the perceptions of themselves (as cited in Riordan, 1989, p.312)." However, neither of these researchers provides a framework for how this process works in an organizational setting.

This was reconciled by Leary and Kowalski (1990) who proposed a threecomponent model of impression management as a motive-action process. The model consists of three components: 1) impression monitoring, 2) impression motivation, and 3) impression construction. Impression monitoring refers to an individual monitoring or openly scrutinizing the impressions they make of others. Based on these monitorings, 
impression motivation begins. This concept refers to the notion that individuals are motivated to alter the impressions made of others. This is contingent upon the impression being less than a favorable one. Finally, impression construction occurs when individuals begin to alter or to build the impressions made on others through their actions. Leary and Kowalski (1990) also claim that these processes exist or occur in a cyclical pattern. The complete model incorporates both social contexts and personal dispositions in explaining the transition across the monitoring, motivation and construction phases (depicted in Figure 3).

Impression motivation represents the motives for the actions. The actions in this stage are dealt with in the impression construction phase of the model. Leary and Kowalski (1990) found empirical support for the model and, more specifically, found evidence for the transition between impression motivation and impression construction. In fact, they included a provision to the model so that impression construction could cycle back to or re-enter the cycle at the impression motivation stage. They further speculated that this occurred since motives could be altered as the construction of impressions proceeded. This model is important because it includes both the social context as well as personal or individual difference variables. This comprehensiveness enhances the model's applicability in the workplace. For instance, from a social context view, it becomes apparent that the model is valuable when dealing with interactions between employees.

In terms of motives for organizational citizenship behaviors, as seen in Figure 3, personality dispositions are likely to influence the monitoring, motivation, and construction phases. However, the actual motivation to engage in OCBs is mainly an 
attempt to realize a positive image of oneself in others. Thus, the literature on impression management and ingratiatory tactics suggest that to the extent an individual engages in OCBs, the motivation comes from a need to generate a positive image for oneself. Accordingly, self-serving motives are proximal antecedents to OCBs. Having reviewed how these two literatures (impression management and ingratiatory tactics) suggest how and when self-serving motives predict OCBs, I turn to the extant literature on volunteerism that suggests a role for genuine or other-serving motives for engaging in OCBs.

\section{Volunteerism and Motives for $O C B$}

When evaluating the other-serving or genuine motives behind organizational citizenship behaviors, researchers have found that there are a variety of motivations that fall under the umbrella of volunteerism (Penner, Midili, \& Kegelmeyer, 1997; Rioux \& Penner, 2001; Stukas, Snyder, \& Clary, 1999). Volunteerism can be defined as "a general trait manifested by one's general inclination to aid others and/or provide relief for those under distress as well as a general inclination to be willing to perform" (Penner et al., 1997, p. 113). Stukas, Snyder, and Clary (1999) found similar characteristics for volunteerism. Both Penner et al. (1997) and Stukas et al. (1999) go on to define manifestations of volunteerism as meeting one of two criteria: 1) willingness to perform a given action and 2) willingness to help others. Thus, it is the contention of Penner et al. (1997) that if one is high on volunteerism, and the behaviors that are manifested as volunteer behaviors (i.e., helping others or wanting others to be well), they should be willing to "genuinely" help others in the work setting or perform organizational citizenship behaviors. Moreover, when considering actions such as volunteering for 
more work, it becomes even more evident that dispositional characteristics play a role in defining whether or not one partakes in organizational citizenship behaviors. Still another example, which from the self-serving motive point of view is considered a selfpromotion action, is complying with organizational rules such as not taking office supplies from the workplace even if being used to work at home. From the volunteer/other-serving motive point of view, this action can be seen as volunteering to follow the rules set by the organization so that order is maintained within the workplace. Thus, this would be an example of generalized compliance (i.e., sportsmanship or civic virtue) as identified by Organ (1990). Both Penner et al. (1997) and Rioux and Penner (2001) have found evidence for the proposition that volunteerism and behaviors such as volunteering for more work (OCBs) are linked in that volunteers are those that tend to perform in the workplace while the other is manifested in other places. The works of Penner and colleagues provide evidence of the relationship between volunteerism and manifestations such as OCBs.

Thus in discussing motives and OCBs, I have presented three models or frameworks. In traditional models of OCB (Borman \& Motowidlo, 1993; Organ \& Near, 1988; Podsakoff et al., 1991), no distinction is made between self-serving and genuine motives. The literature on impression management and ingratiatory tactics suggest how self-serving motives drive OCBs whereas the literature on volunteerism elaborates on the role of genuine motives in causing OCBs. Regardless of the actual motives causing OCBs in an organizational context, it is the attributions that others make of a person engaging in OCB that has important consequences. 
It is with these considerations in mind that I discuss how individuals establish the perceptions of motives for organizational citizenship behaviors. First, I review a general model of how attributions are made. I then discuss a general framework of how dispositional factors as well as compositional factors affect the way one perceives actions like organizational citizenship behaviors and how these motives are attributed. These dispositional and compositional factors, and their influence on attributions, are the focus of this dissertation.

\section{A Mechanism for the Attribution of Motives}

The key to understanding the attribution of behavioral motives is to understand it is a process of perceiving the causes of behaviors (i.e., OCBs), which is the focus of this study. Moreover, it is important to understand if all individuals try to perceive the causes of the behaviors of others in the same way. In this study I am interested in looking specifically at the relationship between a coworker's organizational citizenship behaviors and a peer's rating of these behaviors as well as their attribution of the motives as either self-serving or non self-serving in nature.

When dealing with the attribution of motives, the most relevant theory is that posited by Harold H. Kelley in 1967. Kelley's theory of causal attribution is a comprehensive mechanism by which individuals attribute causes (or motives) of behavior performed by others. Empirical support for this theory has also been provided by other research (Kelley, 1972; Jones, Kanouse, Kelley, Nisbett, Valins, and Weiner, 1987). The model provides an integrated framework for understanding why individuals associate certain behavioral characteristics like consistency and distinctiveness with either internal or external causes. In other words, observers of specific behaviors attempt to attribute 
causes or motives based on several characteristics of the behavior as well as the performer.

The theory of causal attribution posited by Kelley (1967) consists of three major behavioral distinctions that provide information to observers about specific behaviors. These behavioral descriptors are consensus, consistency, and distinctiveness. Consensus can be described as a characteristic of behavior that allows one to say that many individuals would or would not behave in this manner. In essence, the appropriate question is whether or not individuals would react (i.e., behave) to stimuli in the same manner as other individuals would (Jones et al., 1987). Thus, when trying to assess causes for behavior one would consider whether or not this behavior is one that would be performed by most others in the same situation. In terms of consensus, it stands to reason that when there is low consensus, observers would turn to internal attributions simply because there are few external causes such as peer pressure or environmental influences to influence the actions (Kelley, 1972). For high consensus, it could be obvious that behaviors may be derived from the very presence of external causes such as peer pressure and/or environmental influences such as organizational culture.

Consistency can be depicted as a characteristic of behaviors that allows observers to determine how often the person would act in the same manner in the same situation. Basically, the question of interest for consistency is one of frequency and regularity of behavior. In other words, would this person regularly perform the same behavior when facing the same situation? Moreover, if this person does act in the same fashion how often would they do so? 
The final characteristic of behaviors provided by Kelley's theory is distinctiveness. This refers to the very nature of the behavior. That is, does the individual react in the same manner to a variety of stimuli or situations and, does this individual react differently to different situations? What exists here is a distinction between low and high distinctiveness of behaviors. In cases of low distinctiveness, individuals are thought to be acting or behaving based on internal motives because their motivation is the only similarity across varying situations. By contrast, in cases of high distinctiveness, actors would be motivated by external causes because the behaviors are distinct from one situation to the next. There is no similarity from one situation to another. These three characteristics are vital to understanding the process by which individuals use a person's behavior to attribute a cause or motive. Without these three primary characteristics of behavior, the attributions of causes would be even more confusing than they already are. In addition, these characteristics of behavior make it easier for others to understand why others act the way they do as well as why they themselves act in the manner they do. Again, these are important because they allow one to understand how they should react to these behaviors performed towards them. This, in turn, affects their motives for reaction and/or assessment of behaviors.

To understand the theory of causal attribution one must examine a potential situation or behavior and assess the three characteristics as provided in the following situation. The following is a sample situation taken from Baron and Byrne (1994): "Sue is arguing with Professor James. Almost no one argues with Professor James. Sue argues with Professor James on other occasions. Sue also argues with other professors." Here, we receive information about a behavior being performed (i.e., Sue arguing with 
Professor James). We are also given information about consensus, consistency, and distinctiveness, respectively. For instance, consensus is addressed when the fact that no one argues with Professor James is mentioned. Consistency is touched upon when it is written that Sue argues with Professor James on other occasions. Distinctiveness is depicted when the notion of Sue arguing with other professors is mentioned. From this information it becomes clear that there is a situation of low consensus, high consistency, and low distinctiveness. According to Kelley $(1967 ; 1972)$, in this situation, individuals are prone to attribute internal causes as the motives of behaviors. However, in the case of high consensus, high consistency, and high distinctiveness, individuals are prone to attribute external causes as motives for behaviors. This example makes the process of attribution of causes, or the perception of causes, for behaviors quite clear for a variety of situations and settings (See Figure 4).

When attributing causes to behavior it is often not enough to evaluate or attribute internal versus external causes. Often individuals attempt to assess the sincerity or genuine nature of such behaviors along with the origination of motives or causes. This becomes apparent when dealing with social interactions, which are of interest in the proposed study. For instance, when dealing with peer ratings of performance, and in particular OCBs, it is apparent that one would want to know why these behaviors are being performed. Moreover, one would speculate about whether or not individuals are performing specific behaviors because of self-serving internal causes or genuine internal causes. In order to comprehend why individuals attribute behaviors to self-serving or genuine motives, it is not enough to understand that behaviors can be attributed to internal or external causes. 
By their very nature, OCBs represent behaviors that are low in consensus, high in consistency, and low in distinctiveness. OCBs are not performed by all workers because if they were they would be considered task performance (Organ, 1988). This is an example of a low consensus situation. In regards to consistency, most individuals who perform OCBs perform them consistently over time (Borman \& Motowidlo, 1993; 1997; Organ, 1990). This is representative of a high consistency situation. As for distinctiveness, performers of organizational citizenship behaviors often perform these behaviors across a variety of situations. For instance, in terms of altruistic activities and/or generalized compliance activities, individuals who are prone to perform citizenship behaviors will do so in both cases (Bolino, 1999; Borman, White, \& Dorsey, 1995). It is because of these behavioral characteristics that OCBs would more likely than not be attributed to internal causes like the personality of performers. Nonetheless, little research is found dealing with the attribution of motives and how other variables affect this attribution. These other variables of interest include personality traits of the observer and compositional factors of performers like gender and ethnicity.

A New General Framework for the Attribution of Motives

When dealing with the attribution of motives for organizational citizenship behaviors it is important to remember that these behaviors are defined as having internal causes (Kelley, 1967). Accordingly, it is important to delineate a framework of variables that explain how one attributes certain motives behind OCBs. Moreover, it is important to remember that for the purposes of this study, I am comparing motives based on whom they serve. For instance, self-serving motives are exemplified by actions that are motivated towards personal attention or gain. In fact, actions such as helping others at 
work can even be driven by a self-serving motive such as wanting to be noticed by a supervisor or trying to gain recognition from others at work (Bolino, 1999). Essentially, this can be viewed as a form of impression management using a hands-on approach (Jones, 1964). Self-serving motives are not the only ones attributable to organizational citizenship behaviors though; observers or performance evaluators can also attribute genuine or self-serving motives to organizational citizenship behaviors. Thus, one may actually help others simply to help a person and not for self-serving motives. This positive view although somewhat unrealistic to some (Bolino, 1999; Rioux \& Penner, 2001 ) is shared by others (Penner et al., 1997; Stukas et al., 1999). Nonetheless, the following represents a model for the attribution of motives for organizational citizenship behaviors by observers like coworkers and peers and the focus of this dissertation shifts to providing a new framework for the attribution of motives. This new framework will take into account the factors that affect the attribution of motives. This includes compositional factors like gender and ethnic composition of the performer-observer dyad, dispositional factors of the observer like personality traits, and the potential for interactions between compositional factors and dispositional factors. Furthermore, the relationship between motives and specific dimensions of organizational citizenship behaviors will be examined.

Composition of the Performer-Observer Dyad \& Motives

It is necessary to examine the relationship between the effects of compositional factors like gender and ethnic makeup of the performer-observer dyad in order to assess the potential effect these demographic cues can have on social categorization and/or the development of stereotypes. Social categorization theory (Festinger, 1957) serves as a 
stepping-stone for the attribution of motives behind organizational citizenship behaviors. As seen in Figure 5, social categorization is driven by the notion of comparison of individuals based on individual information and stereotyping (Turner, 1987). For instance, Triandis (1995) defined stereotypes as an "assumed characteristic of a group, a category, of people (p. 72)." Other researchers still point to the fact that stereotypes help individuals make the world more acceptable, predictable, and perceivable (Tsui \& Gutek, 1999; Turner, 1987; Zimbardo \& Leippe, 1991, p. 236). For instance, one stereotype that permeates many cultures is that all Hispanics are loud and talk with their hands.

Although this may be true of many Hispanics it is not necessarily the case for all of them. Moreover, it is easy to see how this helps an individual understand the world or simplify the unpredictable.

The notion of social information from interactions and from stereotyping helps portray the process by which individuals are categorized (Festinger, 1957). However, it is important to understand that before one can employ a stereotype to categorize, one must first interact with a person in order to garner information about the person. This information then helps with categorization, or the tendency for individuals to organize information about others by classifying them into social categories based on demographic or other attributes (Turner, 1987). Furthermore, it is clear that in order for individuals to categorize others one must categorize him/herself. This falls in line with the social identity theory put forth by Festinger (1954) (See Figure 6). In essence, the process of social categorization and social comparison constantly reshapes one's social identity. In a cyclical fashion, social comparison begins with interaction with an individual, is followed by social categorization, and the final leg occurs with a revision of one's own 
social identity. Again, it is important to remember that the driving force behind this whole process cycle is the need for positive self-distinctiveness. In other words, categorization is part of a process whereby individuals create categories based on demographic cues and attributes of other individuals and then assigns these individuals to an "us" or "them" group. Naturally, those falling into the "us" group are seen in a more favorable light. This is not unlike the notion of leader-member exchange (Graen \& UhlBien, 1998) where individuals are put into cadre and out-groups. Finally, categorization is the basis for the decision to attribute liking to those to the "us" group and disliking in the "them" group. This is important because during the process of categorization individuals tend to overemphasize that which is similar and positive about the "us" group and to exaggerate that which is negative about the "them" group (Tsui \& Gutek, 1999). In fact, individuals have a tendency to use information such as gender and ethnicity as categorizational tools. It is information akin to this that can be useful in assessing whether or not individuals are part of the "us" group and, if so, how similar their motives are to those of oneself. Thus, information such as the demographic cues of individuals, as well as the dispositional attributes of the categorized other, can be used to make an assessment of their actions and the motives behind these actions (Chatman, Polzer, Barsade, \& Neale, 1998). This is particularly true because one can make the assumption that those in the "us" group would behave in the same manner as they would. This assumption is bolstered by the fact that the motives of those in the "us" group and their attributes might be overemphasized. Therefore, in the case of organizational citizenship behaviors a peer may be swayed to attribute genuine motives to such behaviors simply because a person can be categorized in the "us" group. However, if someone is 
dissimilar in terms of demographic cues and dispositional attributes (i.e., not in the "us" group but in the "them" group), a peer may be swayed to rate such behaviors as being driven by motives that are negative and not genuine. The example given above demonstrates how one's ratings of others can be affected by demographic and dispositional attributes. Social categorization can be considered the key to understanding how motives can be attributed (either mistakenly or correctly). Therefore, the following hypotheses are proposed:

Hypothesis 1: Observers will be more likely to attribute genuine motives to organizational citizenship behaviors for those who are similar in gender and ethnicity than for those who are dissimilar in gender and ethnicity. Conversely, hypothesis 2 is based on dissimilarity in gender and ethnicity between the dyad members. In other words, the more dissimilar the gender and ethnicity of the actor and observer, the more likely the observer will attribute self-serving motives to organizational citizenship behaviors.

Hypothesis 2: Observers will be more likely to attribute self-serving motives to organizational citizenship behaviors for those who are dissimilar in gender and ethnicity than for those who are similar in gender and ethnicity.

\section{Dispositional Characteristics of the Observer \& Motives}

However, demographic cues are not the only variables that affect the process of social categorization and, subsequently, the attribution of motives. The dispositions of the observer will influence the attributions of motives. Dispositional factors like the Big Five personality factors (Barrick \& Mount, 1991; Costa \& McCrae, 1992) and other dispositional factors of the observer can affect the attribution of the motives (Warech, 
Smither, Reilly, Millsap, \& Reilly, 1998). Basically, an observer's characteristics can be used to predict what motives they would attribute to performers and to actions.

Yet another reason to include predictors such as the Big Five personality factors is that the majority of the research linking personality traits and attribution theory tend to focus on the relationship between traits of the person performing behaviors (the actor) and the cause attributed to the behaviors. For example, Funder (1999) examined the relationship between personality traits of individuals (i.e., self esteem, self-monitoring, conscientiousness, and emotional stability) and the attribution of causes to their behavior in both home and work settings. Funder found support for the notion that the trait being judged does have an affect on the causes attributed to behaviors. Essentially, the behaviors were attributed to a favorable internal cause if the salient trait was perceived to be a favorable trait. For instance, for individuals who performed behaviors such as volunteering for charity events (the salient trait being altruism), the attribution of cause or motive was internal and favorable. Similarly, if a behavior such as ignoring the requests for money by the destitute was performed, the cause attributed was internal, indicating that this was attributed to a personality trait; however, this trait was seen as less favorable than altruism (Funder, 1999). Research examining the relationship between personality traits and causal attribution has mostly concentrated on actor traits and observer attributions. Little research, however, has been done on the effect of observer traits on observer attributions, and only a few researchers (e.g., Funder, 1999; Hazebroeck, Howells, \& Day, 2001) have attempted to relate the traits of attributers (observers) and the causes that are attributed to the behaviors of others. Hazebroeck et al. (2001) examined the relationship between trait anger of the observer and attributions of internal 
causes to behaviors that are combative. The primary focus was to determine if the trait anger was predictive of whether or not individuals attributed internal causes to combative behaviors; results in this case were mixed. Funder (1999) attempted to examine a similar relationship with self-esteem of the observer and the attribution of causes to accomplishment behaviors in the workplace. Again, the support for such a relationship was uncertain. Nonetheless, given the works of these researchers, it is apparent that there is a need to examine the effects of observer traits on the attribution of motives. The Big Five personality traits are not the only dispositional factors that should be considered. Other factors such as self-monitoring, individualism-collectivism, and negative affectivity need to be considered; this dissertation will evaluate all of these.

When considering the relationship between observer or attributer traits, and the attribution of motives, it is natural to begin with dispositional factors. For instance, it is possible that individuals who are open to new experience will be more prone to attribute genuine motives than self-serving motives to those performing OCBs. The reasoning for this is that those who are open to experience are flexible or adaptable to new situations. If flexible, a person who observes organizational citizenship behaviors might be willing to entertain the possibility of behaviors being performed out of genuine motivations. In other words, it is this flexibility that limits the amount of cynicism one engages in. This limited cynicism prevents open individuals from simply ruling out genuine motives as a cause of behavior. Similarly, individuals who are agreeable exhibit a tendency to attribute genuine motives more so than self-serving motives. The reason for this is that individuals who are highly agreeable exhibit a tendency to agree with the actions or thoughts of others. Self-serving motives carry with them a connotation that is somewhat 
negative simply because they are selfish in nature. Therefore, since few would contend that their own actions are motivated by selfish reasons, it is very unlikely that those who are agreeable would view their own actions as selfish much less attribute self-serving motives to the actions of others. In addition, those who are agreeable would be less likely to attribute self-serving motives to OCBs because this would on the surface appear to be a disagreement between act and motive (e.g., act is selfless; motive is selfish). Thus, agreeable individuals would attribute genuine motives because it is disagreeable or conflictive to attribute a selfish motive to a seemingly selfless act. In terms of extroversion, self-serving motives are also less likely to be attributed than genuine motives. The belief here is that individuals who are extroverted are concerned with appeasing others and/or making sure that others like them. To attribute self-serving motives to OCBs performed by others would potentially adversely affect the relationship between the attributer and others. Since it is this very relationship that the observer (attributer) is concerned with maintaining, it is highly unlikely that an extroverted individual would jeopardize this relationship by attributing a self-serving motive. These are not the only personality variables associated with the attribution of genuine and selfserving motives. For instance, it is important to consider that conscientious individuals tend to be thoughtful and dependable. As a result, these individuals will take into account the type of behavior being performed as well as the type of person who performs it. Thus, conscientious individuals will consider if they themselves would perform such behaviors. More often than not they would indeed consider themselves capable of performing these behaviors because it is their genuine nature. As a result, they would 
attribute these actions to genuine motives more so than to self-serving motives. As a result, the following hypotheses are thus proposed:

Hypothesis 3: There is a positive relationship between the openness to experience of the observer and the attribution of genuine motives.

Hypothesis 4: There is a positive relationship between the agreeableness of the observer and the attribution of genuine motives.

Hypothesis 5: There is a positive relationship between the extroversion of the observer and the attribution of genuine motives.

Hypothesis 6: The conscientiousness of the observer is positively related to the attribution of genuine motives to organizational citizenship behaviors.

Individuals who are low on emotional stability have been shown to possess a low tolerance for stressful or unnerving situations (Goldberg, 1999). As such, suggesting that individuals who perform seemingly selfless acts like OCBs are asking for selfish reasons is conflictive in nature and can be unnerving if one makes such attributions. Thus, individuals who are low in emotional stability might attempt to avoid such conflictive or stressful attributions and would tend to avoid making self-serving attributions to evade stress. On the other hand, individuals high on emotional stability will not be fearful of attributing self-serving motives. So, the following hypothesis results:

Hypothesis 7: There is a positive relationship between the emotional stability of the observer and the attribution of self-serving motives.

Self-monitoring should be considered a predictor of the attribution of self-serving motives because having the desire to monitor one's ability to make impressions on others, or to affect the thoughts and actions of others, carries with it an inherent condition that 
one must believe that they are in control of their actions and/or the consequences of these actions. This lends credence to the possibility that similar introspection goes on about the action of others. In other words, individuals who are high on self-monitoring are very likely to engage in impression management activities (Leary \& Kowalski, 1990). Because of this propensity to self-monitor, these individuals are extremely likely to view behaviors that are similar to ingratiatory tactics (e.g., OCBs) as resulting from selfserving motives. As a result, it is entirely feasible that there is a relationship between the self-monitoring of the observer to the cause attributed to the actions of others. Further, in terms of self-monitoring, or the tendency to examine one's own actions in order to manage one's own impression towards others (Jones, 1964), it is even more important to understand that there is a clear relationship between self-serving motives and impression management tactics (Bolino, 1999). The clear association is that one who self monitors is more prone to partake in impression management techniques and will be more likely to do things for self-serving purposes. In other words, those who self monitor are more likely to attribute the actions of others to self-serving motives because of their propensity to perform similar actions for self-serving motives. As such, the following hypothesis results:

Hypothesis 8: The tendency of the observer to self-monitor is positively associated to the attribution of motives as self-serving motives.

When dealing with individualism-collectivism (Hofstede, 1991; Matsumoto, Weissman, Preston, Brown, \& Kupperbusch, 1997), it is important to understand that the tendency of the observer to be individualistic or to be collectivistic can be clearly related to the attribution of motives. For instance, individuals who are extremely collectivistic 
will be prone to categorize actors as being part of an "us" or a "them" group. In order to make this categorization, demographic cues can be used. Subsequently, it stands to reason that collectivistic individuals will view those who are demographically (e.g., gender and ethnically) similar as performing OCBs for genuine motives. Conversely, for those individuals who are not similar, the collectivistic observer is not as likely to attribute genuine motives. For individualistic observers (low collectivism), one would not expect there to be a difference between the attributions of genuine motives to OCBs performed by similar individuals or dissimilar individuals. This situation depicts an interaction between the similarity of the performer-observer dyad and the collectivism of the observer as it relates to the attribution of genuine motives. The following hypotheses result:

Hypothesis 9: The relationship between the collectivism of the observer and the attribution of genuine motives is moderated by the similarity of the performerobserver dyad. For individualistic observers, there will not be a difference between the attribution of genuine motives for similar individuals and dissimilar individuals. For collectivistic observers, genuine motives will be attributed to similar individuals but not to dissimilar individuals.

The final dispositional factor to be considered is positive and/or negative affectivity, which has been compared to temperament or mood (Watson, Clark, \& Tellegen, 1988). Positive affectivity can be operationalized as the tendency to have a positive mood or temperament while negative affectivity can be considered as the tendency to have a negative mood or temperament. The relationship between affectivity (positive or negative) and motives of organizational citizenship behaviors is apparent 
when considering the tendency for those who have negative moods to distrust others (Earle, 1926). As a result, a person who is high on negative affectivity may be lead to attribute self-serving motives to organizational citizenship behaviors. In addition, affect can have a serious effect on attribution motives since a person's mood can alter the level of trust one has in others. Furthermore, the connotation that comes with not trusting individuals who perform OCBs is that one does not necessarily trust individuals who are doing things to help them because they are not sure these actions are done for genuine or unselfish reasons. This suggests that the following hypothesis will be supported:

Hypothesis 10: Negative affectivity of the observer is positively related to the attribution of self-serving motives to organizational citizenship behaviors.

The afore-mentioned hypotheses underscore the importance of examining the relationship between compositional factors of observer-actor dyads and the attribution of motives to OCBs. Similarly, the relationships between dispositional factors of observers and the attribution of motives are examined. Still another issue that needs examining is the potential for interactions between compositional factors of the observer-actor dyads and dispositional factors of observers. Moreover, what is the effect that these potential interactions have on the attribution of motives to organizational citizenship behaviors? Traditionally, conscientiousness has been linked more than any other predictor to organizational citizenship behaviors (Alonso et al., 2000; Conway, 1999) and the importance of looking into potential interaction effects, which include the conscientiousness of observers and the similarity between observers and actors, becomes apparent. Given the nature of conscientiousness as a trait of observers, the examination of potential interactions with similarity is also essential. For example, individuals who 
tend to be highly conscientious possess a tendency to be thoughtful, dependable, and take lots of information into account before making decisions. For people who are not highly conscientious the same is not always true, particularly for the final characteristic (attention to complete information). As a result, individuals who have a tendency to be highly conscientious might take into account demographic cues more so than those who are not highly conscientious. Although this is not necessarily vital information when attributing a motive to OCBs, those who are conscientiousness might still take into account how similar one is to him/herself. That said, researchers such as Borman and Motowidlo (1997) and Bolino (1999) have called for an examination of potential moderators of the relationship between personality factors and job performance behaviors such as OCBs. Finally, justification for a hypothesis dealing with the interaction between dispositional factors and compositional factors is provided by Rioux and Penner (2001) who found evidence for a strong negative relationship between conscientiousness and self-serving motivations of OCBs. They also suggest that this may be due to a strong positive relationship between conscientiousness and positive motivations such as genuine or other-serving motives. The following hypothesis is aimed at examining the combined effects of observer personality factors and the compositional homogeneity of the dyad.

Hypothesis 11: The relationship between conscientiousness and the attribution of motives as genuine motives is moderated by the similarity of the observer and the actor. For individuals who are similar, conscientiousness will predict the attribution of genuine motives. For individuals who are not similar, conscientiousness will not predict the attribution of genuine motives. 
Another potential set variables to consider when relating the motive of organizational citizenship behaviors are identity or personal identification variables such as cultural mistrust, ethnic orientation, and the similarity of the performer-observer dyad. These variables are not commonly used in the realm of Industrial/Organizational Psychology; however, they should be examined for two reasons. First, identity variables are clearly important when discussing the relationship between similarity and the attribution of motives. Variables such as cultural mistrust and ethnic orientation are vital because of the potential effects they can have on the process of social categorization. For example, if one is not high on ethnic orientation it is possible that no particular ethnicity will be viewed as more similar than another. That is, ethnicity may not be the basis by which one develops similarity. This limits the effects that demographic cues have on the formation of initial impressions and the formulation of causal attributions. In terms of cultural mistrust, this too can have a limiting effect if one is low on this particular trait, since the person might not be as inclined to use stereotypes and/or demographic cues that do affect the process of social categorization, which is the initial stepping-stone in the process of causal attribution. That said, it is clear that the perceived similarity of the performer by the observer does have a major effect on the relationships between cultural mistrust and the ethnic orientation of the observer and the attribution of self-serving motives. That is, these two relationships are moderated by the perceived similarity of the performer by the observer. The rationale behind this moderation becomes clear when examining the difference in the relationships if looking at the most similar performer versus the least similar performer. If looking at the most similar individual, the 
relationship between the cultural mistrust of the observer and the attribution of selfserving motives would not be expected to be large in magnitude. However, if looking at the least similar individuals, one would expect the relationship to be quite large in magnitude. Similarly, for ethnic orientation, if looking at the most similar individuals, one who is high on ethnic orientation would not necessarily attribute a self-serving motive. However, in the case of the least similar individual, one who is high on ethnic orientation would, in fact, be expected to attribute self-serving motives. As a result, the following hypotheses address this moderation:

Hypothesis 12: The relationship between the cultural mistrust of the observer and the attribution of self-serving motives is moderated by the similarity of performerobserver dyad such that in the case of the least similar performer, there is a strong relationship between the cultural mistrust of the observer and the attribution of self-serving motives but no relationship for the most similar performer.

Hypothesis 13: The relationship between the ethnic orientation of the observer and the attribution of self-serving motives is moderated by the similarity of performer-observer dyad such that in the case of the least similar performer, there is a strong relationship between the ethnic orientation of the observer and the attribution of self-serving motives but no relationship for the most similar performer.

\section{OCB Dimensions and Motives}

Finally, it is clear that some categories of OCBs should be more related to selfserving motives than genuine motives (Mersman \& Donaldson, 1994). The converse is also true. For example, behaviors that would be considered part of the altruism 
dimension (Organ \& Ryan, 1995) might more likely be attributed to genuine motives because they are targeted towards other individuals. However, in the case of generalized compliance or sportsmanship, attributions may be made to self-serving motives because the immediate benefactor or recipient may be the organization. These propositions are raised by Bolino (1999) who suggests that the attribution of motives can be tied to specific behaviors performed. Rioux and Penner (2001) also mention the investigation of these hypotheses as potential future directions. The following hypotheses address this issue.

Hypothesis 14: Organizational citizenship behaviors such as altruistic behaviors and conscientiousness behaviors will be attributed to genuine motives.

Hypothesis 15: Organizational citizenship behaviors such as sportsmanship and civic virtue will be attributed to self-serving motives. 


\section{Participants}

Participants consisted of 369 undergraduate students registered for psychology and management courses at Florida International University. Approximately $33 \%$ of the participants were psychology majors, $32 \%$ business majors, and $35 \%$ other majors (e.g., hospitality management, computer science, political science, philosophy, international relations, public relations, or sociology). Sixty-seven percent of the sample was female; about $47 \%$ of all participants were Hispanic, $25 \%$ Caucasian, 24\% African-American, 3\% Asian American, and 3\% of other ethnicities. Nearly $85 \%$ of the sample grew up in the continental United States for at least half of their formative years. Seventy-five percent were employed fulltime or part-time, with an even split between the two. Approximately $74 \%$ of those employed had been working for their employers for 5 years or less and one half of those worked for their current employer for 2 years or less. Nearly three out of every four participants were single, 19\% were married, 5\% were divorced, and 1 person was widowed. Finally, 245 of 369 participants were between 20 and 29 years of age with a range from 18 to 58 .

All participants were exposed to six experimental conditions (counterbalanced first by ethnicity and then by gender) where the gender and ethnicity of the proposed employee being rated (whose motives are being perceived) was manipulated. The sampling strategy employed in this study was a stratified sampling technique where ethnicity was the stratification variable. Individuals were selected according to three ethnicities (Hispanic, African-American, or White); however, participants were allowed to participate if they were not of these three ethnicities $(n=22$; Asian Americans or other 
ethnicities). Moreover, participants were selected according to a secondary stratification variable, which was their academic major. The participant recruitment process consisted of a two-stage stratification model where participants who signed up were first chosen according to their ethnicity and then by academic major. All those who did sign up but did not meet the requirements of the study according to ethnicity and major were allowed to fill out a survey but their data was not employed in the data set.

\section{$\underline{\text { Design }}$}

A three-by-two within-subjects experimental design was used in which the variables manipulated were similarity in gender (male or female) and ethnicity (AfricanAmerican or Hispanic or Caucasian). The design entailed asking participants to rate the motives (self-serving versus genuine) behind organizational citizenship behaviors for six hypothetical coworkers. The six hypothetical coworkers were manipulated using names to depict all gender and ethnicity combinations. The combinations or conditions were as follows: 1) African-American female, 2) Hispanic female, 3) Caucasian female, 4) African-American male, 5) Hispanic male, and 6) Caucasian male. All participants were asked to respond to a variety measures such as personality factors and other dispositional measures. These measures were to be used to assess a host of rater or observer characteristics.

Manipulation

For the manipulation of the variables of interest, particularly gender and ethnicity, it was important to make sure that the integrity of the manipulation was maintained without making it so subtle that all effect was lost (Cohen, 1982). In essence, the goal of this manipulation was to impart a variation in gender and ethnicity upon the participant 
who was playing the role of a coworker rating a peer. The gender and the ethnicity of the peer were manipulated by changing the name of the hypothetical peer. For example, in the case of a Caucasian male, the name was "Chandler Young." In the case of an African-American female, the name was "Takeisha Jackson." Yet another example is the case of the Hispanic male, the name was "Guillermo Rodriguez." Each condition was represented by one of the names chosen.

\section{$\underline{\text { Measures }}$}

Manipulation checks. In order to ensure that the manipulation was effective, each participant was asked what they perceive each hypothetical peer (e.g., Guillermo Rodriguez or Margaret Shorthouse) to be in terms of ethnicity and gender. For instance, participants were asked to circle the most appropriate gender and ethnicity for each hypothetical peer to be assessed. Participants were asked to respond by circling "male" or "female" for the peer; for ethnicity, the participants were requested to respond by circling "Hispanic," "Caucasian," or "African-American" for the hypothetical peer (see Appendix A). Thus, for Margaret Shorthouse, participants were expected to indicate that she is a Caucasian female. Similarly, they were asked to do so for all six hypothetical peers.

Similarity/Dissimilarity of Peers. The best way to assess perceived similarity or dissimilarity between the rater and the peer being rated was to ask the participants (raters) to rate the six hypothetical peers in terms of similarity according to gender and ethnicity. Thus, if the participant happened to be an African-American male, he was asked to rate how similar and dissimilar each hypothetical peer was to him. This provided a way for the participant to give his/her interpretation of similarity and dissimilarity. Moreover, 
they were given a definition of similarity that read as follows: "Similarity refers to the how much the peer is like you in gender and ethnicity. If you perceive the hypothetical peer to be of the same gender and ethnicity then he/she should be the most similar to you. Dissimilarity refers to how much the peer is dislike you in gender and ethnicity. If you perceive the hypothetical peer to be of a different gender and ethnicity (most different from yours) then he/she should be the most dissimilar to you." This operational definition was given to all participants as part of the instructions for this particular measure (see Appendix B). The response scale for the measure ranged from 1 "very dissimilar" to 5 "very similar." Perceptions of similarity and dissimilarity were also obtained by asking the participants to rank order how similar each of the hypothetical peers was to them in terms of ethnicity and gender. The most similar individual was to be ranked "1" and the most dissimilar individual was to be ranked " 6 ". This allowed for the participants to think of the hypothetical peers comparatively.

Organizational Citizenship Behaviors. In 1983, Bateman and Organ put forth the theory of organizational citizenship behaviors as a series of behaviors that are part of everyday organizational functioning but that are not part of the prescribed task. These researchers found evidence of five underlying factors for this construct. These factors were altruism, conscientiousness, sportsmanship, civic virtue, and courtesy. Although there was strong support for the existence of confirmatory factors such as altruism, conscientiousness, sportsmanship, and civic virtue, there was not much support for the factor known as courtesy when validating their measure. In 1994, Elizabeth A. Morrison introduced a new measure of OCBs that confirmed the notion that there were four clear underlying factors. This measure consists of 23 items, which represent an activity that 
would be considered part of one of the four underlying behavioral factors such as conscientiousness and sportsmanship (see Appendix C); many of the items in this measure were derived from the Bateman and Organ (1983) measure. For this measure, participants were asked to rate whether or not they considered these behaviors part of the job tasks. However, Morrison (1994) left the instructions of her revised measure open so that if used by others they could tailor the measure instructions for their purposes. For this study, the participants were given a hypothetical peer and a vignette describing the peer in terms of ethnicity and race. The participants were then asked to assume that these peers are performing the following behaviors and were told to rate whether or not the hypothetical peer performed such activities because of self-serving motives or for genuine motives; a separate rating was given for each activity. The response scale for both the self-serving motive and genuine motive dimensions ranged from 1 "strongly disagree" to 5 "strongly agree."

In terms of psychometric properties of Morrison's measure, the internal consistency was assessed using the coefficient alpha. The alphas for the measure ranged from .60 to .77 . Moreover, the test-retest reliability was also assessed. These reliability coefficients for each dimension of OCBs identified by Morrison (1994) ranged from .70 to .85 .

Big Five Personality Factors. The Big Five personality factors were measured using the Individual Perceptions Inventory (Goldberg, 1990). The Goldberg scale is a 50-item measure for tapping into the Big Five factor model. Empirically, this scale was validated by Goldberg (1999) using a multi-trait multi-method approach by correlating this measure to other more renowned measures of personality such as the $16 \mathrm{PF}$ or the 
NEO-PI (Costa \& McCrae, 1992). Moreover, scale validity coefficients ranged from .76 (emotional stability) to .89 (openness to experience). (See Appendix D).

Positive and Negative Affectivity. In 1988, Watson, Clark, and Tellegen authored a scale to address the notion of affect in the workplace and in other settings. This is scale is known as the Positive and Negative Affect Schedule scales (PANAS) (see Appendix F). The measure is comprised of a series of words that describe feelings and emotions such as "interested" or "ashamed" or "enthusiastic." Participants are asked to indicate to what extent they feel this way on varying time intervals. For instance, time intervals can vary from "feeling this way right now" to "feeling this way in general." The response scale ranges from 1 "very slightly or not at all" to 5 "extremely." For the purposes of this study, participants were asked to rate the feelings in general. The coefficient alpha for this scale as reported by the test authors is .88 (positive affectivity) and .87 (negative affectivity).

Self-Monitoring. Warech et al. (1998) developed a measure of self-monitoring based on two specific factors of monitoring: 1) motivation and 2) ability. That is, the motivation to self-monitor and the ability to self-monitor. This construct plays an important role because the test developers themselves note the clear tie to performance ratings and impression management tactics, which Bolino (1999) clearly attributes to self-serving motives. The measure is comprised of 16 items ( 8 tapping into motivation and 8 tapping into ability) (see Appendix G). The authors provide instructions asking the participants to rate all 16 items on how true the statement is of him/herself on a response scale ranging from 1 "Never true of me" to 5 "Always true of me." The writers report the 
internal consistency of the self-monitoring ability subscale to be .80 and the alpha for the self-monitoring motivation subscale to be .88 .

Individualism-Collectivism Scale. For individualism-collectivism, it was my intention to use a scale that examined these values at the individual instead of the cultural level. This scale was chosen to prevent potential confounds when assessing individual values if a scale intended to assess cultural values was used (Triandis, 1995). Therefore, I chose to use the Matsumoto et al. (1997) Individualism-Collectivism Interpersonal Assessment Inventory (ICIAI). Moreover, the authors of this assessment tool have noted many interesting findings in terms of gender and ethnic differences during the validation of this measure making the scale all the more appropriate.

The ICIAI consists of 25 items where respondents are asked to indicate the importance of the value items in relation to colleagues on a scale anchored at 1 from "not important at all" to 6 "very important"(see Appendix H). The scale has been shown to have internal consistency with an alpha equal to .86 and a test-retest reliability across six studies of .77 .

Demographic Information. This scale is a 13-item scale that includes such questions as age, gender, ethnicity, and employment status. Other questions include queries about income, marital status, and educational background and have been used effectively in previous studies (e.g., Sanchez et al., 1999) (see Appendix I).

Ethnic Orientation. This measure is a 13 -item scale comprised of items that focus on how a person views their ethnic identity. Items range from asking whether a person considers him/herself to be "multi-ethnic" to whether or not their views, beliefs, and 
attitudes are consistent with those of their self-perceived ethnic group. This scale was used to examine the effect of ethnic identity on similarity.

Cultural Mistrust. This is a 9-item questionnaire dealing with one's attitudes towards trusting members of their ethnic/racial group and members of other ethnic/racial groups. Sample questions include asking if you "would be suspicious of a stranger who tries to be friendly if that person was Black." This scale used a 5-point Likert scale ranging from 1 "Strongly Disagree" to 5 "Strongly Agree".

\section{Procedure}

Participants were asked to participate during class on two occasions according to when the instructors would allow them. They were first asked to sign an informed consent letter explaining what participation in the study required (see Appendix J). Despite the fact that participants provided their signatures, their names and student identification numbers were held in the strictest confidentiality. Participants were next asked to respond to a series of scales in one questionnaire. These scales included the IPI, the PANAS, the SM-A/SM-S, the individualism-collectivism scale, cultural mistrust, ethnic orientation, and the demographic information survey. During the next class period assigned by the instructor, the participants were asked to fill out the Morrison (1994) scale of organizational citizenship behaviors. This part of the administration entailed answering the same items for the six different hypothetical peers. These scales were counterbalanced first by ethnicity and then by gender. Participants were randomly assigned to any of the twelve resulting orders of administration. Once finished with these six repetitive scales, the participants were asked to fill out the gender and ethnicity perceptions scale followed by the similarity/dissimilarity scale, which concluded the 
participants' involvement in the study. The reason for the separation of the two types of measures was my desire to reduce the effects of fatigue and priming.

\section{$\underline{\text { Analysis }}$}

In this section of the document, I addressed an analytic strategy for each hypothesis purported. As a result, I did so for each hypothesis, the following analyses.

Hypotheses 1 and 2 referred to the relationship between the attribution of motives as either self-serving or genuine and the similarity or dissimilarity between the actor and the observer. Similarity and dissimilarity were treated by comparing both the most similar and the most dissimilar hypothetical peers to one another. In essence, Hypothesis 1 was treated by conducting a matched pairs t-test where a person's rating or attribution of genuine motives for all OCB actions for both the most similar and most dissimilar coworker will be compared for significant difference. It was expected that the most similar co-worker's rating of genuine motives would be significantly greater than that of the most dissimilar co-worker. Likewise, for Hypothesis 2 a matched pairs t-test was used to compare the ratings of self-serving motives for the most similar and the most dissimilar co-worker. Here, the expected result was to see a significantly greater rating for the most dissimilar co-worker.

Hypotheses 3 through 8 and 10 entailed the prediction of the attributions of motives using seven dispositional predictors. All these predictors were operationalized as continuous variables as were the attributions of motives. In order to tackle these hypotheses, a zero-order correlation matrix was computed to assess the direction and magnitude of the relationships predicted in all the hypotheses. Furthermore, a simultaneous regression was run. The goal was to find evidence for the prediction of the 
attribution of motives either genuine or self-serving by such factors as conscientiousness, agreeableness, emotional stability, openness to experience, extraversion, individualismcollectivism, work locus of control, self-monitoring, positive-negative affectivity, cultural mistrust, ethnic orientation, and perceived similarity. Two regressions, one with genuine motives as the dependent variable and the other with self-serving motives as the dependent variable were examined. In running these regressions and correlation analyses, all six cases for each respondent were averaged.

Hypotheses 9, 11, 12, and 13 referred to the moderation of the relationship between dispositional factors or identity factors and the attribution of genuine motives by the similarity of actor and observer. As a result, the preferred method for analyzing this hypothesis was delineated by Baron and Kenny (1986). This procedure is referred to as moderated regression or analysis of variance. In essence, the goal was to look for a significant interactive term or significant interaction between the predictor and the moderator. In one case, this was the conscientiousness of the observer and the similarity between the actor and the observer, respectively. The significance of the interaction term was assessed both by looking for a significant change in $r$-square when the step is presented in the hierarchical regression as well as by the corresponding beta which should have been significant. Yet another approach was to assess the variance accounted for by the interaction term using an analysis of variance also suggested by Baron and Kenny (1986). Initially, it is recommended that researchers examine the difference between correlations amongst variables based on categories. Then, the focus would shift to the interaction term which would be assessed by looking for a significant F-ratio. 
Hypotheses 14 and 15 referred to the comparison of means according to the specific behaviors performed. Basically, the point of the hypotheses was to examine which OCBs were attributed to what motives. As a result, the point was to compare the means for the attribution of genuine motives and self-serving motives in terms of altruistic and conscientiousness behaviors. Similarly, the comparison also took place for the behaviors such as sportsmanship and civic virtue. It was hypothesized that the genuine motives mean for altruistic and conscientiousness behaviors would be significantly higher than the mean of self-serving motives. Likewise, the self-serving mean would be significantly greater than the mean of genuine motives for the sportsmanship and civic virtue behaviors. In order to test for statistically significant differences between specific behaviors, a matched-pairs t-test will be computed.

For a complete guide to every analytic tool and the analytic strategy employed in this study please refer to Table 2 . 


\section{CHAPTER 4: Results}

The following chapter is structured to address the findings of the study in accordance with the analytic strategy proposed earlier. First, I address the descriptive statistics associated with each of the key study variables. Second, I examine the psychometric properties of the scales employed in the study. Third, the focus of this section shifts to checks of the manipulations (e.g., gender \& ethnicity). Finally, I turn to the tests of the specific hypotheses purported in this study.

\section{$\underline{\text { Descriptives }}$}

The first step in the analytic strategy was to assess the means, standard deviations, minimum and maximum values for each of the key study variables. The first set of descriptive statistics computed were those for the set of genuine motives attributions (see Table 3), which use a response scale of 1 "strongly disagree that this action is performed for genuine motives" to 5 "strongly agree that this action is performed for genuine motives". The first six means reported are those associated with the six hypothetical peers presented to participants during the course of the study. The range for these means is 3.06 to 3.56 with the lowest being for "Tyrone Jefferson" (African-American male) and the highest being for "Margaret Shorthouse" (White female). This finding suggests that more often than not participants felt that hypothetical peer \#2 was acting out citizenship behaviors out of genuine reasons. Meanwhile, participants were not as sure that hypothetical peer \#4 was acting out the same behaviors out of genuine reasons. This finding is mirrored by the fact that the mean for hypothetical peer \#3 (Takeisha Jackson; African-American female) was also considerably lower than that of all remaining hypothetical peers $(\underline{M}=3.09)$. One might say that these differences are not indicative of 
any true effect; however, upon examination of the standard deviations for all six peers, it is clear that the respective standard deviations of "Takeisha Jackson" and "Tyrone Jefferson" $\left(\underline{\mathrm{SD}}_{\mathrm{p} 3}=.77 ; \underline{\mathrm{SD}}_{\mathrm{p} 4}=.83\right)$ are also notably higher than that of other peers $\left(\underline{\mathrm{SD}}_{\mathrm{p} 1}\right.$ $\left.=.67 ; \underline{\mathrm{SD}}_{\mathrm{p} 2}=.67 ; \underline{\mathrm{SD}}_{\mathrm{p} 5}=.67 ; \underline{\mathrm{SD}}_{\mathrm{p} 6}=.65\right)$, which are all remarkably similar.

Nonetheless, upon examination of the standard deviations and their confidence intervals, it becomes apparent that there is no statistically significant difference between any of these differences. Finally, the aggregate (average) rating or attribution of genuine motives had a mean value of $3.32(\underline{\mathrm{SD}}=.53)$.

In the case of the attribution of self-serving motives, there was not nearly the same amount of variability as was the case with the attribution of genuine motives. For instance, the highest value associated with the attribution of self-serving motives is that of hypothetical peer \#3 (Takeisha Jackson; African-American female) $\left(\underline{\mathrm{M}}=3.36 ; \underline{\mathrm{SD}}_{\mathrm{p} 3}=\right.$ .73). The lowest value associated with the attribution of self-serving motives was that associate with hypothetical peer \#1 (Chandler Young; White male) $\left(\underline{\mathrm{M}}=3.25 ; \underline{\mathrm{SD}}_{\mathrm{pl}}=\right.$ .79). Certainly, the variability (i.e., range) is much more truncated when it comes to the attribution of self-serving motives as compared to the attribution of genuine motives. The overall mean for the attribution of self-serving motives was equal to 3.31 with a standard deviation equal to .60 .

The means and standard deviations are also reported in Table 3. First, the eight personality traits associated with either the attribution of genuine motives or self-serving motives are reported. These traits refer to the personality traits of the observer (attributer of motives). With regards to the Big Five personality traits, the means range from 2.80 for emotional stability $\left(\underline{\mathrm{SD}}_{\mathrm{es}}=.61\right)$ to 4.05 for agreeableness $\left(\underline{\mathrm{SD}}_{\mathrm{agr}}=.57\right)$. For other 
personality variables such as negative affectivity, the range of scores is far greater particularly because of the way the measures associated with each are scored. For instance, the mean score for negative affectivity was $41.98\left(\underline{S D}_{\text {neg affect }}=9.48\right)$. For selfmonitoring, the mean was remarkably similar to that of emotional stability and was the lowest of all personality traits $\left(\underline{\mathrm{M}}=2.75 ; \underline{\mathrm{SD}}_{\text {self mon }}=.57\right)$; the mean for collectivism was the highest of all personality traits $\left(\underline{\mathrm{M}}=4.14 ; \underline{\mathrm{SD}}_{\text {collect }}=.61\right)$. Finally, in the case of identification personality traits (i.e., cultural mistrust or ethnic orientation), the mean for cultural mistrust was expectedly low $\left(\underline{\mathrm{M}}=2.33 ; \underline{\mathrm{SD}}_{\text {cul mistrust }}=.66\right)$; the mean for ethnic orientation was unexpectedly low $\left(\underline{\mathrm{M}}=3.72 ; \underline{\mathrm{S}}_{\text {ethnic orient }}=.72\right)$ given the fact that the majority of the sample was Hispanic or African-American as opposed to Caucasian.

Finally, in terms of perceived similarity to hypothetical peers, the means range from $2.16\left(\underline{\mathrm{SD}}_{\mathrm{p} 3}=1.14\right)$ for "Takeisha Jackson" to $3.08\left(\underline{\mathrm{SD}}_{\mathrm{p} 3}=1.31\right)$ for "Consuelo Hernandez". The overall composite value of the perceived similarity was equal to 2.50 with a standard deviation of .67 .

$\underline{\text { Psychometrics }}$

In terms of reliability, the scales employed in the study exhibited a high degree of internal consistency as measured by coefficient alpha. Using another method of assessing reliability was impractical given the fact that participants were only given measures once and because of the large number of variables being measured (i.e., 14 variables). The coefficient alphas reported in Table 4 range from $\underline{\alpha}_{\text {emotional stability }}=.72$ to $\underline{\alpha}_{\text {self-serving motives }}=.93$. The remaining coefficient alphas are respectable given the fact that they are all above .70 (the limit of acceptability for internal consistency (Cronbach, 1965). One finding of note with regards to psychometrics is the internal consistency of 
the measures of the dependent variables (genuine motives and self-serving motives). The values reported in Table 4 are the mean coefficient alphas of all six scales of genuine motives or self-serving motives, which vary according to the hypothetical peer listed with the respective measure. That is, the coefficient alphas for the genuine motives scales range from .90 to .94 ; for the self-serving motives scales the range is .91 to .94 . This invariance is part of the reason why the average alpha is reported for these scales and not at the hypothetical individual level.

\section{Manipulation Checks}

In terms of the manipulation checks employed for the gender and ethnicity variables, a measure was used which assessed whether or not participants accurately perceived what the gender and ethnicity of each hypothetical peer was. Participants were asked to answer two questions for each of the six hypothetical peers. First, they were asked to choose what the peer's gender was by circling one of two choices: 1) male and 2) female. Second, the participants were asked to choose what they perceived the peer's ethnicities to be. This was done by circling one of three choices: 1) African-American, 2) Caucasian or White, or 3) Hispanic. The purpose of these manipulation checks were to assess the ability of the participants to recognize the differences in ethnicity and gender associated with each of the hypothetical peers.

The gender manipulation check was assessed first by establishing the number of individuals who were able to perceive the gender of all hypothetical peers. Eighty-four percent of the sample was able to match all hypothetical peers to their respective genders. In other words, 319 of 369 participants were able to perceive all six genders associated with the hypothetical peers. Forty-four more individuals or $11.9 \%$ were able to evaluate 
five of the six genders associated with the hypothetical peers. Five more individuals were able to associate four of six appropriate genders and only one was not able to select at least four of the appropriate genders. This heavily skewed distribution provides convincing evidence that the gender manipulation was effective.

The manipulation check also indicated that the ethnicity manipulation was also effective, since $84.8 \%$ of the participants were able to assign all the correct ethnicities to the respective hypothetical peers. Another $10.3 \%$ or 38 participants were able to match five out of six ethnicities to the hypothetical peers. Fourteen members of the sample were not able to match more than four of the six ethnicities associated to the hypothetical peers. The remaining 6 individuals $(1.6 \%)$ did not answer any of the questions and, as a result, are considered missing data points.

When combined the manipulation checks provide evidence that participants were clearly able to establish both the gender and ethnicity of the hypothetical peers to which they were exposed, as $74.3 \%$ of the sample ( 274 participants) was able to correctly choose all twelve genders and ethnicities. Another $16.4 \%$ were able to correctly choose eleven out of twelve genders and ethnicities. Yet another six percent were able to choose ten out of twelve and only ten participants could not select more than nine of the twelve correct genders and/or ethnicities. This provides convincing evidence that a large majority ( 3 out of 4 participants) were clearly able to assess the changes and/or differences in ethnicity and gender for the hypothetical peers. Hypothesis Tests

The remainder of this results section will address the tests of each hypothesis purported earlier. First, the tests will focus on assessing the validity of hypotheses 1 and 2, which 
dealt with the association of motives with similar and dissimilar individuals. Second, the tests will turn to the establishing of the relationships between observer personality traits with the two dependent variables. Third, the hypothesis tests will concentrate on testing the potential interaction between observer personality traits and identity traits with the similarity of hypothetical peers as it relates to the attribution of genuine motives or selfserving motives. Finally, the tests will center on the likelihood of association of specific organizational citizenship behaviors to either genuine motives or self-serving motives.

Hypothesis 1 referred to the likelihood of motives of similar individuals being associated to genuine motives rather than self-serving and it was hypothesized that organizational citizenship behaviors performed by similar individuals were more likely to be attributed to genuine motives than self-serving motives. In order to test this hypothesis, a matched-pairs t-test was used to compare the mean attribution of genuine motives for the most similar individuals to the mean attribution of genuine motives for the most dissimilar individuals. The means were $3.43\left(\underline{\mathrm{SD}}_{\mathrm{sim}}=.67\right)$ and $3.15\left(\underline{\mathrm{SD}}_{\mathrm{dis}}=\right.$ .84), respectively. The difference between the two means was significant, $\underline{t}(368)=5.13$ (p .05) providing support for Hypothesis 1 . In other words, results indicated that the motives for organizational citizenship behaviors performed by similar individuals are more likely to be attributed to genuine motives than those performed by dissimilar individuals.

Hypothesis 2 was similar to Hypothesis 1 in that it compared the mean attribution of motives to organizational citizenship behaviors. However, in this case, the mean attributions of self-serving motives were compared. In other words, it was hypothesized that organizational citizenship behaviors were more likely to be attributed to self-serving 
motives for dissimilar individuals than for similar individuals. A matched-pairs t-test, where the mean attribution of self-serving motives for dissimilar individuals was compared to the mean attribution of self-serving motives for similar individuals, was used to test this hypothesis test. The mean for the attribution of self-serving motives for similar individuals was $3.32\left(\underline{S D}_{\text {sim }}=.75\right)$ and the mean for the attribution of self-serving motives for dissimilar individuals was $3.33\left(\underline{S D}_{\mathrm{dis}}=.81\right)$. The difference between attributions of self-serving motives was $-.01(\underline{t}(368)=-.17 ; \mathrm{p}=.87)$. Contrary to expectations, this hypothesis was not supported indicating that similarity and/or dissimilarity does not make a difference when attributing self-serving motives but does make a difference when attributing genuine motives.

Hypotheses 3 through 8 and 10 refer to the relationships between specific personality traits and the dependent variables (genuine motives and self-serving motives). The first step in addressing these hypotheses is to compute zero-order correlations between the predictor variables (i.e., the Big Five, negative affectivity and selfmonitoring) and the attribution of genuine motives and self-serving motives. The next step is to simultaneously regress each of the dependent variables on to the predictor variables while accounting for covariates such as major, ethnicity, and age. This step is important because it accounts for the covariation that exists between the predictors and covariates. If the estimates of the relationship between variables are significant at both steps then the hypotheses would be supported. One fact that should be restated before moving on to the actual results of the hypothesis tests is that the dependent variables were formulated by computing the mean attribution across all six hypothetical peers. One might argue that this should not be done because of the correlation between means for all 
six peers, however, for the purposes of these hypotheses, the focus is on the overall attribution of motives and not the individual rating of motives for individual peers, as is the case with the initial hypotheses.

Hypothesis 3 through 6 dealt with the relationships between openness to experience, agreeableness, extroversion, and conscientiousness and genuine motives where it was hypothesized that each of these personality factors would be positively related to the attribution of genuine motives. In assessing the strength of these hypothesized relationships it becomes apparent (see Table 4), that only one of the four correlations is significant (the correlation between agreeableness and genuine motives is equal to .19). The correlations for openness to experience, conscientiousness, and extroversion with genuine motives were $-.03, .01$, and .02 , respectively, which indicates that there is virtually no relationship between the attribution of genuine motives and these personality traits. Furthermore, the regression weights for these three are -.07, -..01, and .02 , respectively and one of the betas was statistically significant. In summary, Hypothesis 3, 5, and 6 were not supported; however, hypothesis 4 was fully supported.

Hypothesis 7 refers to the relationship between emotional stability and selfserving motives. It was hypothesized that emotional stability would be positively related to the attribution of self-serving motives. The correlation between the attribution of selfserving motives and emotional stability of the observer (attributer or rater) was significant with a value equal to .11 ( $\mathrm{p} \quad .05)$. The regression results, however, did not yield a significant relationship between emotional stability and the attribution of selfserving motives. This provided partial support for Hypothesis 7. 
Hypothesis 8 centered around the relationship between the self-monitoring trait of the observer and the attribution of self-serving motives by the observer. It was hypothesized that there would be a positive relationship between self-monitoring and self-serving motives. The correlation between self-monitoring and self-serving motives was large as compared to relationships found with other personality traits $(\underline{r}=.12 ; \underline{p}$ $.05)$. When examining the unstandardized beta for this variable as reported in the simultaneous regression (see Table 7), it is clear that the relationship is not statistically significant after accounting for covariates $(\underline{\beta}=-.04)$. As a result, Hypothesis 8 received partial support.

Hypothesis 9 dealt with the potential interaction between the collectivism of attributers and the similarity of the observer-actor dyad when looking at the attribution of genuine motives. In order to examine this relationship it is necessary to conduct a moderated regression analysis or 2X2 ANOVA as described by Baron and Kenny (1986). In this instance, the similarity of the observer-actor dyad is the moderator of the collectivism-genuine motives relationship. Before conducting this procedure, however, an examination of the collectivism-genuine motives correlations was conducted in order to determine whether or not the respective relationships varied from similar to dissimilar hypothetical peers (actors). If there was a significant difference between the two variables then there would be initial evidence of a potential interaction. Upon examination of these correlations, it becomes clear that there is no significant difference between the two relationships (see Table 10). The z-test for the statistically significant difference between the two correlations was $\underline{z}(368)=.54$. Given the fact that the two 
correlations were not significantly different, the moderated regression was deemed unnecessary. In other words, Hypothesis 9 was not supported.

Hypothesis 10 addressed the relationship between the general temperament (i.e., affectivity) of the observer and the attribution of self-serving motives to OCBs. Hypothesis 10 claimed that the observer's negative affectivity and the attribution of selfserving motives are positively related. The correlation between negative affectivity and self-serving motives $(\underline{r}=.03)$ was not significant. Upon examination of the regression analysis, the beta for negative affectivity was equal to .00 . As a result, Hypothesis 10 was clearly not supported.

Hypothesis 11 examined the possibility of moderation of the relationship between conscientiousness and the attribution of genuine motives. In the case of the most similar hypothetical peer, the correlation between genuine motives and attributer conscientiousness was significant and equal to .13 ( $\mathrm{p} \quad .05)$ (see Table 8). For the least similar hypothetical peer, the correlation was -.12 ( $\mathrm{p} \quad .01)$ (see Table 9). In order to make sure that the difference between these to correlations was indeed significant (which would be indicative of differential effects or moderation), a z-to-r transformation was computed $(\underline{z}(368)=1.84 ; \underline{p} \quad .01)($ see Table 10$)$. This provided evidence that there was some differential functioning occurring. The next step was to test the moderation hypothesis using a 2X2 ANOVA to determine if the interaction term was statistically significant. In order to do this, the conscientiousness variable was dichotomized using a median split strategy, which would make all individuals below the median "low conscientiousness" individuals and all above "high conscientiousness" individuals. All individuals who were at the median would be excluded from the analysis; however, in 
this case, no one participant exhibited conscientiousness equal to the median. Upon examination of the ANOVA (see Table 11), the interaction term was significant with an F-ratio equal to $7.80(\underline{F}(1,734)=7.80 ; \underline{p} \quad .01)$. This suggests that there is indeed a moderation effect. Further examination of the interaction plot (see Figure 8), provides evidence of an ordinal interaction where the mean genuine motives attributed for similar individuals by low conscientiousness individuals is equal to 3.37 and 3.25 for dissimilar individuals by low conscientiousness individuals. For high conscientiousness individuals, the mean for similar individuals is 3.5 and for dissimilar individuals is 3.07 . All this provides further evidence of an interaction. That is, there is moderation of the relationship between conscientiousness and the attribution of genuine motives and hypothesis 11 was supported. Also noteworthy, is the fact that no other personality variable demonstrated such a discrepancy between the correlations of the most similar hypothetical peer compared to the least similar hypothetical peer.

Hypotheses 12 and 13 referred to the identity variables (i.e., cultural mistrust and ethnic orientation) and the potential for interactions with similarity between observer and actor when attributing self-serving motives. Similar to Hypotheses 9 and 11, the procedure to use was that suggested by Baron and Kenny (1986), moderated regression or 2X2 ANOVA. Before I conducted this analysis, I made sure to compare the correlations for the relationship between cultural mistrust and self-serving motives as well as the correlations for ethnic orientation and self-serving motives to ensure that the correlations for similar and dissimilar actors were significantly different. Upon examination of Table 10 , it became apparent that the correlations for cultural mistrust and self-serving motives were not significantly different for similar and dissimilar individuals $(\underline{z}(368)=.41)$. 
However, the correlations for ethnic orientation of the observer and self-serving motives were significantly different for similar and dissimilar individuals $(\underline{z}(368)=-2.30, \underline{p}$ $.05)$. Because the correlations were significantly different, a 2 X2 ANOVA was run to examine the potential interaction with similarity. An ANOVA was chosen over the regression approach because the ethnic orientation variable's distribution was bimodal and cut in half using a median split technique. The results of the ANOVA can be found in Table 12. The F-ratio for the interaction between similarity and ethnic orientation was clearly significant, $\underline{F}(1,734)=3.98(\underline{p} \quad .05)$. As can be seen in Figure 9 , the interaction between similarity of the peer-observer dyad and ethnic orientation of the observer is a disordinal one. That is, in the case of low ethnic orientation individuals, the attribution of self-serving motives for similar peers is equal to $\underline{M}=3.27$ while for dissimilar individuals it is equal to $\underline{\mathrm{M}}=3.40$. In the case of high ethnic orientation individuals, the attribution of self-serving motives for similar peers has a mean of 3.39 while for dissimilar peers a mean of 3.19. This was a rather unexpected finding. As a result, Hypotheses 12 and 13 were not supported.

Hypothesis 14 and 15 referred to the associations among the dependent variables and the four specific kinds of organizational citizenship behaviors. Hypothesis 14 proposed that the mean attribution of genuine motives for altruism OCBs and conscientiousness OCBs would be significantly different from the mean attribution of self-serving motives. In order to test this hypothesis, a matched-pairs t-test was computed to compare the differences among means. For the altruism OCBs, the mean difference was statistically significant, $\underline{t}(368)=6.21 ; \underline{p} \quad .01$ (see Table 14). For the conscientiousness OCBs, the tequaled -4.35 with 368 degrees of freedom (p .01). As 
expected, altruism OCBs were more likely attributed to genuine motives than self-serving motives. However, quite unexpectedly, conscientiousness OCBs were more often than not attributed to self-serving rather than genuine motives. Thus, hypothesis 14 was partially supported.

Hypothesis 15 dealt with the associations between the dependent variables and the sportsmanship and civic virtue dimensions of organizational citizenship. It was hypothesized that sportsmanship OCBs and civic virtue OCBs would be more frequently attributed to self-serving motives than genuine motives. Similarly, testing this hypothesis entailed computing a matched-pairs t-test to compare the differences among means for OCBs attributed to self-serving versus genuine motives. As seen in Table 14, the mean difference between sportsmanship OCBs attributed to genuine motives and sportsmanship OCBs attributed to self-serving motives was not statistically significant, $\underline{t}(368)=1.84$. However, in the case of civic virtue OCBs, the mean difference was statistically significant, $\underline{t}(368)=-2.01(\underline{p} \quad .05)$. This finding suggests that more often than not acts of civic virtue tend to be attributed to self-serving motives (as expected) while acts of sportsmanship do not to have a distinguishable tendency for attribution of motives. In other words, Hypothesis 15 was partially supported.

For a complete tabular presentation or summary of findings, please refer to Table 15. 


\section{CHAPTER 5: Discussion}

The results of this study provide insight into the process of attribution and how it affects the rating of specific job performance behaviors. The implications of this study's findings are threefold in that there are effects on the realm of attribution theory (Kelley, 1967), the body of work on organizational citizenship behaviors (Bateman \& Organ, 1982; Organ, 1988; 1990) and work on social comparison processes (Festinger, 1957). The emphasis in this chapter will first focus on the impact of social demographic cues on the process of attribution, particularly, when attributing genuine versus self-serving motives. The focus then shifts to the implications of the findings on the attribution of genuine versus self-serving motives to organizational citizenship behaviors. Third, the discussion will center on the potential effects of interactions between personality traits of the attributer (observer) and perceived similarity to actors (performers). Finally, the chapter finishes with potential limitations, future research directions, and conclusions.

\section{$\underline{\text { Social Demographic Cues }}$}

The process of social comparison as devised by Festinger (1957) deals with the need for positive distinctiveness that is desired by all individuals when comparing themselves to others. The works of Tsui and Gutek (1999) suggest that the first step in the process of social comparison is to use demographic cues (e.g., gender, ethnicity) to determine those who are similar and those who are not. Once this step is complete, the process of stereotyping begins which leads to the notion of initial impressions. The findings of the present study suggest that this process of social comparison affects not only initial impressions, but also the attribution of motives to behavior. To say that the attribution of motives is affected refers to the notion that similarity does indeed alter the 
motive that one attributes to another's behavior. The test of hypotheses 1 and 2 provided clear evidence that not only was the first step of social comparison taking place as the attribution of motives occurred but, that it had a distinguishable effect on what motives were attributed to the actions of others. That is, perceived similarity did have a large effect on whether or not individuals attributed genuine or self-serving motives to organizational citizenship behaviors. In fact, an individual perceived to be similar in gender and ethnicity was clearly considered to be performing actions out of genuine motivations. Likewise, individuals viewed as dissimilar in gender and ethnicities were mostly considered to be performing actions out of self-serving motivations. The key here is to understand that few researchers (Rioux \& Penner, 2001) before have attempted this approach of linking demographic variables to the process of attribution. The important implication of such a finding is that even though others perform charitable or seemingly selfless actions, the social cues associated with the actor will still take precedence in determining the cause behind such helping behaviors. This finding was expected and provided further support for Tsui and Gutek's (1999) assertions that demographic information is not only the vital input in the first step of forming initial impressions about others and their behavior; it also suggests that demographic information is in large part a vital initial input in the process of attributing causes to behavior of others. The relevance of such a finding becomes apparent when considering that in today's highly globalized workplace organizations may be better served to employ training programs which focus on eliminating the reliance on demographic cues to form impressions, and the attribution of motives to actions, simply to avoid interpersonal conflict amongst employees. To 
some degree this might even be incorporated in training programs such as diversity training, which has been marred with reactivity and residual conflict amongst employees. Genuine versus Self-Serving Motives and OCBs

Mark Bolino in 1999 suggested that not enough was known about the relationships between motives and organizational citizenship behaviors, which had primarily been considered as selfless acts. As discussed earlier, the motive behind organizational citizenship behaviors has never been a concern to organizations because OCBs are thought to be beneficial to organizations regardless of motivations (Rioux \& Penner, 2001). However, because of the potential effects that attributing motives can have on ratings of performance (i.e., causal attribution error), it would behoove organizations to at the very least be mindful of the findings of this study. For instance, the potential for causal attribution error, has a negative impact on the criterion validity of performance ratings. Subsequently, that loss in validity can be symptomatic of criterion contamination that yields losses in the utility of performance ratings (Sackett, 1998). It is these losses in utility that can lead to problems in the essential organizational functions of personnel evaluation, employee advancement, and organizational productivity. As a result, it is important for organizations to be aware not only of the underlying process that leads to motives being attributed, but also which specific types of organizational citizenship behaviors are linked to specific motives (i.e., genuine or self-serving). Understanding this can provide insight into what behaviors should be encouraged throughout the organization and it also lends credence to the notion that some behaviors, although beneficial in the short-term, can be costly in the long run (Bolino, 1999; Organ, 1990). That is, the consequences of such behaviors can be costly in corrective measures 
as well as potential legal losses and make it necessary to understand what other behaviors are potentially costly. Moreover, Alonso, et al. (2000) and Conway (1999) suggest that organizational citizenship behaviors are so eagerly rewarded and encouraged by organization that they are almost a part of task performance and not behaviors that go above and beyond the call of duty. For instance, in military settings, providing support for fellow soldiers is a requirement not a choice made on individuals. This permeation of organizational citizenship behaviors as required behavior throughout organizations is yet another reason why knowing which behaviors are attributed to safe or less potentially costly motives (i.e., genuine motives) is so important to organizations and supervisors alike.

The findings of this study suggest that particular organizational citizenship behaviors are more likely linked to one kind of motive than another. The tests of hypotheses 14 and 15 provided partial support for the notion that some behaviors are more likely to be attributed to genuine versus self-serving, or vice versa. In essence, the altruism dimension of organizational citizenship was unmistakably attributed to genuine motivations. These behaviors include covering for absent coworkers, help others by taking on part of their respective workloads, orienting new employees, and volunteering to do things without being asked. According to most participants in the present study, these behaviors will more often than not be attributed to motives that are genuine in nature. The same cannot be said for conscientiousness behaviors. In the case of behaviors such as being punctual everyday or not spending time on personal calls or nonwork related talk, there was a distinguishable difference between the motives to which they are attributed (genuine or self-serving). This could be a result of the fact that these 
behaviors tend to be ambiguous when assessing internal versus external causes. For instance, these behaviors are low in distinctiveness and generally high in consistency and in consensus according to Kelley's theory of attribution (1967). This combination of behavioral descriptors makes it more likely to attribute behaviors to self-serving motives or external causes. This is unlike the case of altruism where behaviors are high in distinctiveness, high in consistency and low in consensus clearly making it an internal cause or genuine motive; this finding was quite unexpected. Nonetheless, a potential explanation is that being punctual and avoiding non-work related talk are behaviors that are characteristic of Hispanic societies. Given that the sample was comprised in large part of Hispanics (47\%), this artifact of Hispanic societies could have a negative impact on the relationship between genuine motives and conscientious behaviors. Yet another potential explanation is that all these behaviors tend to benefit the organization directly and other individuals indirectly. In other words, since the immediate benefactor is the organization and not other people, few are willing to say that what motivates these behaviors are intrinsic motivators rather extrinsic motivators which are generally derived from the organization and not others (Bem, 1995).

In terms of sportsmanship (part 1 of Hypothesis 15), behaviors were not clearly attributable to either genuine motives or self-serving motives. As expected, these behaviors did marginally lean towards being attributed to self-serving motives (see Table 14). This occurs because most of the sportsmanship behaviors benefit the organization, and not other individuals, directly. In fact, when considering what behaviors comprise the sportsmanship dimension, it is obvious that most lean towards benefiting the organization and not others. These behaviors include not taking excess time off, finding 
fault with others, and not complaining about trivial issues. One potential reason for the marginal significance of this hypothesis is the fact that one of the three behaviors listed in the measure does not distinctly benefit the organization or others; this lack of clarity for that behavior can lead to a misattribution of motives. However, if this item was removed from the computation of the sportsmanship variable, the internal consistency of the scale would be extremely detrimentally effected. Finally, in terms of civic virtue behaviors, or behaviors such as attending voluntary organizational functions, organizing get-togethers, keeping up with organizational changes, assessing what is best for the organization, the attribution of self-serving rather than genuine motives was heavily supported. This was expected as all of these behaviors directly benefit the organization.

Since these four dimensions have varying attributions of motives based on the target of the action support the implication that some behaviors although encouraged by the organization can have a variable impact on organizational functions is supported. In essence, it is important for the organization to avoid directly encouraging OCBs such as conscientiousness, sportsmanship, and civic virtue because it can lead employees to view others who perform these behaviors as self-serving. On the surface, this may not seem deleterious to organizational functioning, however, in cases where organizations operate using team structures, this connotation can be quite severe as team members can be pitted against one another causing relationship conflict (Sternberg \& Dobson, 1987). This potential conflict can lead to lost efficiency, poor communication, and monetary costs incurred from trying to salvage the team effort. All of these factors can have an adverse effect on productivity and the potential costs are not worth dealing with for any organization. Simply knowing and treating the less potentially costly organizational 
citizenship behaviors appropriately can help minimize these effects. In other words, if an organization allows such OCBs to occur without being openly rewarded or recognized, it might prevent the potential losses. Yet another approach might be to remove these OCBs, or similar dimensions, from peer performance appraisals so that the issue of criterion contamination does not create potential losses of utility. Doing so could prevent raters from committing causal attribution error and all of these suggestions are potential time and money savers for organizations who employ peer ratings.

Personality, Similarity, and Potential Interactions

One area of research that is lacking elaboration is the role of attributer (observer) characteristics on the attribution of causes (motives). In other words, little is known about what traits of the person attributing causes to behaviors (i.e., personality traits, identity traits, affect) relate to the causes that are attributed. Although researchers (Hazebroek, Howells, \& Day, 2001) have attempted to address these kinds of relationships, these researchers have only examined very specific personality traits and causes. Hazebroek, Howells, and Day (2001) looked at the relationship between one personality trait (e.g., trait anger of the rater or observer) and the intent of an antagonist in critical incident techniques. This is one of very few works that has developed the theoretical perspective of rater traits as they relate to causes attributed by the rater. This same kind of relationship was examined using an expanded scale in the present study.

Hypotheses 3 through 13 examined a series of relationships between attributer (observer or rater) traits and the causes (motives) attributed by these raters. In essence, the goal was to examine how one's own traits affect one's attribution of causes to behaviors such as organizational citizenship behaviors. This series of hypotheses dealt 
with variables such as extroversion, conscientiousness, agreeableness, emotional stability, openness to experience, self-monitoring, collectivism, negative affectivity, cultural mistrust, ethnic orientation, and perceived similarity to hypothetical peers as they each relate to genuine and self-serving motives. These hypotheses attempt to provide a very comprehensive look at the effects of attributer characteristics on the attribution of motives. Finally, a set of hypotheses ( $\mathrm{H} 9, \mathrm{H} 11, \mathrm{H} 12$, \& H13) examined the possibility of interactions between observer traits and the similarity of the observer-actor dyad; evidence was found for some interaction effects.

The tests of the personality trait hypotheses suggest that some rater personality traits do indeed have an impact on the motives attributed to organizational citizenship behaviors. For example, collectivism (H9) was significantly predictive of self-serving motives. This finding was unexpected and not hypothesized. Nonetheless, there are simple explanations that can be provided for this finding. For collectivistic individuals the initial thought is to assume that they will view such behaviors as being collectivistic. However, if as discussed earlier, the process of social comparison is taking place, collectivistic individuals might tend to view themselves favorably when compared to others. This is symptomatic of a common attribution error known as self-serving bias (Festinger, 1957). In essence, individuals possess a need for positive distinctiveness and if there is one trait that makes them distinct from others, they might have a tendency to view all others as lesser on that same trait. In the case of collectivists, the actions of others (assumed by collectivists as being motivated by self-serving purposes) would be seen as indicators of individualism and not collectivism. Yet another potential explanation might be that collectivism is almost inherent in organizational citizenship 
behaviors. For example, three out of the four types of organizational citizenship behaviors were more associated with self-serving motives than with genuine motives. These behaviors were all targeted at benefiting the overall organization and not individuals. In Western cultures, much emphasis is placed on being self-reliant and individualistic. Given that emphasis on individualism and the aversion for collectivism (especially as it relates to the organization as compared to family settings), it is obvious that many would view organizational citizenship behaviors as being attributable to selfserving motives which are often linked to extrinsic motivators (provided more often than not by the organizational collective). Both of these plausible explanations provide insight into the underlying mechanism beneath this unexpected finding.

One finding that was expected was the positive relationship between perceived similarity to hypothetical peers and the attribution of genuine motives. As discussed earlier, the need for positive distinctiveness that drives the process of social comparison causes individuals to attribute genuine motives to similar individuals more so than to dissimilar individuals. As such, this finding was undoubtedly expected.

Another area of research that has yet to be addressed is the potential for interactions between similarity and specific personality traits. In the present study, it was hypothesized that such an interaction would be exhibited between the personality trait conscientiousness (which has traditionally been the most clearly predictive of organizational citizenship behaviors (Borman \& Motowidlo, 1993)) and the perceived similarity of the hypothetical peer. Respondents were divided into two categories as either high or low conscientiousness individuals. The responses on the genuine motives scale of these high versus low individuals were compared for the most similar and most 
dissimilar hypothetical peer. Indeed, the hypothesis was supported and there was an interaction between the conscientiousness of the attributer and the similarity of the perceived hypothetical peer as it related to the attribution of genuine motives. For individuals low on conscientiousness, the mean attributions of genuine motives for similar and dissimilar hypothetical peers were not extremely different. However, for individuals high on conscientiousness, the mean attributions of genuine motives for similar and dissimilar hypothetical peers were considerably distinct from one another (see Figure 8). This distinction provided support for an ordinal interaction. That is, because conscientious individuals tend to be thoughtful and dependable, it was expected that they would indeed be easily cued to the changes in similarity of hypothetical peers. Because these high conscientiousness individuals would be so easily cued, they would be most reactive to the changes in gender and ethnicity. This has one clear implication for organizations whose employees work at marginalized locations but in concert with one another: if organizations have individuals who work together, but through electronic mediums, in different locations, peer ratings amongst these peers might be skewed because of the limited amount of information the peers have about one another. This finding suggests that the more information peers have about one another, the less likely the chances are of moderation. This clearly provides support for the notion that the more individuals know about one another the more informed appraisals they can make of one another's behaviors. However, this assumption is not without peril. Simply stated, the more individuals know about each other, the greater the likelihood that rater errors will occur when rating performance. As such, this dual pitfall leads to the possibility of an inverse parabolic relationship between known information about one another and errors 
(e.g., halo) that harm the validity of peer ratings. It seems that the ideal situation would be one where conscientious individuals know a moderate amount of information about peers, which is very much like the relationship exhibited between anxiety and performance (cf. Muchinsky, 2002).

\section{$\underline{\text { Limitations }}$}

The present study suffers from a few maladies that are common among all withinsubject experiments that use student samples. First, the external validity of the present study's findings is questionable for a few reasons. The use of student samples when considering behaviors that generally occur in an organizational setting can lead to questions about the veracity of results. The argument here is that the characteristics of students are fundamentally different from employees of an organization. For example, students are not similar to employees in that they are not all fulltime employees and, students generally tend to be employed in positions that are not permanent. In addition, students do not tend to be committed to organizations, which is one behavioral descriptor of organizational citizenship. All of these differences and more lend credence to the idea that the findings yielded from student samples are not always generalizable to other samples, particularly, organizational samples. Despite the fact that this lack of generalizability may affect the validity of results yielded from student samples, it is important to note that the sample used in the present study is comprised of a large number of fulltime employees and students who are returning to school after time spent out in the workforce. These characteristics make this student sample much more like organizational samples than expected. 
The use of student sample causes another potential problem with external validity since the rating process employed in the within-subjects experiment may lack fidelity. This possible lack of realism in the process of rating the performance of others might cause one to say that results yielded using a student sample cannot be applied to organizational settings. One reason for this criticism is that some believe students are not experienced at rating the performance of others. Another reason is that students do not generally rate more than one peer at a time. In the present study, however, I would counter these criticisms by noting that students do have experience rating others. For instance, students are asked to rate the performance of their professors and/or instructors at the end of each semester. One might say that these evaluations differ from those used in the present study because they do not tap into behaviors that would be considered above and beyond the call of duty. However, I would argue that the performance evaluations used for professors do tap into behaviors that go above and beyond the call of duty. One such example is the professor's job task of willingness to help students with problems outside of classroom hours. This is an example of an OCB that is organizationally supported to the point that it is almost a requirement. Furthermore, I would argue that the fidelity of the rating process in the present study is similar to other rating processes in that most organizations performance evaluations take place all at once similar to the method used in the present study. Moreover, it is important to note that the evaluation of motives is quite different from the rating of performance. As a result, fidelity of the evaluation might not even be an issue. Finally, it is important to note that often external validity is not the primary focus of experiments (Mook, 1983) and, the 
findings of experiments in traditionally controlled settings should not be ignored because they lack external validity.

Another limitation with the present study is the general demographic makeup of the sample. First, nearly $47 \%$ of the sample is Hispanic, which is equal to the combined number of African-Americans (23.4\%) and Whites (24.9\%). Second, and more importantly, is the fact that two-thirds of the sample was female. These two characteristics of the sample also limit the external validity of the findings of the present study. That is, the findings of this study are more generalizable to markets where Hispanics are a majority such as South Florida, the Southwestern United States, and Southern California. Moreover, the fact that Hispanics comprise almost one half of the sample has potential effects on the findings, particularly, when dealing with hypotheses that include personality traits whose emphasis and value can vary from culture to culture (e.g., individualism-collectivism).

The limitations involved in the present study are not limited only to issues of external validity but also to issues of internal validity. One threat to internal validity that could influence the results is the possibility of fatigue amongst participants. The effects of fatigue would be detrimental to the responding towards the end of the complete administration of measures. In other words, the fact that there were so many measures included in the study could have had an effect on the responses provided by participants on measures toward the end of the data collection process. I would counter this by noting that the complete process of administration was divided into halves so as to counteract the effects of fatigue. One problem that did arise was that a small number of participants did not complete both halves of the administration process $(n=32)$. 
Another potential issue for internal validity is that the dependent variables were measured with a questionnaire that used the same twenty-three items but from a different frame of reference. One problem that was expected because of the common method variance is that there would be a high intercorrelation between the genuine motives and self-serving motives variables. Notwithstanding this potential collinearity, the correlation between the dependent variables was not significant providing evidence that there was no relationship between the two (see Table 4). This had ramifications not only the internal validity of the measures but also on the analysis strategy employed to test Hypothesis 14 and Hypothesis 15.

Finally, it can be said that the manipulations made according to gender and ethnicity were too obvious or transparent which can create reactivity issues with the measure. However, in this case, I would argue that the goal was to make the manipulation obvious so that participants would be cued to the changes in gender and ethnicity. This obvious nature lends strength to the manipulation.

\section{Future Research Directions}

There are two major research directions that can be elaborated upon based on the results of this study. The first area of concentration that needs to be expanded upon is the effect of attributer characteristics on the attribution of causes to behavior. There are a variety of relationships that should be tested including: 1) the relationship between self esteem and internal causes or external causes, 2) the relationship between self efficacy of the attributer and the attribution of internal and/or external causes, and 3) the relationship between the five-factor personality structure and the three distinct behavioral descriptors (i.e., consensus, consistency, and distinctiveness) that yield attributions of internal and/or 
external causes. Understanding how the attributes of an individual relate to the process of causal attribution in which they partake can provide insight into the underlying mechanisms of fundamental attribution error and/or self-serving biases.

The other area that future research should explore is the relationship between motives for organizational citizenship behaviors and organizational productivity. In other words, it would be extremely beneficial to provide empirical evidence that motives lead to losses in utility and that these losses in utility cause monetary losses. In order to test this model, however, it is recommended that researchers use a longitudinal design as opposed to a cross-sectional design. Moreover, I would still recommend that individuals interested in testing this model continue to use a within-subjects design. The reason for this recommendation is that in order to test this model correctly one should employ an organizational sample, which is limiting in nature because of the dearth of organizations willing to lend large numbers of employees to work on non-task activities. As such, a within-subjects design would be appropriate and most feasible. A longitudinal design would be necessary because it allows a researcher to examine changes in productivity over time, which can then be predicted by differences in motives attributed. Using this combination of methodological components would make testing this important structural model as comprehensive as possible.

\section{Conclusions}

The crucial implications of this study are threefold. First, perceived similarity has an important impact on the attribution of motives to specific job performance behaviors. The relevance of this finding is that causal attribution errors in performance ratings may more often than not be associated with the perception of demographic cues. Second, 
specific organizational citizenship behaviors such as altruism, conscientiousness, sportsmanship, and civic virtue are more likely to be associated to specific motives that are centered on the target of the behavior being performed. The implication here is that organizations may be best served not to encourage certain types of organizational citizenship behaviors because of their propensity to spark interpersonal conflict that could be costly to the organization. Lastly, there is evidence that similarity does moderate the relationship between personality traits of the attributer and the attribution of genuine motives. The belief here is that there differential functioning occurs according to the demographic similarity of others, which can in turn lead to differences when attributing causes to behaviors on performance ratings. 
Table 1

Multiple definitions of organizational citizenship behaviors \& constructs

Author

Definition of Contextual Performance

Organ (1988)

Defined Organizational Citizenship

Behavior as similar to contextual

performance or the performance on

activities that are not required to succeed on the job but can affect rating of performance as well as one's standing in an organization. Contained factors of organizational commitment but no mention of prosocial behavior outside the workplace.

Borman \& Motowidlo (1993)

Aspects of job performance which comprise all that which goes "above and beyond" what is prescribed by one's job description.

Motowidlo \& Van Scotter (1994)

Same as above; Different in that they claim that contextual performance is not similar for all jobs.

Borman \& Motowidlo (1997)

Supplemented previous definition by claiming that contextual performance could be considered as an overarching construct which included OCBs and prosocial behavior

Goodman (1999)

Contextual performance is that which does not comprise the required tasks of job performance but entails features such as interpersonal facilitation, commitment, and counterproductive behaviors. 
Table 2

Analytic Strategies for Individual Hypotheses

Hypothesis

Analytic Strategy

Hypotheses 1-2

1) Matched-Pairs t-test

Hypotheses 3-8, 10

1) Zero-Order Correlations

2) Multiple Regression

1) Moderated Regression or $2 X 2$

Hypothesis 9, 11-13 ANOVA (if r's warrant the analysis)(Baron \& Kenny, 1986)

Hypotheses 14-15

1) Matched-Pairs t-test 
Table 3

Descriptive Statistics for key study variables

\begin{tabular}{|c|c|c|c|c|}
\hline Variable & Mean & SD & Minimum & Maximum \\
\hline Genuine Motives Person 1 & 3.45 & .67 & 1.00 & 5.00 \\
\hline Genuine Motives Person 2 & 3.56 & .67 & 1.00 & 5.00 \\
\hline Genuine Motives Person 3 & 3.09 & .77 & 1.00 & 5.00 \\
\hline Genuine Motives Person 4 & 3.06 & .83 & 1.00 & 5.00 \\
\hline Genuine Motives Person 5 & 3.32 & .67 & 1.00 & 5.00 \\
\hline Genuine Motives Person 6 & 3.45 & .65 & 1.00 & 5.00 \\
\hline Genuine Motives $^{\mathrm{a}}$ & 3.32 & .53 & 1.00 & 4.88 \\
\hline Self-Serving Motives Person 1 & 3.25 & .79 & 1.00 & 5.00 \\
\hline Self-Serving Motives Person 2 & 3.28 & .83 & 1.00 & 5.00 \\
\hline Self-Serving Motives Person 3 & 3.36 & .73 & 1.04 & 5.00 \\
\hline Self-Serving Motives Person 4 & 3.33 & .76 & 1.00 & 5.00 \\
\hline Self-Serving Motives Person 5 & 3.32 & .72 & 1.04 & 5.00 \\
\hline Self-Serving Motives Person 6 & 3.32 & .75 & 1.00 & 5.00 \\
\hline Self-Serving Motives ${ }^{\mathrm{a}}$ & 3.31 & .60 & 1.26 & 4.89 \\
\hline Extroversion & 3.33 & .81 & 1.00 & 5.00 \\
\hline Conscientiousness & 3.58 & .66 & 1.70 & 5.00 \\
\hline Agreeableness & 4.05 & .57 & 1.80 & 5.00 \\
\hline Emotional Stability & 2.80 & .61 & 1.20 & 4.30 \\
\hline Openness to Experience & 3.80 & .54 & 1.60 & 4.90 \\
\hline Self-Monitoring & 2.75 & .57 & 1.06 & 4.94 \\
\hline Collectivism & 4.14 & .61 & 2.20 & 5.76 \\
\hline Negative Affectivity & 41.98 & 9.48 & 23.00 & 74.00 \\
\hline Cultural Mistrust & 2.33 & .66 & 1.00 & 4.00 \\
\hline Ethnic Orientation & 3.72 & .72 & 1.20 & 5.00 \\
\hline Perceived Similarity Person 1 & 2.33 & 1.24 & 1.00 & 5.00 \\
\hline Perceived Similarity Person 2 & 2.53 & 1.19 & 1.00 & 5.00 \\
\hline Perceived Similarity Person 3 & 2.16 & 1.14 & 1.00 & 5.00 \\
\hline Perceived Similarity Person 4 & 2.29 & 1.25 & 1.00 & 5.00 \\
\hline Perceived Similarity Person 5 & 2.60 & 1.22 & 1.00 & 5.00 \\
\hline Perceived Similarity Person 6 & 3.08 & 1.31 & 1.00 & 5.00 \\
\hline Perceived Similarity ${ }^{a}$ & 2.50 & .67 & 1.00 & 4.83 \\
\hline Manipulation Check & 11.61 & .82 & 6.00 & 12.00 \\
\hline Age $^{b^{2}}$ & 2.09 & .75 & 1.00 & 5.00 \\
\hline
\end{tabular}

Note. $\mathrm{N}=369$.

${ }^{a}$ Refers to the aggregate value or the overall mean across hypothetical peers.

${ }^{b}$ The range for the age variable is $1=$ Less than 20 years of age, $2=20$ to $29,3=30$ to $39,4=40$ to $49,5=$ More than 49 . Therefore, a mean of 2.09 is equivalent to a mean of age range of 20 to 29 . 
Table 4

Intercorrelations among key study variables

\begin{tabular}{|c|c|c|c|c|c|}
\hline Variable & 1 & 2 & 3 & 4 & 5 \\
\hline 1.Genuine Motives & $(.92)^{\mathrm{a}}$ & & & & \\
\hline 2.Self-Serving Motives & -.03 & $(.93)^{\mathrm{a}}$ & & & \\
\hline 3.Extroversion & .02 & -.01 & $(.87)$ & & \\
\hline 4. Conscientiousness & .01 & .04 & .02 & $(.79)$ & \\
\hline 5. Agreeableness & $.19 * *$ & .05 & $.29 * *$ & $.13^{*}$ & $(.74)$ \\
\hline 6. Emotional Stability & -.07 & $-.11 *$ & -.01 & .07 & $-.12 *$ \\
\hline 7. Openness to Experience & -.03 & .08 & $.27^{* *}$ & $.17^{* *}$ & $.23^{* *}$ \\
\hline 8. Self-Monitoring & .04 & $.12 *$ & $.33 * *$ & .09 & -.07 \\
\hline 9. Collectivism & .06 & $.15^{* *}$ & $.11^{*}$ & $.13^{* *}$ & $.37 * *$ \\
\hline 10. Negative Affectivity & -.01 & .03 & $-.39 * *$ & $-.32 * *$ & $-.25 * *$ \\
\hline 11. Cultural Mistrust & $-.11 *$ & -.04 & $-.18 * *$ & .04 & $-.27 * *$ \\
\hline 12. Ethnic Orientation & $.13 *$ & .00 & .06 & .06 & $.15^{* *}$ \\
\hline 13. Perceived Similarity & $.12 *$ & .03 & .02 & -.07 & .00 \\
\hline 14. Manipulation Check & -.04 & .02 & -.06 & .02 & -.06 \\
\hline 15. Age & -.05 & -.08 & -.01 & $.19^{* *}$ & .01 \\
\hline 16. Major & -.05 & -.09 & $-.12^{*}$ & -.07 & $-.18 * *$ \\
\hline 17. Ethnicity & -.04 & -.09 & .04 & .09 & -.04 \\
\hline
\end{tabular}

Note. $\mathrm{N}=369 .{ }^{\mathrm{a}}$ Average of the coefficient alphas for the six genuine motive and six self-serving motive scales.

"--." = Reliability estimate not computed because variables are comprised of one item.

$*=\mathrm{p} \quad .05 ; * *=\mathrm{p} \quad .01$. 
Table 4 (cont'd)

Intercorrelations among key study variables

\begin{tabular}{lcccc}
\hline \multicolumn{1}{c}{ Variable } & 6 & 7 & 8 & 9 \\
\hline & & & & \\
1. Genuine Motives & & & & \\
2.Self-Serving Motives & & & & \\
3.Extroversion & & & & \\
4. Conscientiousness & & & & \\
5. Agreeableness & & & & \\
6. Emotional Stability & $(.72)$ & & & \\
7. Openness to Experience & .01 & $(.73)$ & & \\
8. Self-Monitoring & $.10^{*}$ & $.20^{* *}$ & $(.76)$ & \\
9. Collectivism & $-.16^{* *}$ & .03 & $-.23^{* *}$ & $(.88)$ \\
10. Negative Affectivity & $-.42^{* *}$ & $-.34^{* *}$ & $.18^{* *}$ & $-.13^{*}$ \\
11. Cultural Mistrust & -.04 & $-.16^{* *}$ & -.04 & -.05 \\
12. Ethnic Orientation & -.10 & -.04 & -.07 & $.24^{* *}$ \\
13. Perceived Similarity & -.01 & -.08 & -.06 & $.17^{* *}$ \\
14. Manipulation Check & $.11^{*}$ & -.01 & .03 & -.07 \\
15. Age & $.16^{* *}$ & -.04 & $.11^{*}$ & -.01 \\
16. Major & -.04 & -.07 & -.02 & .02 \\
17. Ethnicity & .04 & .01 & .09 & .00 \\
\hline
\end{tabular}

Note. $\mathrm{N}=369 .{ }^{\mathrm{a}}$ Average of the coefficient alphas for the six genuine motive and six self-serving motive scales.

"--" = Reliability estimate not computed because variables are comprised of one item. $*=\mathrm{p} \quad .05{ }^{* *}=\mathrm{p} \quad .01$. 
Table 4 (cont'd)

Intercorrelations amongst key study variables

\begin{tabular}{|c|c|c|c|c|c|}
\hline Variable & 10 & 11 & 12 & 13 & 14 \\
\hline \multicolumn{6}{|l|}{ 1.Genuine Motives } \\
\hline \multicolumn{6}{|l|}{ 2.Self-Serving Motives } \\
\hline \multicolumn{6}{|l|}{ 3.Extroversion } \\
\hline \multicolumn{6}{|l|}{ 4. Conscientiousness } \\
\hline \multicolumn{6}{|l|}{ 5. Agreeableness } \\
\hline \multicolumn{6}{|l|}{ 6. Emotional Stability } \\
\hline \multicolumn{6}{|l|}{ 7. Openness to Experience } \\
\hline \multicolumn{6}{|l|}{ 8. Self-Monitoring } \\
\hline \multicolumn{6}{|l|}{ 9. Collectivism } \\
\hline 10. Negative Affectivity & $(.83)$ & & & & \\
\hline 11. Cultural Mistrust & $.21^{* *}$ & (.84) & & & \\
\hline 12. Ethnic Orientation & $-.12 *$ & .01 & $(.85)$ & & \\
\hline 13. Perceived Similarity & -.05 & -.07 & .09 & -- & \\
\hline 14. Manipulation Check & -.05 & .03 & -.05 & -.03 & -- \\
\hline 15. Age & $-.17 * *$ & .06 & .06 & -.08 & .03 \\
\hline 16. Major & $.14^{* *}$ & .04 & -.03 & .06 & .00 \\
\hline 17. Ethnicity & .03 & -.04 & $-.13 *$ & -.01 & $.13^{*}$ \\
\hline
\end{tabular}

Note. $\mathrm{N}=369 .{ }^{\text {a }}$ Average of the coefficient alphas for the six genuine motive and six self-serving motive scales.

"--" = Reliability estimate not computed because variables are comprised of one item.

$*=\mathrm{p} \quad .05 ; * *=\mathrm{p} \quad .01$. 
Table 4 (cont'd)

Intercorrelations amongst key study variables

\section{Variable}

15

16

1.Genuine Motives

2.Self-Serving Motives

3.Extroversion

4. Conscientiousness

5. Agreeableness

6. Emotional Stability

7. Openness to Experience

8. Self-Monitoring

9. Collectivism

10. Negative Affectivity

11. Cultural Mistrust

12. Ethnic Orientation

13. Perceived Similarity

14. Manipulation Check

15. Age

16. Major

17. Ethnicity

$\begin{array}{ll}-- & \\ -.14^{* *} & - \\ -.03 & .05\end{array}$

Note. $\mathrm{N}=369 .{ }^{a}$ Average of the coefficient alphas for the six genuine motive and six self-serving motive scales.

"--" = Reliability estimate not computed because variables are comprised of one item.

$*=\mathrm{p} \quad .05 ; * *=\mathrm{p} \quad .01$. 
Table 5

Mean Differences between similar and dissimilar individuals (Test of Hypotheses $1 \& 2$ )

\begin{tabular}{cccccc}
\hline Individuals & $\begin{array}{c}\text { Similar Peer } \\
\text { Mean(SD) }\end{array}$ & $\begin{array}{c}\text { Dissimilar } \\
\text { Peer } \\
\text { Mean(SD) }\end{array}$ & $\mathrm{t}$ & $\mathrm{df}$ & Significance \\
\hline Genuine & $3.43(.67)$ & $3.15(.84)$ & 5.13 & 368 & .00 \\
Self-Serving & $3.32(.75)$ & $3.33(.81)$ & -.17 & 368 & .87 \\
\hline
\end{tabular}

Note. The test for mean comparisons was a matched-pairs t-test. 
Table 6

Hierarchical regression analysis for key study variables predicting the attribution of genuine motives

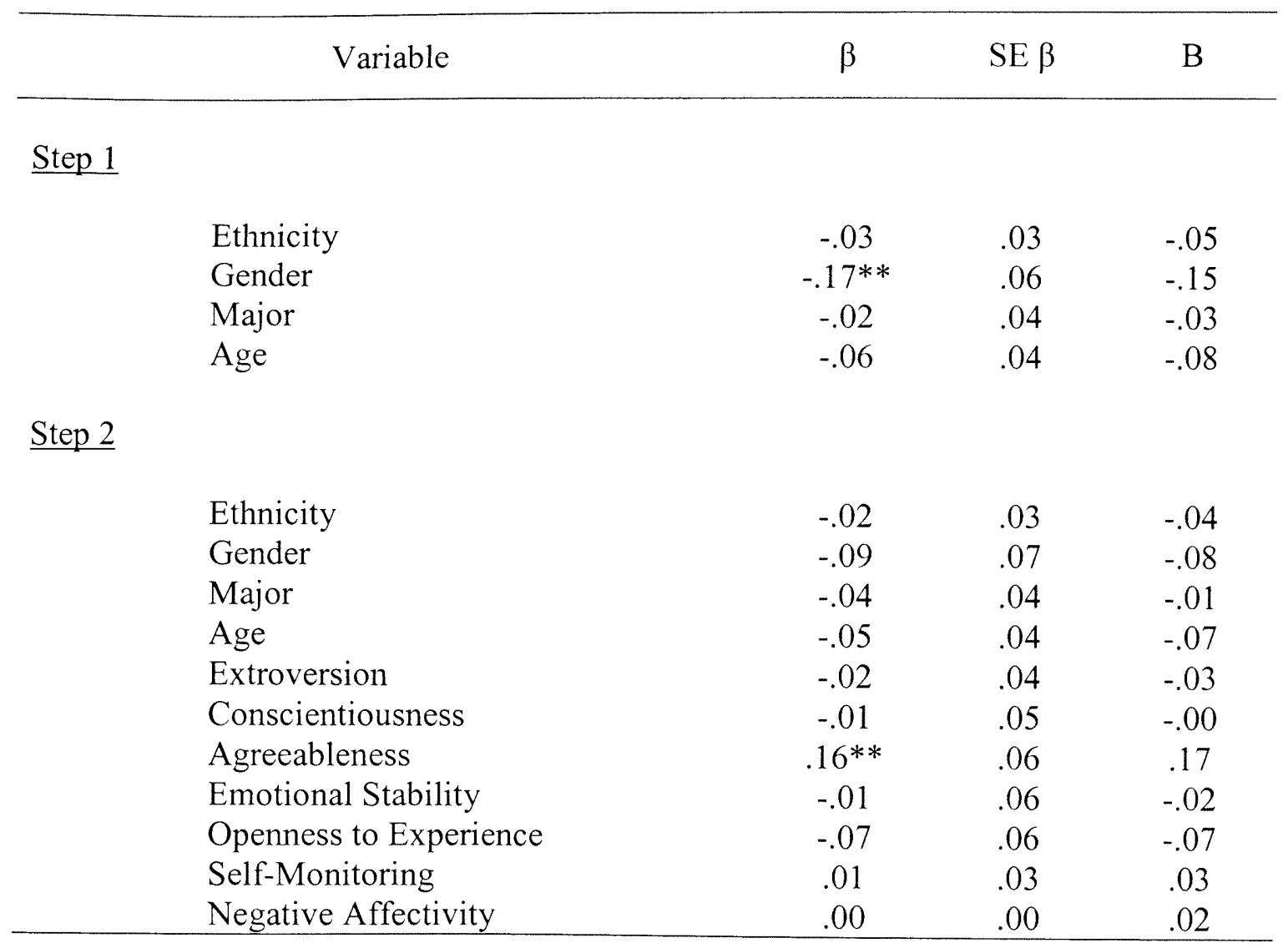

$\mathrm{N}=369$. Step $1 \mathrm{R}^{2}=.03 * ; \quad \mathrm{R}^{2}=.06^{* *}$.

$*=\mathrm{p} \quad .05 ; * *=\mathrm{p} \quad .01$. 
Table 7

Hierarchical regression analysis for key study variables predicting the attribution of selfserving motives

Variable

$\underline{\text { Step } 1}$

Ethnicity

Gender

Major

Age $\beta$

$-.07$

$-.06$

$-.05$

$-.07$
$\operatorname{SE} \beta$

B

Step 2

Ethnicity

Gender

Major

Age

Extroversion

Conscientiousness

Agreeableness

Emotional Stability

Openness to Experience

Self-Monitoring

Negative Affectivity $\begin{array}{lll}-.06 & .04 & -.09\end{array}$

$\begin{array}{lll}-.07 & .08 & -.05\end{array}$

$\begin{array}{lll}-.06 & .04 & -.08\end{array}$

$\begin{array}{lll}-.06 & .05 & -.07\end{array}$

$\begin{array}{lll}-.07 & .05 & -.09\end{array}$

$\begin{array}{lll}.03 & .05 & .04\end{array}$

$\begin{array}{lll}-.05 & .07 & -.05\end{array}$

$\begin{array}{lll}-.06 & .06 & -.06\end{array}$

$\begin{array}{lll}.07 & .07 & .07\end{array}$

$\begin{array}{lll}-.04 & .03 & -.08\end{array}$

$-.00$

.01

$-.03$

$\mathrm{N}=369$. Step $1 \mathrm{R}^{2}=.02 ; \quad \mathrm{R}^{2}=.05^{*}$.

$*=\mathrm{p} \quad .05 ; * *=\mathrm{p} \quad .01$. 
Table 8

Correlations between genuine motives, self-serving motives, and key personality variables for similar individuals

\begin{tabular}{lcc}
\hline \multicolumn{1}{c}{ Variables } & Genuine Motives & Self-Serving Motives \\
\hline & $.10^{*}$ & .08 \\
Extroversion & $.13^{*}$ & .03 \\
Conscientiousness & $.25^{* *}$ & .02 \\
Agreeableness & -.03 & -.07 \\
Emotional Stability & -.02 & .09 \\
Openness to Experience & .02 & $-.11^{*}$ \\
Self-Monitoring & -.06 & $-.11^{*}$ \\
Collectivism & .00 & .01 \\
Negative Affectivity & -.09 & $-.11^{*}$ \\
Cultural Mistrust & .09 & .09 \\
Ethnic Orientation & &
\end{tabular}

$\mathrm{N}=369 . *=\mathrm{p} \quad .05 ; * *=\mathrm{p} \quad .01$.

Table 9

Correlations between genuine motives, self-serving motives, and key personality variables for dissimilar individuals

Variables

Extroversion

Conscientiousness

Agreeableness

Emotional Stability

Openness to Experience

Self-Monitoring

Collectivism

Negative Affectivity

Cultural Mistrust

Ethnic Orientation
Genuine Motives

$-.03$

$-.12 *$

.06

$-.09$

$-.02$

.04

$-.01$

.08

$-.09$

$.12 *$
Self-Serving Motives

.03

.07

.09

$-.06$

.07

$-.09$

$-.01$

$-.01$

$-.08$

$-.08$

$\mathrm{N}=369 .{ }^{*}=\mathrm{p} \quad .05 ; * *=\mathrm{p} \quad .01$. 
Table 10

Comparison between personality and identity correlations for similar versus dissimilar individuals

\begin{tabular}{lccccc}
\hline \multicolumn{1}{c}{ Relationship } & $\mathrm{r}_{\text {similar }}$ & $\mathrm{r}_{\text {dissimilar }}$ & $\mathrm{z}$ & $\mathrm{df}$ & Significance \\
\hline $\begin{array}{l}\text { Collectivism/ } \\
\text { Genuine Motives } \\
\text { Conscientiousness/ }\end{array}$ & -.06 & -.01 & .54 & 368 & .29 \\
$\begin{array}{l}\text { Genuine Motives } \\
\text { Cultural }\end{array}$ & .13 & -.12 & 1.84 & 368 & .03 \\
$\begin{array}{l}\text { Mistrust/Self- } \\
\text { Serving Motives }\end{array}$ & -.11 & -.08 & .41 & 368 & .35 \\
$\begin{array}{l}\text { Ethnic } \\
\text { Orientation/Self- }\end{array}$ & .09 & -.08 & -2.30 & 368 & .01 \\
Serving Motives & & & & & \\
\hline
\end{tabular}

Note. Fisher's $\mathrm{r}$ to $\mathrm{z}$ transformation used to compare correlations. $\mathrm{N}=369$. 
Analysis of variance table for moderating effects of similarity on the relationship between conscientiousness and genuine motives

\begin{tabular}{lrccc}
\multicolumn{1}{c}{ Source } & Mean Square & df & F & Significance \\
\hline Conscientiousness $^{\mathrm{a}}(\mathrm{C})$ & .059 & 1 & .01 & .93 \\
Similarity $(\mathrm{S})_{\mathrm{C} \mathrm{X} \mathrm{S}}$ & 13.684 & 1 & 3.08 & .33 \\
Error & 4.450 & 1 & 7.80 & .01 \\
\hline Note & .570 & 734 & & \\
\hline
\end{tabular}

Note. Degrees of freedom for error equal 734 because of the comparison of 369 ratings for similar individuals and 369 ratings for dissimilar individuals.

${ }^{a}$ Conscientiousness was dichotomized using a median split technique.

Table 12

Analysis of variance table for moderating effects of similarity on the relationship between ethnic orientation and self-serving motives

\begin{tabular}{lrccc}
\multicolumn{1}{c}{ Source } & Mean Square & df & F & Significance \\
\hline Ethnic Orientation $^{\mathrm{a}}$ (EO) & .073 & 1 & .01 & .92 \\
Similarity (S) $_{\text {EO X S }}$ & .055 & 1 & .01 & .92 \\
Error & 2.40 & 1 & 3.98 & .05 \\
\hline Not & .603 & 734 & & \\
\hline
\end{tabular}

Note. Degrees of freedom for error equal 734 because of the comparison of 369 ratings for similar individuals and 369 ratings for dissimilar individuals.

${ }^{a}$ Ethnic orientation was dichotomized using a median split technique 
Table 13

Intercorrelations among genuine motives, self-serving motives, and organizational citizenship behavior dimensions

\begin{tabular}{lcccccccc}
\hline \multicolumn{1}{c}{ Variable } & M & SD & 1 & 2 & 3 & 4 & 5 & 6 \\
\hline Genuine Motives & 3.45 & .67 & $(.92)^{\mathrm{a}}$ & & & & & \\
Self-Serving Motive & 3.56 & .67 & -.03 & $(.93)^{\mathrm{a}}$ & & & & \\
Altruism & 3.33 & .41 & $.55^{* *}$ & $.70^{* *}$ & $(.92)$ & & & \\
Conscientiousness & 3.32 & .47 & $.60^{* *}$ & $.66^{* *}$ & $.72^{* *}$ & $(.91)$ & & \\
Sportsmanship & 3.15 & .48 & $.51^{* *}$ & $.56^{* *}$ & $.56^{* *}$ & $.72^{* *}$ & $(.85)$ & \\
Civic Virtues & 3.37 & .45 & $.60^{* *}$ & $.68^{* *}$ & $.80^{* *}$ & $.76^{* *}$ & $.63^{* *}$ & $(.92)$ \\
& & & & & & & &
\end{tabular}

Note. $\mathrm{N}=369 .{ }^{\text {a }}$ Average of the coefficient alphas for the six genuine motive and six self-serving motive scales.

$*=\mathrm{p} \quad .05 ; * *=\mathrm{p} \quad .01$.

Table 14

Mean comparisons of the attribution of genuine versus self-serving motives for specific organizational citizenship behavior dimensions

\begin{tabular}{cccccc}
\hline OCBs & $\begin{array}{c}\text { Genuine } \\
\text { Motives } \\
\text { Mean(SD) }\end{array}$ & $\begin{array}{c}\text { Self-Serving } \\
\text { Motives } \\
\text { Mean(SD) }\end{array}$ & $\mathrm{t}$ & $\mathrm{df}$ & Significance \\
\hline Altruism & $3.49(.58)$ & $3.18(.68)$ & 6.21 & 368 & .00 \\
Conscientiousness & $3.20(.67)$ & $3.44(.74)$ & -4.35 & 368 & .00 \\
Sportsmanship & $3.10(.67)$ & $3.19(.69)$ & -1.84 & 368 & $.07 \dagger$ \\
Civic Virtue & $3.32(.60)$ & $3.42(.66)$ & -2.01 & 368 & .05 \\
\hline
\end{tabular}

Note. $\mathrm{N}=369 . " \dagger "=$ Marginally significant results $(\mathrm{p} \quad .10)$. 
Table 15

Summary of findings

\begin{tabular}{|c|c|}
\hline Hypothesis & Results \\
\hline Hypothesis 1 & Full Support \\
\hline Hypothesis 2 & No Support \\
\hline Hypothesis 3 & No Support \\
\hline Hypothesis 4 & Full Support \\
\hline Hypothesis 5 & No Support \\
\hline Hypothesis 6 & No Support \\
\hline Hypothesis 7 & Partial Support \\
\hline Hypothesis 8 & Partial Support \\
\hline Hypothesis 9 & No Support \\
\hline Hypothesis 10 & No Support \\
\hline Hypothesis 11 & Full Support \\
\hline Hypothesis 12 & No Support \\
\hline Hypothesis 13 & Full Support \\
\hline Hypothesis 14 & Partial Support \\
\hline Hypothesis 15 & Partial Support \\
\hline
\end{tabular}


Figure 1

Organ and Ryan's (1995) Model of Organizational Citizenship Behaviors

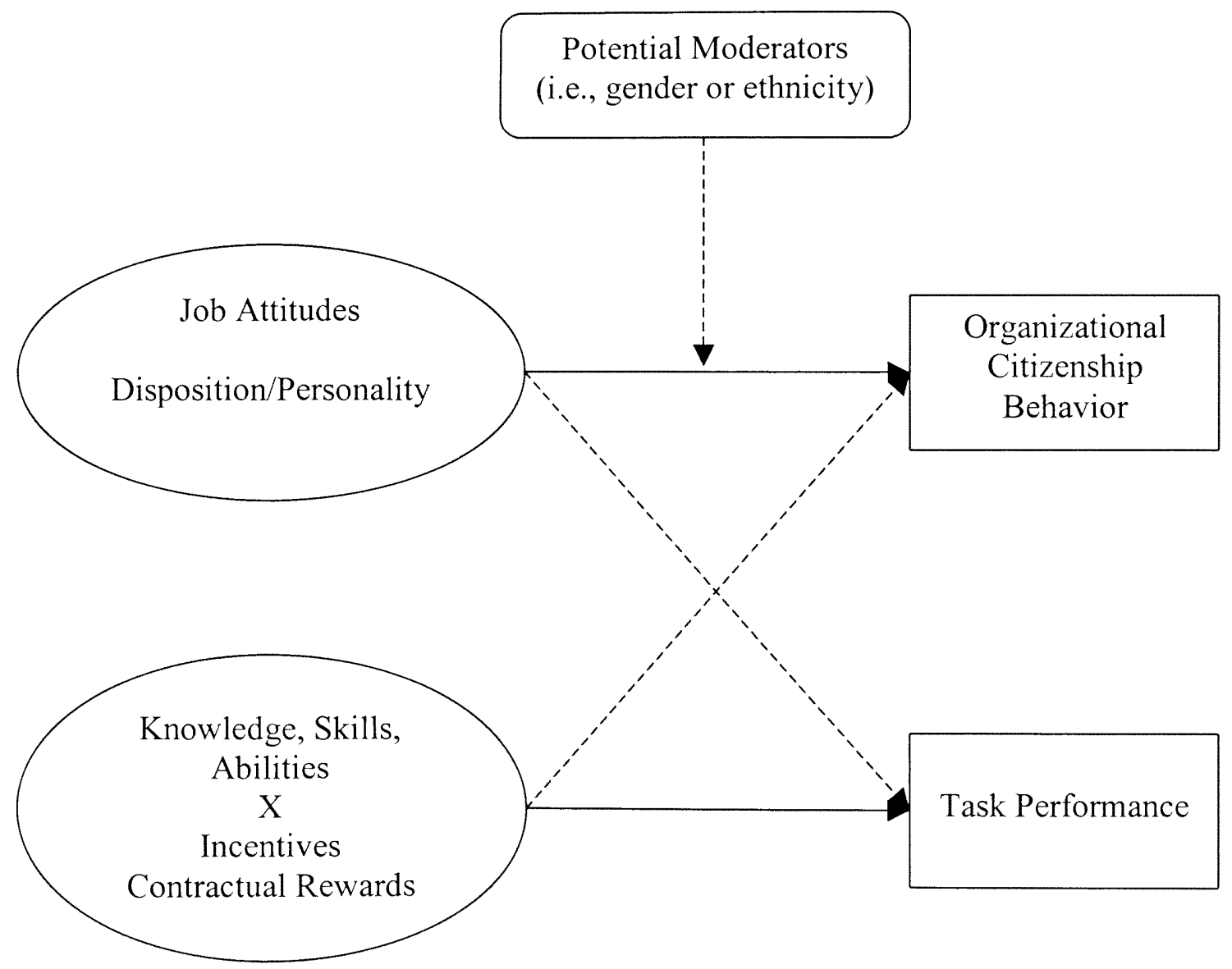

Note. Dotted lines indicate weaker relationships. 
Figure 2

Borman and Motowidlo's (1993; 1997) Model of Contextual Performance
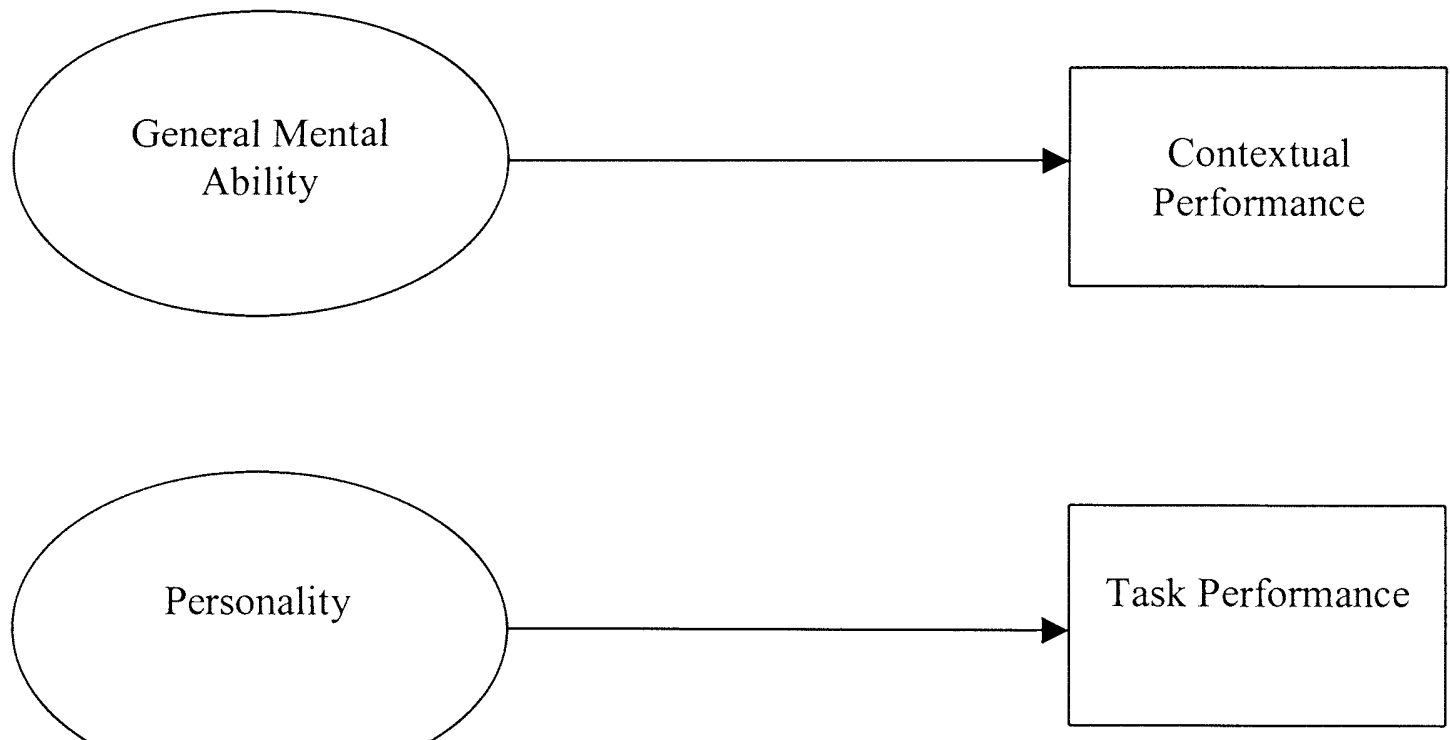
Figure 3

Leary and Kowalski’s (1990) Model of Impression Management

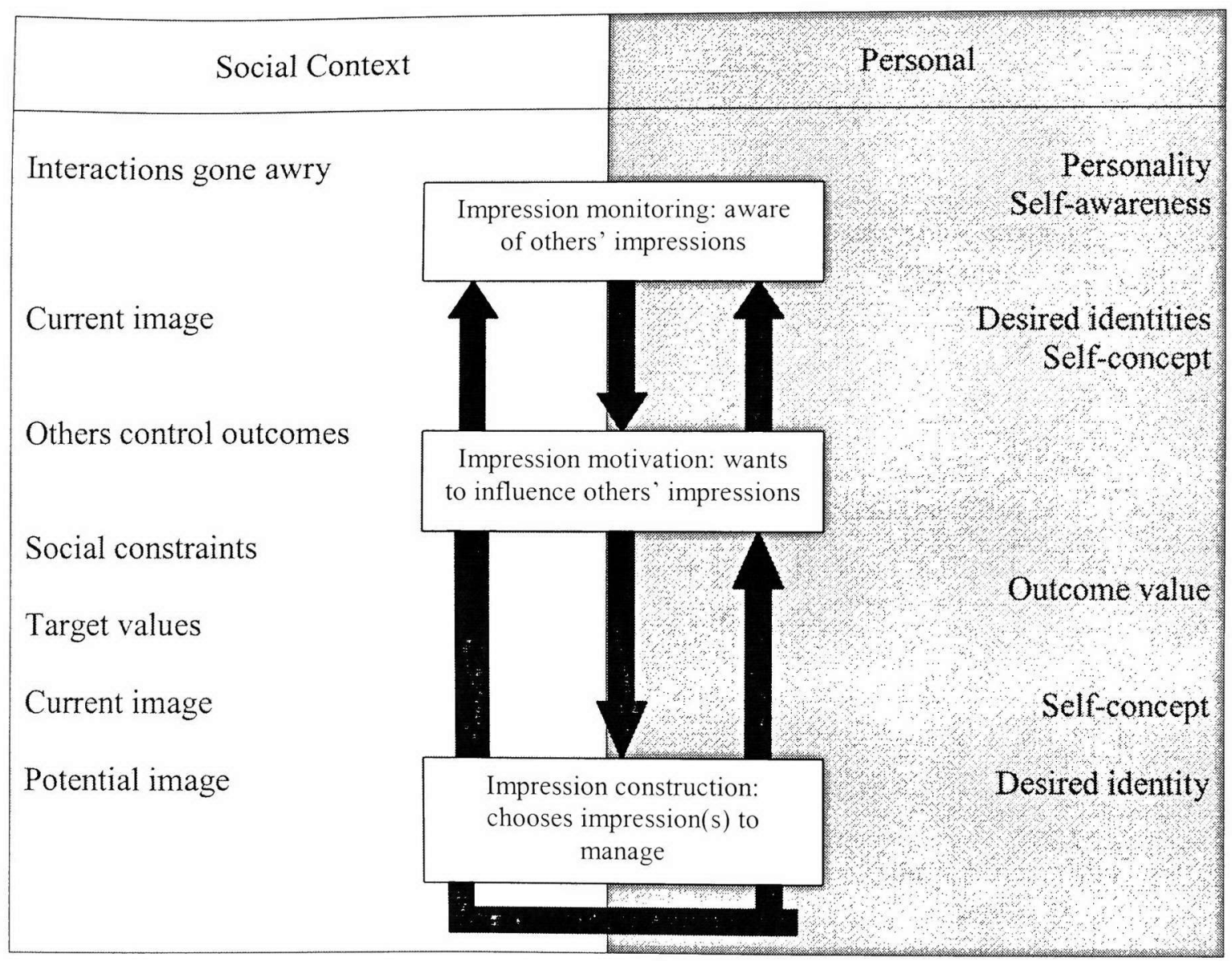


Figure 4

Kelley's Theory of Causal Attribution (1967)

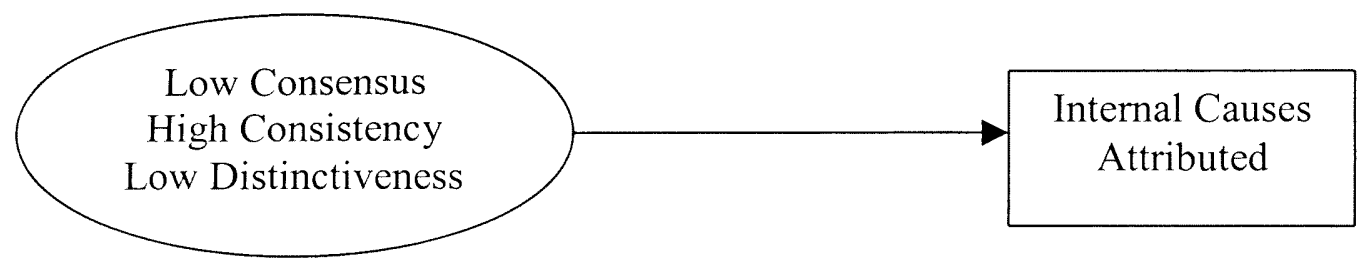

High Consensus

High Consistency High Distinctiveness

External Causes

Attributed 
Figure 5

Turner's Model of Social Categorization Theory (1987)

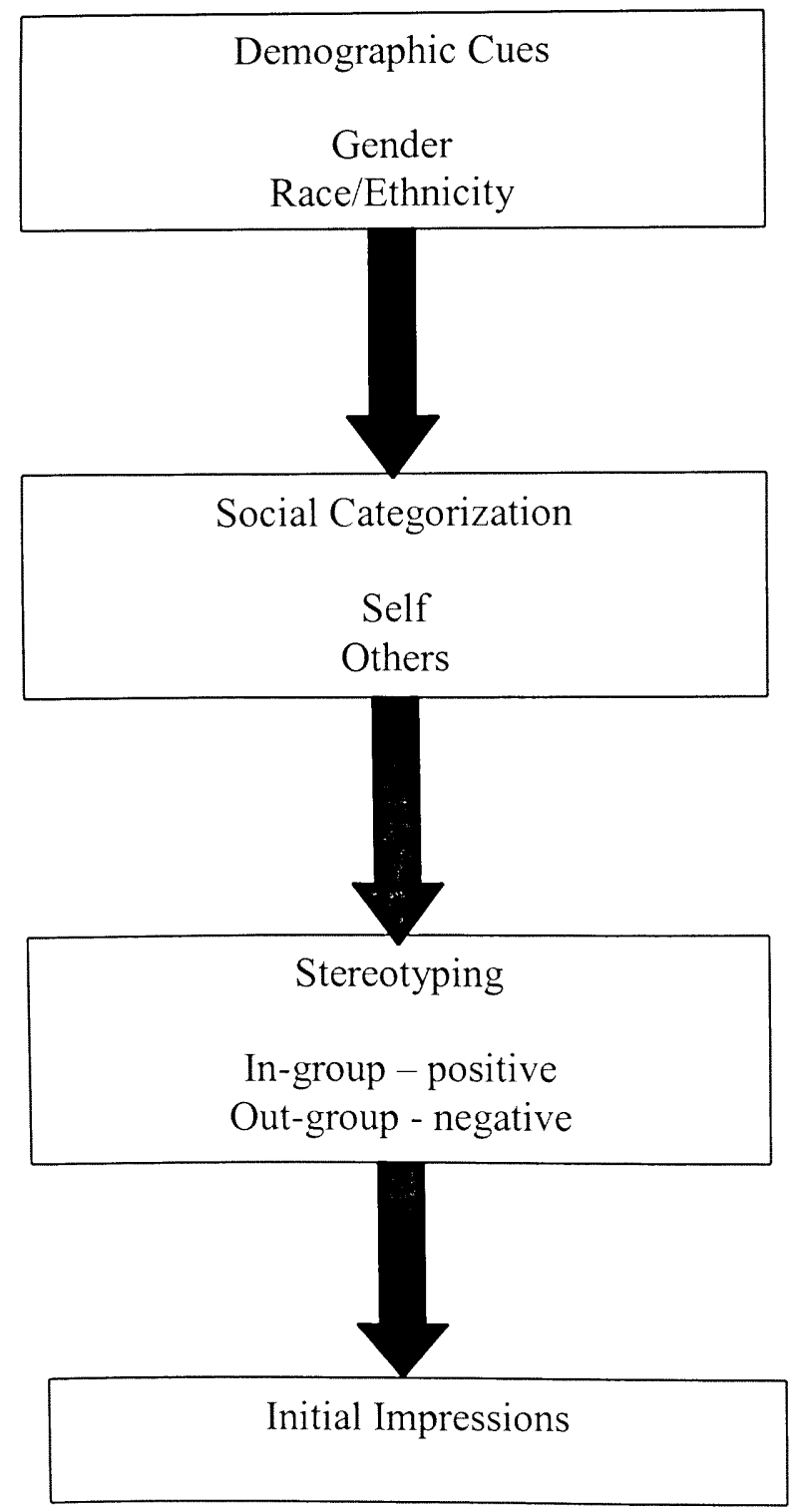


Figure 6

Festinger's Social Comparison Theory (1957)

Need for positive distinctiveness

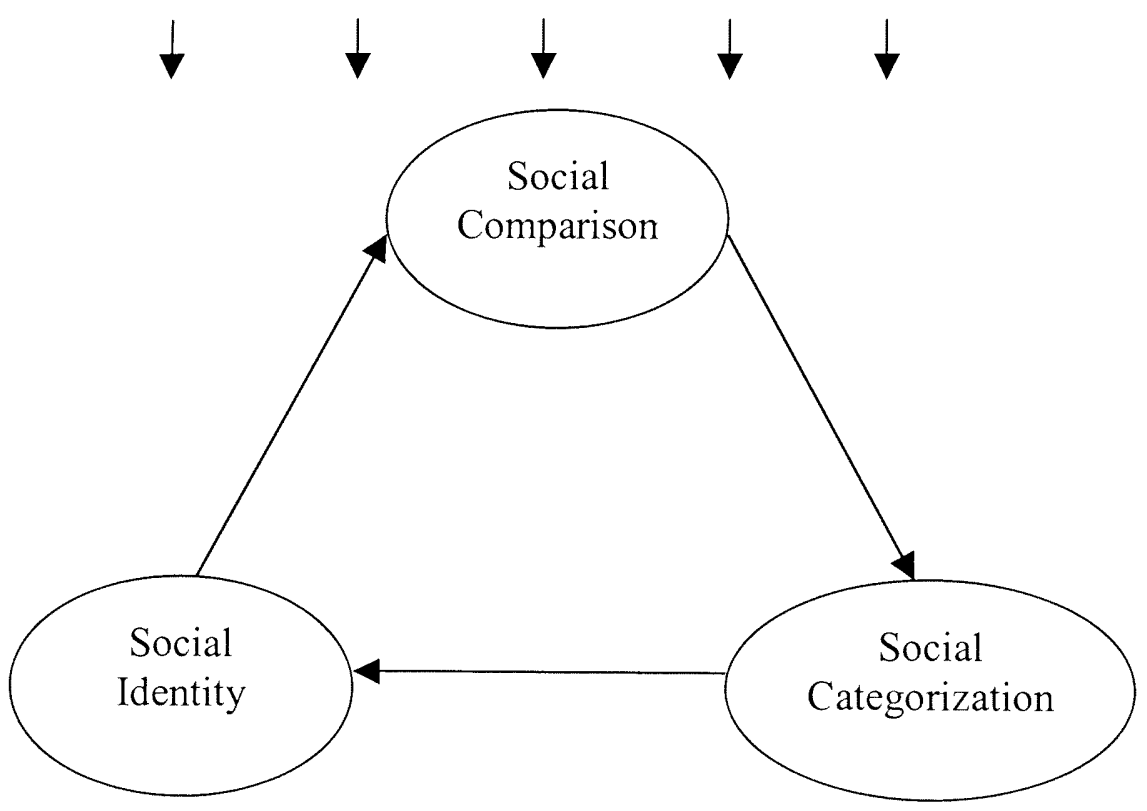


Figure 7

A New Integrated Framework for the Attribution of Motives

$\underline{\text { Step } 1}$

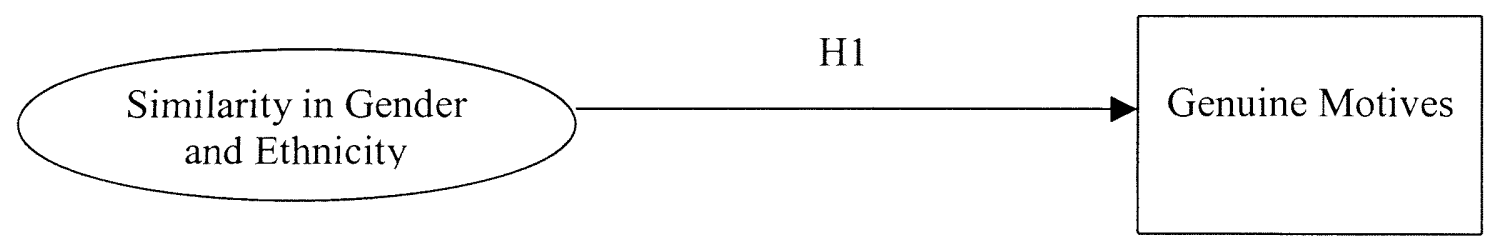

Similarity in Gender and Ethnicity

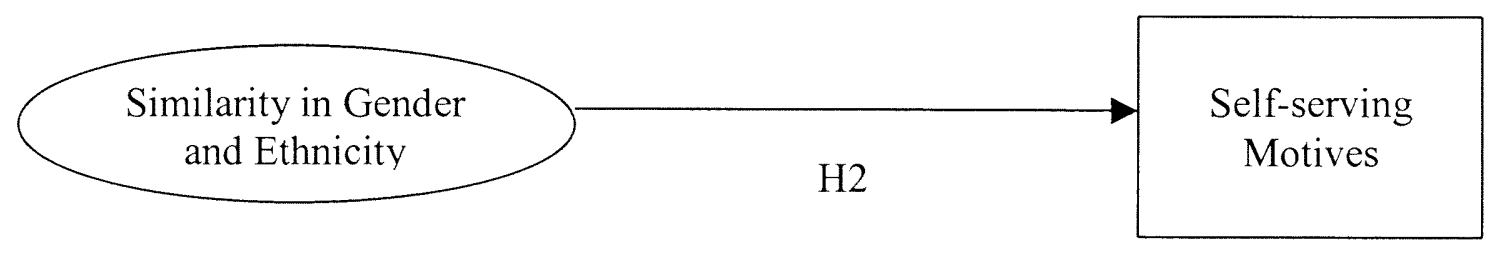


Figure 7 (cont'd)

\section{Step 2}

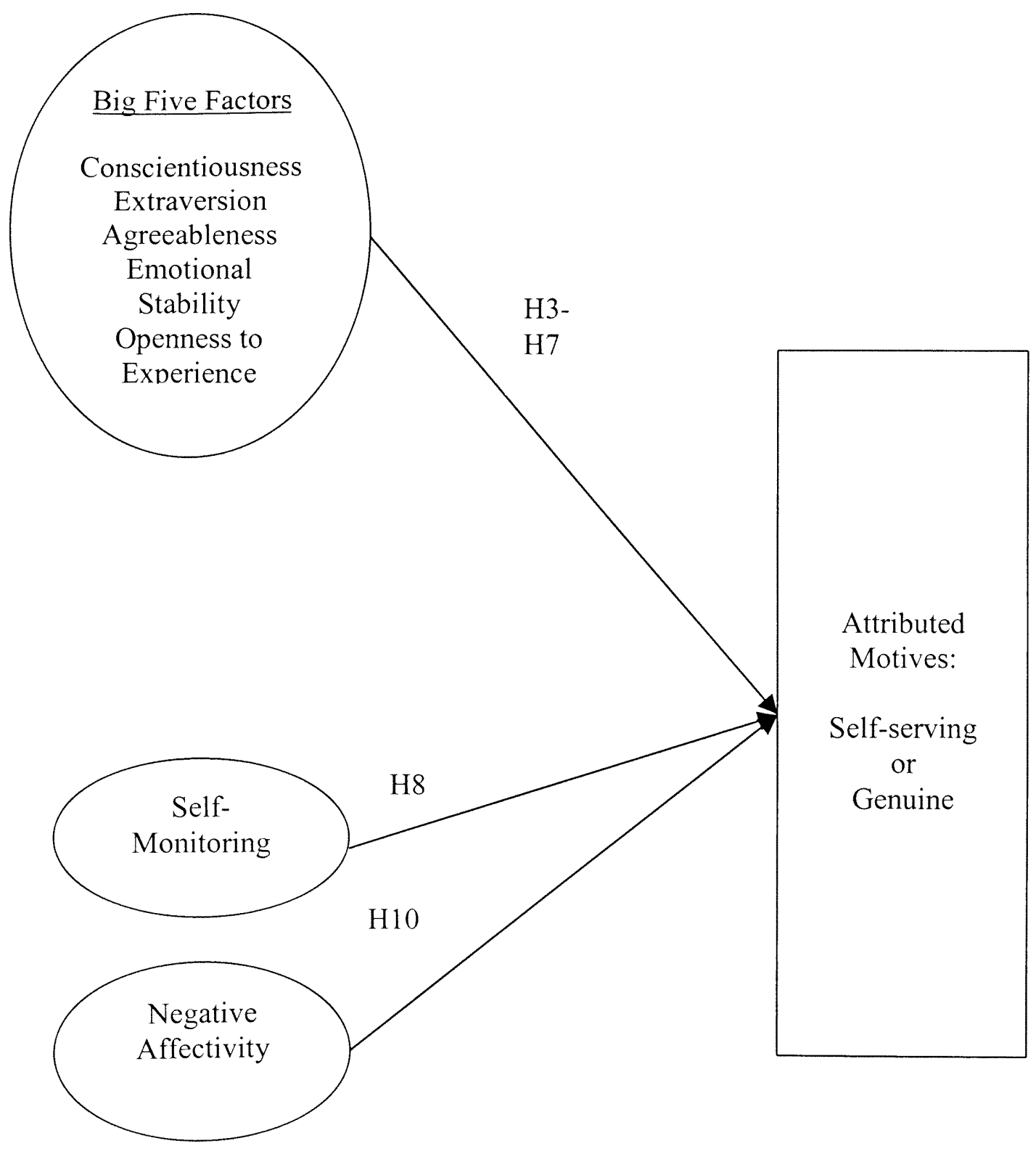


Figure 7 (cont'd)

Step 3
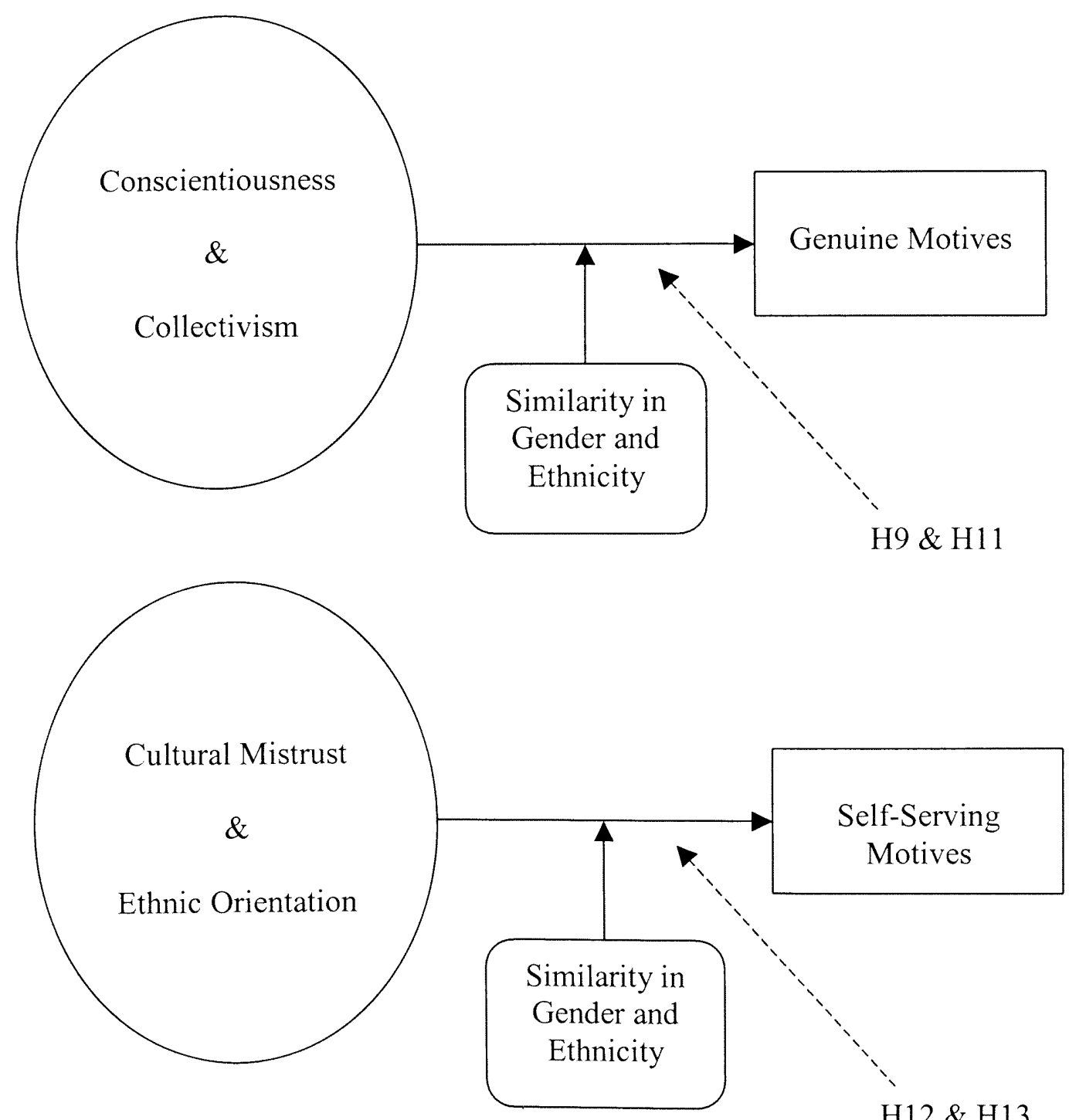

H12 \& H13 
Figure 7 (cont'd)

Step 4
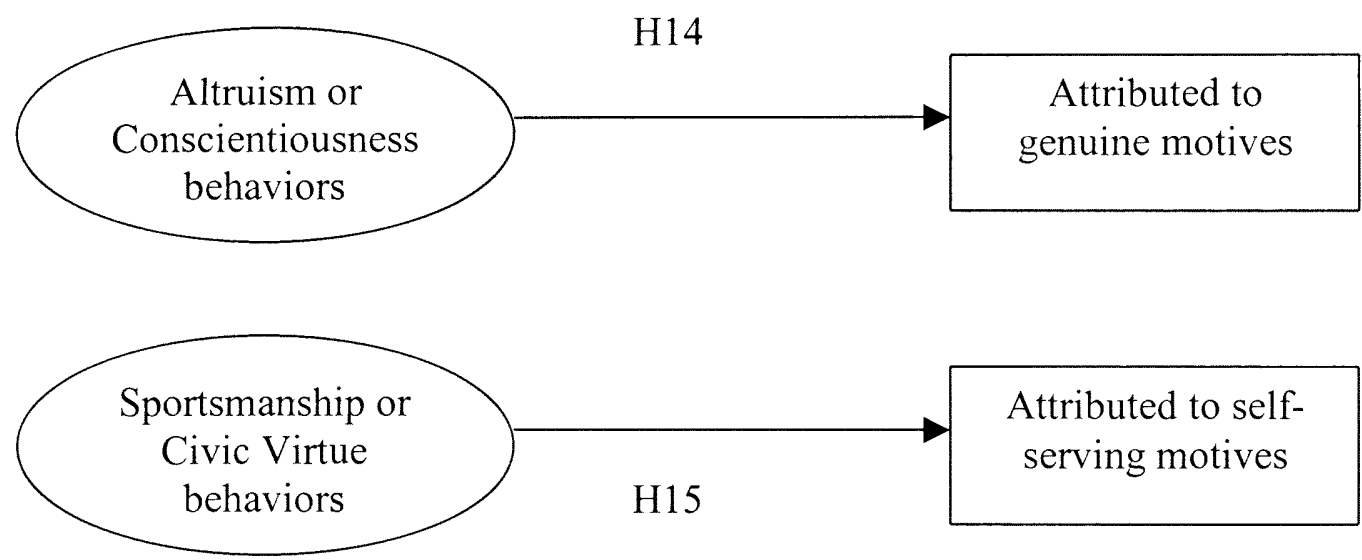
Figure 8

Plot of the Interaction between Conscientiousness and Similarity (C X S) when Predicting the Attribution of Genuine Motives

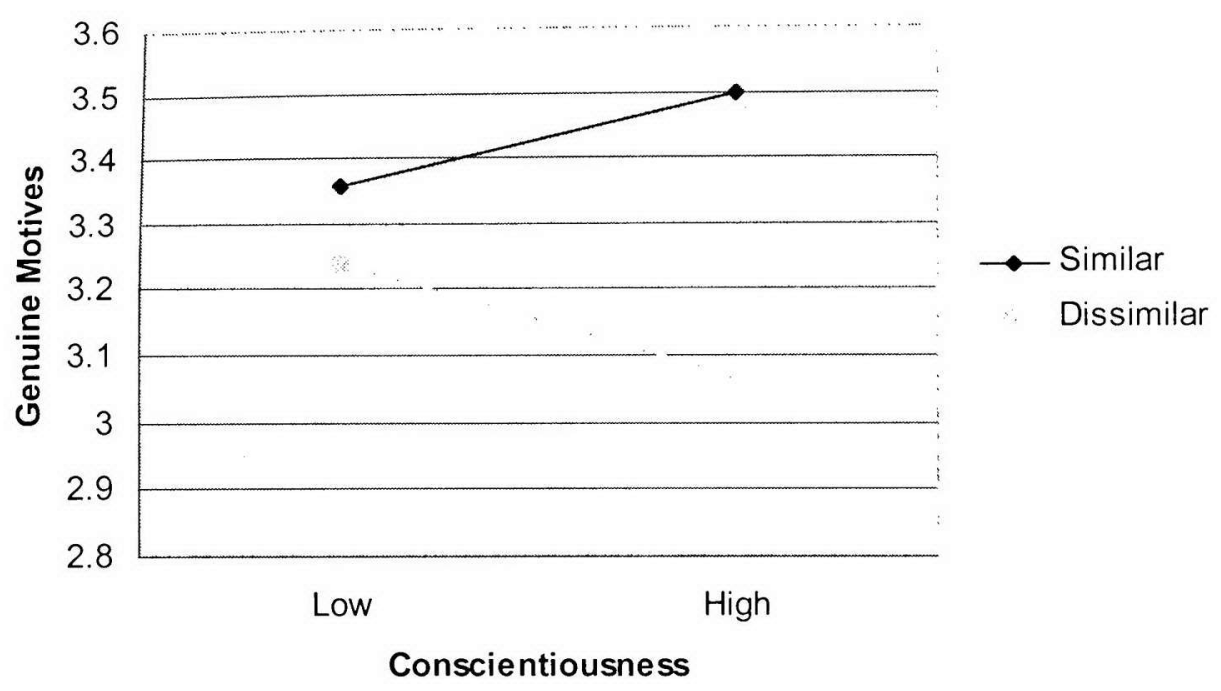

Figure 9

Plot of the Interaction between Ethnic Orientation and Similarity (EO X S) when Predicting the Attribution of Self-Serving Motives

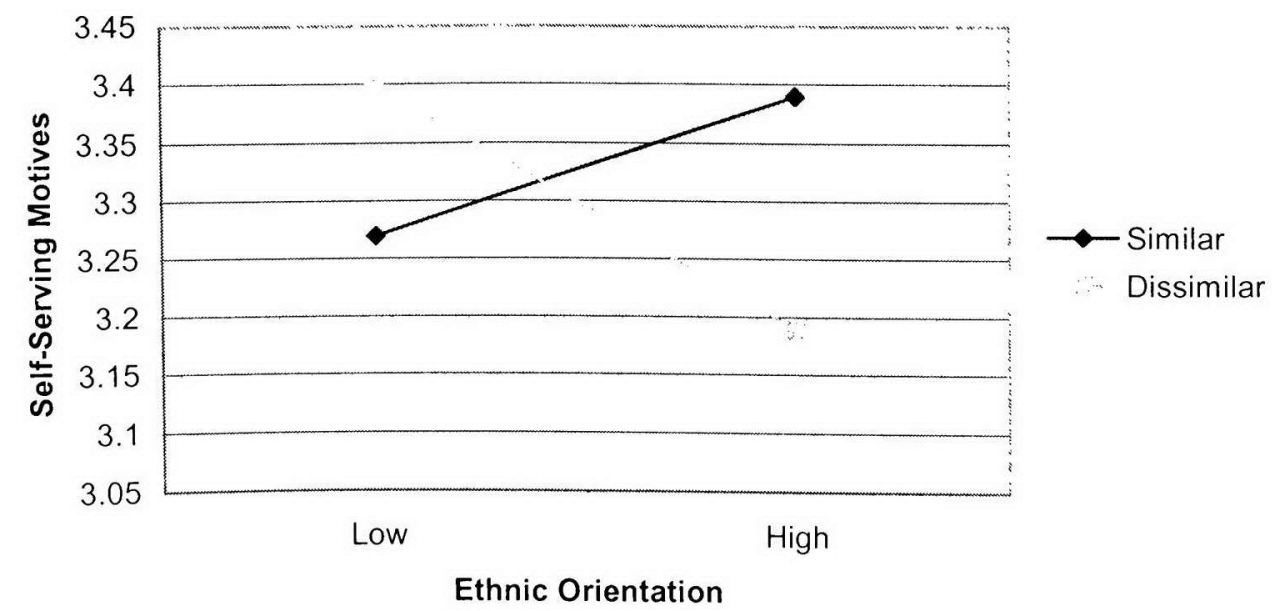




\section{List of References}

Alonso, A., Viswesvaran, C., \& Sanchez, J. I. (2000). The mediating effects of task and contextual performance: A meta-analysis. Paper present at $16^{\text {th }}$ annual conference for the Society for Industrial and Organizational Psychology, April 2001, San Diego, CA.

Austin, J.T. \& Villanova, P. (1992). The criterion problem: 1917-1992. Journal of Applied Psychology, 77, 836-874.

Baron, R. M. \& Kenny, D. A. (1986). The moderator-mediator variable distinction in social psychological research: Conceptual, strategic, and statistical considerations. Journal of Personality and Social Psychology, 51, 1173-1182.

Barrick, M. R. \& Mount, M. K. (1991). The Big Five personality dimensions and job performance: A meta-analysis. Personnel Psychology, 44, 1-26.

Bateman, T. S. \& Organ, D. W. (1983). Job satisfaction and the good soldier: The relationship between affect and employee "citizenship." Academy of Management Journal, 26, 587-595.

Bem, S. (1995). Motivation, cognition, and action. In I. Lubek \& R. van Hezewijk (Eds.), Trends and issues in theoretical psychology. New York, NY: Springer Publishing Company.

Bolino, M. C. (1999). Citizenship and impression management: Good soldiers or good actors? Academy of Management Review, 24, 82-98.

Borman, W. C., Hanson, M. A., \& Hedge, J. W. (1997). Personnel selection. Annual Review of Psychology, 48, 299-337.

Borman, W. C. \& Motowidlo, S. J. (1997). Task performance and contextual performance: The meaning for Personnel Selection Research. Human Performance, 10(2), 99-109.

---. (1993). Expanding the criterion domain to include elements of contextual performance. In N. Schmitt \& W. C. Borman (Eds.), Personnel selection in organizations. San Francisco: Jossey-Bass.

Borman, W. C., White, L. A., \& Dorsey, D. W. (1995). Effects of ratee task performance and interpersonal factors on supervisor and peer performance ratings. Journal of Applied Psychology, 80(1), 168-177.

Brief, A. P. \& Motowidlo, S. J. (1986). Prosocial organizational behaviors. Academy' of Management Review, 11, 710-725. 
Chatman, J. A., Polzer, J. T., Barsade, S. G., \& Neale, M. A. (1998). Being different yet feeling similar: The influence of demographic composition and organizational culture on work processes and outcomes. Administrative Science Quarterly, 43, 749-780.

Cohen, J. (1982). Set correlation as a general multivariate data-analytic method. Multivariate Behavioral Research, 17, 301-341.

Conway, J. M. (1999). Distinguishing contextual performance from task performance for managerial jobs. Journal of Applied Psychology, 84, 3-13.

Costa, J. P. \& McCrae, R. R. (1992). The five-factor model: Issues and applications (Special Topics). Journal of Personality, 60(2), 175-532.

DeChurch, L. A. \& Marks, M. A. (2001). Maximizing the benefits of task conflict: The role of conflict management. International Journal of Conflict Management, 12, 4-22.

Earle, M. G. (1926). The relation between personality and character traits and intelligence. Journal of Applied Psychology, 10, 453-461.

Eastman, K. K. (1994). In the eyes of the beholder: An attributional approach to ingratiation and organizational citizenship behavior. Academy of Management Journal, 37, 1379-1391.

Eysenck, H. J. \& Fulker, D. W. (1983). The components of type A behavior and its genetic determinants. Personality \& Individual Differences, 4, 499-505.

Festinger, L. (1957). A theory of cognitive dissonance. Evanston, IL: Row, Peterson.

Findley, H. M., Giles, W. F., \& Mossholder, K. W. (2000). Performance appraisal process and system facets: Relationships with contextual performance. Journal of Applied Psychology, 85, 634-640.

Funder, D. C. (1999). Personality judgement: A realistic approach to person perception. Riverside, CA: University of California Press.

Garson, B. E. \& Stanwyck, D. J. (1997). Locus of control and incentive in selfmanaging teams. Human Resource Development Quarterly, 8, 247-258.

George, J. M. \& Brief, A. P. (1992). Feeling good doing good: A conceptual analysis of the mood at work organizational spontaneity relationship. Psychological Bulletin, 112, 310-329. 
Giacalone, R. A. \& Rosenfeld, P. (1989). Impression management in organizations. Hillsdale, NJ: Lawrence Erlbaum Associates.

Goffman, E. (1959). The presentation of self in everyday life. Garden City, NY: Doubleday Anchor.

Goldberg, L. R. (1999). A broad-bandwidth, public domain, personality inventory measuring the lower-level facets of several five-factor models. In I. Mervielde, I. Deary, F. De Fruyt, \& F. Ostendorf (Eds.), Personality Psychology in Europe, Vol. 7 (pp. 7-28). Tilburg, The Netherlands: Tilburg University Press.

Goodman, S. A. (1996). Expanding the performance domain: Who says nice guys finish last? Paper presented at the 11 th Annual Conference of the Society for Industrial and Organizational Psychology, 1996, St. Louis, MO.

Graen, G. B., \& Uhl-Bien, M. (1998). Relationship-based approach to leadership: Development of leader-member exchange (LMX) theory of leadership over 25 years: Applying a multi-level multi-domain perspective. Leadership Quarterly, 6, 219-247.

Griffin, M. A., Neal, A., \& Neale, M. (2000). The contribution of task performance and contextual performance to effectiveness: Investigating the role of situational constraints. Applied Psychology: An International Review, 49, 517-533.

Hazebroeck, J. F., Howells, K., \& Day, A. (2001). Cognitive appraisals associated with high trait anger. Personality and Individual Differences, 30, 31-45.

Hofstede, G. (1991). Empirical models of cultural differences. In N. Bleichrodt \& J. D. P. Drenth (Eds). Contemporary issues in cross-cultural psychology. Netherlands: Swets \& Zeitlinger, Lisse.

Jones, E. E. (1964). Ingratiation: A social psychological analysis. New York: Appleton-Century-Crofts.

Jones, E. E., Kanouse, D. E., Kelley, H. H., Nisbett, R. E., Valins, S., \& Weiner, B. (1987). Attribution: Perceiving the causes of behavior. Morristown, NJ: General Scientific Press, Inc.

Jones, E. E. \& Pittman, T. S. (1982). Toward a general theory of strategic selfpresentation. In J. Suls (Ed.), Psychological perspectives on the self. Hillsdale, NJ: Lawrence-Erlbaum Associates.

Kelley, H. H. (1967). Attribution theory in social psychology. Paper presented at the Nebraska Symposium on Motivation, 1967, Lincoln, NE. 
Kiker, S. D. \& Motowidlo, S. J. (1999). Main and interaction effects of task and contextual performance on supervisory reward decisions. Journal of Applied Psychology, $84,602-609$.

Kumar, K. \& Beyerlein, M. (1991). Construction and validation of an instrument for measuring ingratiatory behaviors in organizational settings. Journal of Applied Psychology, 76, 619-627.

Leary, M. R. \& Kowalski, R. M. (1990). Impression management: A literature review and two-component model. Psychological Bulletin, 107, 34-47.

Matsumoto, D., Weissman, M. D., Preston, K., Brown, B. R., \& Kupperbusch, C. (1997). Context-specific measurement of individualism-collectivism on the individual level: The individualism-collectivism interpersonal assessment inventory. Journal of Cross-Cultural Psychology, 28, 743-767.

Mersman, J. L. \& Donaldson, S. I. (2000). Factors affecting the convergence of self-peer ratings on contextual and task performance. Human Performance, 13, 299-322.

Mook, D. G. (1983). In defense of external invalidity. American Psychologist, $38,379-387$.

Morrison, E. W. (1994). Role definitions and organizational citizenship behavior: The importance of the employee's perspective. Academy of Management Journal, 37, 1543-1567.

Motowidlo, S. J. \& Van Scotter, J. R. (1994). Evidence that task performance should be distinguished from contextual performance. Journal of Applied Psychology, $79,475-480$.

Muchinsky, P. M. (2002). Psychology Applied to Work. Belmont, CA: Wadsworth/Thomson Learning.

Organ, D. W. (1988; 1990). Organizational citizenship behavior: The good soldier syndrome. Lexington, MA: Lexington.

Organ, D. W. \& Ryan, K. (1995). A meta-analytic review of attitudinal and dispositional predictors of organizational citizenship behavior. Personnel Psychology, $48,775-802$.

Paulhus, D. L. (1984). Two-component models of socially desirable responding. Journal of Personality \& Social Psychology, 46, 598-609. 
Penner, L. A., Midili, A. R., \& Kegelmeyer, J. (1997). Beyond job attitudes: A personality and social psychology perspective on the causes of organizational citizenship behavior. Human Performance, 10, 111-131.

Podsakoff, P. M., MacKenzie, S. B., Moorman, R. H., \& Fetter, R. (1990). Transformational leader behaviors and their effects on followers' trust in leader, satisfaction, and organizational citizenship behaviors. Leadership Quarterly, 1, 107-142.

Quinn, J. L. (1969). Bias in performance appraisal. Personnel Administration, $32,40-43$.

Riordan, C. A. (1989). Images of corporate success. In R. A. Giacalone \& P. Rosenfeld (Eds.) Impression management in the organization, Hillsdale, NJ: Lawrence Erlbaum Associates.

Rioux, S. M. \& Penner, L. A. (2001). The causes of organizational citizenship behavior: A motivational analysis. Journal of Applied Psychology, 86, 889-916.

Sackett, P. R. (1998). Performance assessment in education and professional certification: Lessons for personnel selection? In M. D. Hakel (Ed.) Beyond multiple choice: Evaluating alternatives to traditional testing for selection. Mahwah, NJ: Lawrence Erlbaum Associates.

Sanchez, J. I., Alonso, A., Spector, P. E., \& Viswesvaran, C. (1999). Linguistics effects of cross-cultural bias on translated organizational measures: A study of bilinguals. Paper presented at the Academy of Management conference, August 1999, Toronto, Ontario, Canada. 119.

Schien, E. H. (1990). Organizational culture. American Psychologist, 45, 109-

Simons, T. L. \& Peterson, R. S. (2000). Task conflict and relationship conflict in top management teams: The pivotal role of intragroup trust. Journal of Applied Psychology, 85, 102-111.

Snyder, M. (1974). Self-monitoring of expressive behavior. Journal of Personality and Social Psychology, 30, 526-537.

Sternberg, R. J. \& Dobson, D. M. (1987). Resolving interpersonal conflicts: An analysis of stylistic consistency. Journal of Personality and Social Psychology, 52, 794812.

Stukas, A. A., Snyder, M., \& Clary, E. G. (1999). The effects of "mandatory volunteerism" on the intentions to volunteer. Psychological Science, 10, 59-64. 
Tang, T. L., Baldwin, L. J., \& Frost, A. G. (1997). Locus of control as a moderator of the self-reported performance feedback-personal sacrifice relationship. Personality and Individual Differences, 22, 201-211.

Triandis, H. C. (1995). A theoretical framework for the study of diversity. In M. M. Chemers \& S. Oskamp (Eds.). Diversity in organizations: New perspectives for a changing workplace. Thousand Oaks, CA: Sage Publications, Inc.

Tseng, M. S. (1972). Needs for achievement as a determinant of job proficiency, employability, and training satisfaction of vocational rehabilitation clients. Journal of Vocational Behavior, 2, 301-317.

Tsui, A. \& Gutek, B. (1999). Demographic differences in organizations: Current research and future directions. Maryland: Lexington Books.

Turner, J. C. (1987). Rediscovering the social group: A self-categorization theory. Mahwah, NJ: Lawrence Erlbaum Associates.

Van Scotter, J. R. \& Motowidlo, S. J. (1996). Evidence for two factors of contextual performance: Job dedication and interpersonal facilitation. Journal of Applied Psychology, 81, 525-531.

Warech, M. A., Smither, J. W., Reilly, R. R., Millsap, R. E., \& Reilly, S. P. (1998). Self-monitoring and 360-degree ratings. Leadership Quarterly, 9, 449-473.

Watson, D., Clark, L. A., \& Tellegen, A. (1988). Development and validation of brief measures of positive and negative affect: The PANAS scales. Journal of Personality and Social Psychology, 54, 1063-1070.

Williams, M. (2000). When is personality a predictor of performance? The moderating role of autonomy. Unpublished doctoral dissertation conducted at Florida International University, Miami, FL.

Wright, P. M., George, J. M., Farnsworth, S. R., \& McMahon, G. C. (1993). Productivity and extra-role behavior: The effects of goals and incentives on spontaneous helping. Journal of Applied Psychology, 78, 374-381.

Zimbardo, P. G., \& Leippe, M. R. (1991). The Psychology of Attitude Change and Social Influence. New York: McGraw-Hill. 
Appendices 


\section{LIST OF APPENDICES}

APPENDIX

PAGE

1. Manipulation Checks.

2. Similarity/Dissimilarity Questionnaire

3. Modified OCB Scale (A-F)

4. Individual Perceptions Inventory

5. The Positive and Negative Affectivity Scale 125

6. Self-Monitoring Scales 126

7. Individualism-Collectivism Scale 127

8. Demographic Information Survey 128

9. Informed Consent Letter 130

10. Ethnic Orientation 131

11. Cultural Mistrust Questionnaire 132

12. Similarity Option \#2 Questionnaire 133 


\section{Appendix A}

\section{Manipulation Checks}

Instructions: Please respond by indicating what you perceive the gender and ethnicity of each individual to be. Please circle the appropriate answer.

\begin{tabular}{|l|c|c|c|c|c|}
\hline \multicolumn{1}{|c|}{ Individual } & \multicolumn{2}{|c|}{ Gender } & \multicolumn{3}{c|}{ Ethnicity } \\
\hline $\begin{array}{l}\text { Chandler } \\
\text { Young }\end{array}$ & Male & Female & White & Hispanic & $\begin{array}{c}\text { African- } \\
\text { American }\end{array}$ \\
\hline $\begin{array}{l}\text { Margaret } \\
\text { Shorthouse }\end{array}$ & Male & Female & White & Hispanic & $\begin{array}{c}\text { African- } \\
\text { American }\end{array}$ \\
\hline $\begin{array}{l}\text { Takeisha } \\
\text { Jackson }\end{array}$ & Male & Female & White & Hispanic & $\begin{array}{c}\text { African- } \\
\text { American }\end{array}$ \\
\hline $\begin{array}{l}\text { Tyrone } \\
\text { Jefferson }\end{array}$ & Male & Female & White & Hispanic & $\begin{array}{c}\text { African- } \\
\text { American }\end{array}$ \\
\hline $\begin{array}{l}\text { Guillermo } \\
\text { Rodriguez }\end{array}$ & Male & Female & White & Hispanic & $\begin{array}{c}\text { African- } \\
\text { American }\end{array}$ \\
\hline $\begin{array}{l}\text { Consuelo } \\
\text { Hernandez }\end{array}$ & Male & Female & White & Hispanic & $\begin{array}{c}\text { African- } \\
\text { American }\end{array}$ \\
\hline
\end{tabular}




\section{Appendix B}

\section{Similarity/Dissimilarity Questionnaire}

Instructions: Please rank the following individuals from most similar to you in terms of gender and ethnicity to least similar to you in terms of gender and ethnicity. Please mark the most similar individual with " 1 " and the least similar with " 6 ".

\begin{tabular}{|c|c|}
\hline Rank & Individual \\
\hline & Chandler Young \\
\hline & Margaret Shorthouse \\
\hline & Takeisha Jackson \\
\hline & Tyrone Jefferson \\
\hline & Guillermo Rodriguez \\
\hline & Consuelo Hernandez \\
\hline
\end{tabular}




\section{Appendix C}

\section{Modified OCB Scale (A)}

Instructions: Please rate each of the following activities performed by the listed hypothetical coworker. When you rate please make sure to answer both dimensions: 1) Genuine Motives and 2) Self-serving Motives. Please indicate for each action both whether or not the individual is performing the action because of a self-serving motive as well for a genuine motive. Remember that a "genuine motive" is one that motivates action because it is in the individual's nature. A "self-serving motive" is one that motivates action because the individual has some other purpose, an ulterior motive (i.e., it is to their own personal benefit or gain). Please answer each question honestly. Please rate each dimension according to the following response scale:

$\begin{array}{lll}1 & = & \text { Strongly Disagree } \\ 2 & = & \text { Disagree } \\ 3 & = & \text { Neither Disagree nor Agree } \\ 4 & = & \text { Agree } \\ 5 & = & \text { Strongly Agree }\end{array}$

Chandler Young is a co-worker of yours. He listens to country music all day long. He has mentioned to you that it reminds him of home. His family came to the United States nearly 80 years ago. English is the only language he speaks. He does all the following:

\begin{tabular}{|c|c|c|}
\hline GM & Action & SSM \\
\hline & Covers for absent coworkers & \\
\hline & Helps others with workloads & \\
\hline & Helps orient new people & \\
\hline & Helps others who have been absent & \\
\hline & Helps others with problems & \\
\hline & Volunteers to do things & \\
\hline & Helps people outside the department & \\
\hline & Helps clients and visitors & \\
\hline & Begins shifts on time & \\
\hline & Is punctual every day & \\
\hline & Does not spend time on personal calls & \\
\hline & Does not engage in non-work related talk & \\
\hline & Comes to work early if needed & \\
\hline & Does not take excess time off & \\
\hline & Does not find fault with organization & \\
\hline & Does not complain about things & \\
\hline & Does not blow problems out of proportion & \\
\hline & Attends voluntary functions & \\
\hline & Attends voluntary meetings & \\
\hline & Helps organize get-togethers & \\
\hline & Keeps up with changes & \\
\hline & Reads announcements & \\
\hline & Assesses what is best for organization & \\
\hline
\end{tabular}


Instructions: Please rate each of the following activities performed by the listed hypothetical coworker. When you rate please make sure to answer both dimensions: 1) Genuine Motives and 2) Self-serving Motives. Please indicate for each action both whether or not the individual is performing the action because of a self-serving motive as well for a genuine motive. Remember that a "genuine motive" is one that motivates action because it is in the individual's nature. A "self-serving motive" is one that motivates action because the individual has some other purpose, an ulterior motive (i.e., it is to their own personal benefit or gain). Please answer each question honestly. Please rate each dimension according to the following response scale:

$\begin{array}{lll}1 & = & \text { Strongly Disagree } \\ 2 & = & \text { Disagree } \\ 3 & = & \text { Neither Disagree nor Agree } \\ 4 & = & \text { Agree } \\ 5 & = & \text { Strongly Agree }\end{array}$

Margaret Shorthouse is a co-worker of yours. She watches tapes of Martha Stewart on her lunch break. Often times she has mentioned to you that she enjoys watching it because she and Martha are so much alike. She speaks predominantly English. Her family has lived in the US for more than 100 years. She does all the following:

\begin{tabular}{|l|l|l|}
\hline GM & Action & SSM \\
\hline & Covers for absent coworkers & \\
\hline & Helps others with workloads & \\
\hline & Helps orient new people & \\
\hline & Helps others who have been absent & \\
\hline & Helps others with problems & \\
\hline & Volunteers to do things & \\
\hline Helps people outside the department & \\
\hline & Helps clients and visitors & \\
\hline & Begins shifts on time & \\
\hline & Is punctual every day & \\
\hline Does not spend time on personal calls & \\
\hline Does not engage in non-work related talk & \\
\hline & Comes to work early if needed & \\
\hline & Does not take excess time off & \\
\hline & Does not find fault with organization & \\
\hline & Does not complain about things & \\
\hline & Does not blow problems out of proportion & \\
\hline & Attends voluntary functions & \\
\hline & Attends voluntary meetings & \\
\hline & Helps organize get-togethers & \\
\hline & Keeps up with changes & \\
\hline & Reads announcements & \\
\hline & Assesses what is best for organization & \\
\hline
\end{tabular}


Instructions: Please rate each of the following activities performed by the listed hypothetical coworker. When you rate please make sure to answer both dimensions: 1) Genuine Motives and 2) Self-serving Motives. Please indicate for each action both whether or not the individual is performing the action because of a self-serving motive as well for a genuine motive. Remember that a "genuine motive" is one that motivates action because it is in the individual's nature. A "self-serving motive" is one that motivates action because the individual has some other purpose, an ulterior motive (i.e., it is to their own personal benefit or gain). Please answer each question honestly. Please rate each dimension according to the following response scale:

$\begin{array}{lll}1 & = & \text { Strongly Disagree } \\ 2 & = & \text { Disagree } \\ 3 & = & \text { Neither Disagree nor Agree } \\ 4 & = & \text { Agree } \\ 5 & = & \text { Strongly Agree }\end{array}$

Takeisha Jackson is a co-worker of yours. She watches tapes of Ricki Lake on her lunch break. Often times she has mentioned to you that she enjoys watching it because she and Latifah are so much alike. Takeisha is a sixth-generation American. She speaks English. She does all the following:

\begin{tabular}{|l|l|l|}
\hline GM & Action & SSM \\
\hline & Covers for absent coworkers & \\
\hline & Helps others with workloads & \\
\hline & Helps orient new people & \\
\hline & Helps others who have been absent & \\
\hline Helps others with problems & \\
\hline & Volunteers to do things & \\
\hline & Helps people outside the department & \\
\hline & Helps clients and visitors & \\
\hline & Begins shifts on time & \\
\hline Is punctual every day & \\
\hline Does not spend time on personal calls & \\
\hline Does not engage in non-work related talk & \\
\hline & Comes to work early if needed & \\
\hline & Does not take excess time off & \\
\hline & Does not find fault with organization & \\
\hline & Does not complain about things & \\
\hline & Does not blow problems out of proportion & \\
\hline Attends voluntary functions & \\
\hline & Attends voluntary meetings & \\
\hline & Helps organize get-togethers & \\
\hline & Keeps up with changes & \\
\hline & Reads announcements & \\
\hline & Assesses what is best for organization & \\
\hline
\end{tabular}


Instructions: Please rate each of the following activities performed by the listed hypothetical coworker. When you rate please make sure to answer both dimensions: 1) Genuine Motives and 2) Self-serving Motives. Please indicate for each action both whether or not the individual is performing the action because of a self-serving motive as well for a genuine motive. Remember that a "genuine motive" is one that motivates action because it is in the individual's nature. A "self-serving motive" is one that motivates action because the individual has some other purpose, an ulterior motive (i.e., it is to their own personal benefit or gain). Please answer each question honestly. Please rate each dimension according to the following response scale:

$\begin{array}{lll}1 & = & \text { Strongly Disagree } \\ 2 & = & \text { Disagree } \\ 3 & = & \text { Neither Disagree nor Agree } \\ 4 & = & \text { Agree } \\ 5 & = & \text { Strongly Agree }\end{array}$

Tyrone Jefferson is a co-worker of yours. He listens to hip-hop music all day long. He has mentioned to you that he enjoys it very much. He speaks English and understands very little Creole. His parents moved to the United States twenty years ago. He does all the following:

\begin{tabular}{|l|l|l|}
\hline GM & Action & SSM \\
\hline & Covers for absent coworkers & \\
\hline & Helps others with workloads & \\
\hline & Helps orient new people & \\
\hline & Helps others who have been absent & \\
\hline & Helps others with problems & \\
\hline & Volunteers to do things & \\
\hline & Helps people outside the department & \\
\hline & Helps clients and visitors & \\
\hline & Begins shifts on time & \\
\hline & Is punctual every day & \\
\hline & Does not spend time on personal calls & \\
\hline & Does not engage in non-work related talk & \\
\hline & Comes to work early if needed & \\
\hline & Does not take excess time off & \\
\hline & Does not find fault with organization & \\
\hline & Does not complain about things & \\
\hline & Does not blow problems out of proportion & \\
\hline & Attends voluntary functions & \\
\hline & Attends voluntary meetings & \\
\hline & Helps organize get-togethers & \\
\hline Keeps up with changes & \\
\hline & Reads announcements & \\
\hline & Assesses what is best for organization & \\
\hline & & \\
\hline
\end{tabular}


Instructions: Please rate each of the following activities performed by the listed hypothetical coworker. When you rate please make sure to answer both dimensions: 1) Genuine Motives and 2) Self-serving Motives. Please indicate for each action both whether or not the individual is performing the action because of a self-serving motive as well for a genuine motive. Remember that a "genuine motive" is one that motivates action because it is in the individual's nature. A "self-serving motive" is one that motivates action because the individual has some other purpose, an ulterior motive (i.e., it is to their own personal benefit or gain). Please answer each question honestly. Please rate each dimension according to the following response scale:

$\begin{array}{lll}1 & = & \text { Strongly Disagree } \\ 2 & = & \text { Disagree } \\ 3 & = & \text { Neither Disagree nor Agree } \\ 4 & = & \text { Agree } \\ 5 & = & \text { Strongly Agree }\end{array}$

Guillermo Rodriguez is a co-worker of yours. When at home he watches re-runs of his favorite Spanish soap opera, "Betty La Fea". He says it reminds him of his life when he was a little boy in Argentina. He immigrated to the United States nearly twenty-nine years ago. He speaks predominantly Spanish. He does all the following:

\begin{tabular}{|l|l|l|}
\hline GM & Action & SSM \\
\hline & Covers for absent coworkers & \\
\hline & Helps others with workloads & \\
\hline & Helps orient new people & \\
\hline & Helps others who have been absent & \\
\hline & Helps others with problems & \\
\hline & Volunteers to do things & \\
\hline & Helps people outside the department & \\
\hline & Helps clients and visitors & \\
\hline & Begins shifts on time & \\
\hline & Is punctual every day & \\
\hline & Does not spend time on personal calls & \\
\hline & Does not engage in non-work related talk & \\
\hline & Comes to work early if needed & \\
\hline & Does not take excess time off & \\
\hline & Does not find fault with organization & \\
\hline & Does not complain about things & \\
\hline & Does not blow problems out of proportion & \\
\hline & Attends voluntary functions & \\
\hline & Attends voluntary meetings & \\
\hline & Helps organize get-togethers & \\
\hline & Keeps up with changes & \\
\hline & Reads announcements & \\
\hline & Assesses what is best for organization & \\
\hline & & \\
\hline
\end{tabular}


Instructions: Please rate each of the following activities performed by the listed hypothetical coworker. When you rate please make sure to answer both dimensions: 1) Genuine Motives and 2) Self-serving Motives. Please indicate for each action both whether or not the individual is performing the action because of a self-serving motive as well for a genuine motive. Remember that a "genuine motive" is one that motivates action because it is in the individual's nature. A "self-serving motive" is one that motivates action because the individual has some other purpose, an ulterior motive (i.e., it is to their own personal benefit or gain). Please answer each question honestly. Please rate each dimension according to the following response scale:

$\begin{array}{lll}1 & = & \text { Strongly Disagree } \\ 2 & = & \text { Disagree } \\ 3 & = & \text { Neither Disagree nor Agree } \\ 4 & = & \text { Agree } \\ 5 & = & \text { Strongly Agree }\end{array}$

Consuelo Hernandez is a co-worker of yours. She likes to dance to Latin music including salsa and meringue. She came to America from Ecuador with her parents 40 years ago. She is a second-generation American. She speaks both English and Spanish. She does all the following:

\begin{tabular}{|l|l|l|}
\hline GM & Action & SSM \\
\hline & Covers for absent coworkers & \\
\hline & Helps others with workloads & \\
\hline & Helps orient new people & \\
\hline & Helps others who have been absent & \\
\hline & Helps others with problems & \\
\hline & Volunteers to do things & \\
\hline & Helps people outside the department & \\
\hline & Helps clients and visitors & \\
\hline & Begins shifts on time & \\
\hline & Is punctual every day & \\
\hline & Does not spend time on personal calls & \\
\hline & Does not engage in non-work related talk & \\
\hline & Comes to work early if needed & \\
\hline & Does not take excess time off & \\
\hline & Does not find fault with organization & \\
\hline & Does not complain about things & \\
\hline & Does not blow problems out of proportion & \\
\hline & Attends voluntary functions & \\
\hline & Attends voluntary meetings & \\
\hline & Helps organize get-togethers & \\
\hline Keeps up with changes & \\
\hline & Reads announcements & \\
\hline Assesses what is best for organization & \\
\hline
\end{tabular}




\section{Individual Perceptions Inventory (IPI)}

\section{Instructions:}

On the following pages, there are phrases describing people's behaviors. Please use the rating scale below to describe how accurately each statement describes you. Describe yourself as you generally are now, not as you wish to be in the future. Describe yourself as you honestly see yourself, in relation to other people you know of the same sex as you are, and roughly your same age. So that you can describe yourself in an honest manner, your responses will be kept in absolute confidence. Please read each statement carefully, and then choose the corresponding number on the scale.

\section{Response Options}

1: Very Inaccurate

2: Moderately Inaccurate

3: Neither Inaccurate nor Accurate

4: Moderately Accurate

5: Very Accurate

Am the life of the party.

Feel little concern for others.

Am always prepared.

Get stressed out easily.

Have a rich vocabulary.

Don't talk a lot.

Am interested in people.

Leave my belongings around.

Am relaxed most of the time.

Have difficulty understanding abstract ideas.

Feel comfortable around people.

Insult people.

Pay attention to details.

Worry about things.

Have a vivid imagination.

Keep in the background.

Sympathize with others' feelings.

Make a mess of things. 
Seldom feel blue.

Am not interested in abstract ideas.

Start conversations.

Am not interested in other people's problems.

Get chores done right away.

Am easily disturbed.

Have excellent ideas.

Have little to say.

Have a soft heart.

Often forget to put things back in their proper place.

Get upset easily.

Do not have a good imagination.

Talk to a lot of different people at parties.

Am not really interested in others.

Like order.

Change my mood a lot.

Am quick to understand things.

Don't like to draw attention to myself.

Take time out for others.

Shirk my duties.

Have frequent mood swings.

Use difficult words.

Don't mind being the center of attention.

Feel others' emotions.

Follow a schedule.

Get irritated easily.

Spend time reflecting on things.

Am quiet around strangers.

Make people feel at ease.

Am exacting in my work.

Often feel blue.

Am full of ideas. 


\section{Appendix E}

The Positive and Negative Affect Schedule scales (PANAS)

Instructions: Read each item and then mark the appropriate answer in the space next to that word. Indicate to what you generally feel this way, how you feel on the average. Use the following scale to record your answers.

1

2

3

4

5

Very

slightly

A little Moderately

Quite a

bit

Extremely

interested

distressed

excited

upset

strong

guilty

scared

hostile

enthusiastic

proud

irritable

alert

ashamed

inspired

nervous

determined

attentive

jittery

active

afraid 
Appendix F

\section{Self-monitoring scales}

Instructions: Please indicate whether or not each item is true of you. Please answer according to the following response scale:

$\begin{array}{lll}1 & = & \text { Never true of me } \\ 2 & = & \text { Sometimes true of me } \\ 3 & = & \text { Neutral } \\ 4 & = & \text { Sometimes false } \\ 5 & = & \text { Always false }\end{array}$

1) I am highly motivated to control how others see me.

2) I feel there are many good reasons to control how others see me.

3) Controlling others' impressions of me is not important to me.

4) In social situations, one of my goals is to get others to form a certain kind of impression of me.

5) I never try to lead others to form particular impressions of me.

6) I don't try to control the impression others form of me when I first meet them.

7) I try to affect others' impressions of me most of the time.

8) At parties and social gatherings, I do not attempt to say or do things that others will like.

9) When I feel that the image I am portraying isn't working, I can readily change it to something that does.

10) Even when it might be to my advantage, I have difficulty putting up a good front.

11) I am not particularly good at making other people like me.

12) In social situations, I have the ability to alter my behavior if I feel that something else is called for.

13) I feel a bit awkward in company and do not show up quite so well as I should. 14) I have trouble changing my behavior to suit different people and different situations.

15) Once I know what the situation calls for, it's easy for me to regulate my actions accordingly.

16) I have found that I can adjust my behavior to meet the requirements of any situation I find myself in. 


\section{Individualism-Collectivism Scale}

Instructions: Please rate each of the following value items on their importance to you as they relate towards interactions with colleagues. Please rate them using the following response scale:

$\begin{array}{lll}1 & = & \text { Not at all important } \\ 2 & = & \text { Unimportant } \\ 3 & = & \text { Somewhat unimportant } \\ 4 & = & \text { Somewhat important } \\ 5 & = & \text { Important } \\ 6 & = & \text { Very important }\end{array}$

To comply with direct requests from colleagues. To maintain self-control toward colleagues. To maintain status differences between you and colleagues To share credit for accomplishments of colleagues To share blame for failures of colleagues To respect and honor traditions and customs among colleagues To be loyal to colleagues To sacrifice your goals for colleagues To sacrifice your possessions for colleagues To respect elder colleagues To compromise your wishes to act together with colleagues To maintain harmonious relationships among colleagues To nurture or help colleagues To maintain a stable environment (e.g., the status quo) among colleagues To accept you position or role among colleagues To follow advice for major decisions from colleagues To exhibit "correct" behaviors (i.e., proper manners and etiquette), regardless of how you really feel, toward colleagues

To exhibit "correct" emotions, regardless of how you really feel, toward colleagues

To be like or similar to colleagues

To accept awards or recognition based only on age or position rather than merit from colleagues

To cooperate with colleagues

To communicate verbally with colleagues

To "save face" of colleagues

To follow norms established by colleagues

To identify yourself with colleagues 
Appendix $\mathrm{H}$

Demographic Information Survey

Instructions: Please answer the following demographic questions by circling the correct answer.

1. Sex:

1. Female 2. Male

2. The ethnic group that best reflects your background is:

1. Asian or Oriental

2. Non-Hispanic Black or Afro-American

3. Hispanic

4. Non-Hispanic White

5. Other

3. Your parents were:

1. Both born in the Continental U.S.

2. One of them was born in the Continental U.S., the other outside.

3. Both of them were born outside the Continental U.S.

4. Indicate the place in which you grew up:

1. Only in the Continental U.S.

2. Mostly in the Continental U.S.

3. Half in the Continental U.S., half outside.

4. Mostly outside the Continental U.S.

5. Only outside the Continental U.S.

5. Which one of the following groups do you see as closest to you?

1. Cuban-Americans

2. North Americans

3. Latin Americans

4. Asian-Americans

5. Other

6. Indicate your approximate age:
1. Less than 20.
2. 20 to 29 .
3. 30 to 39 .
4. 40 to 49 .
5. More than 49 .

7. Indicate your marital status:
1. Single
2. Married
3. Divorced
4. Widowed 
8. Indicate your current employment status:
1. Part-time
2. Full-time
3. Not currently working

9. What is the maximum level of education you have completed?

1. Grammar school

2. High school

3. University or college level studies

10. How long have you been working for your current employer?
1. Less than 2 years
2. 2 to 5 years
3. 6 to 10 years
4. 11 to 15 years
5. More than 15 years

11. In the company you currently work for:

1. Almost everyone is Hispanic

2. A majority of people are Hispanic

3. Approximately half of them are Hispanic

4. A majority of people are not Hispanic

5. Almost everyone is not Hispanic

12. What language do you prefer to speak?
1. Spanish
2. English
3. Creole
4. Other 


\section{Appendix I}

\section{CONSENT TO PARTICIPATE IN A RESEARCH STUDY}

I freely and voluntarily consent to be a participant in the research project entitled "The Attribution of Motives to Organizational Citizenship Behaviors: The Influence of Personality, Gender and Ethnicity on Ratings" to be conducted at Florida International University during the summer and fall semesters, 2002, with Alexander Alonso as the principal investigator. I have been told that this experiment will last approximately one hour. I have been told that this experiment will require me to answer questionnaires pertaining to specific job behaviors and attitudes. I will be participating in this study with approximately 200 other students.

I understand that the purpose of this research is to examine how individuals attribute motives to specific work behaviors by filling out a battery of survey-type instruments.

I understand that there are no known risks or benefits involved in my participation in this experiment. I have been told that my responses will be kept confidential. A code number will be used to identify all scores, and my individual performance will not be revealed to anyone without my express written consent.

I understand that I may withdraw my consent and discontinue participation in this research project at any time with no negative consequences. I have been given the right to ask questions concerning the procedure, and have any questions answered to my satisfaction.

I understand that if I would like further information about this research project I should contact project director Alexander Alonso at (305) 348-2880. I have been offered a copy of this informed consent form. I also understand that if I have any questions concerning the rights of human subjects or injury that I feel I have incurred related to this study, I may contact Dr. Bernard Gertsman, the Chairperson of the Institutional Review Board at Florida International University at (305) 348-3115 or (305) 348-2494.

I have read and understand the above.

Participant's signature

Printed Name

Date

I have explained and defined in detail the research procedure in which the participant has agreed to participate, and have offered him/her a copy of this informed consent form.

Principal Investigator's signature

Date 


\section{Appendix J}

\section{Ethnic Orientation}

Instructions: We are interested in your Ethnic Identity. By ethnic identity we mean the importance you attach to the personal identity you just described. Please use the numbers on the following scale to indicate your level of agreement with each statement.

$\begin{array}{lll}1 & = & \text { Strongly Disagree } \\ 2 & = & \text { Disagree } \\ 3 & = & \text { Neither Disagree nor Agree } \\ 4 & = & \text { Agree } \\ 5 & = & \text { Strongly Agree }\end{array}$

1) You have a strong sense of yourself as a member of your ethnic/racial group.

2) You identify with other people from your ethnic/racial group.

3) Most of your close friends are from your own ethnic/racial group.

4) Your ethnic/racial heritage is important in your life.

5) You are more comfortable in social settings where others are present from your ethnic/racial group.

6) You are proud of your ethnic/racial heritage.

7) Your ethnic/racial group had a lot to do with who you are today.

8) Your ethnic/racial background plays a big part in how you interact with others.

9) You prefer to date people from your ethnic/racial group.

10) Your values, attitudes and behaviors are shared by most members of your ethnic/racial group.

11) You consider yourself Hispanic or Latino(a).

12) You consider yourself Non-Hispanic Black or Afro-American.

12) You consider yourself to be American.

13) You consider yourself to be multi-ethnic. 


\section{Appendix K}

\section{Cultural Mistrust Questionnaire}

Instructions: Please answer the following questions by responding according to the following response scale. Please answer the questions as honestly as possible. Thank you.

$\begin{array}{lll}1 & = & \text { Strongly Disagree } \\ 2 & = & \text { Disagree } \\ 3 & = & \text { Neither Disagree nor Agree } \\ 4 & = & \text { Agree } \\ 5 & = & \text { Strongly Agree }\end{array}$

\begin{tabular}{|l|l|}
\hline Answer & Item \\
\hline & $\begin{array}{l}\text { Based on your experience, you would be suspicious of a stranger who tries to be } \\
\text { friendly if that person was Black. }\end{array}$ \\
\hline & How about if that person was Hispanic? \\
\hline How about if that person was White? & Based on your experience, you would trust a co-worker who was Black. \\
\hline How about if that person was Hispanic? \\
\hline How about if that person was White? \\
\hline $\begin{array}{l}\text { Based on your experience, a person could be counted on to do what they say if that } \\
\text { person was Black. }\end{array}$ \\
\hline How about if that person was Hispanic? \\
\hline How about if that person was White?
\end{tabular}




\section{Appendix L}

\section{Similarity Option \#2 Questionnaire}

1) Ethnically speaking, please rate how similar/dissimilar you are from "Chandler Young". Please circle the appropriate answer.

2) Ethnically speaking, please rate how similar/dissimilar you are from "Margaret Shorthouse". Please circle the appropriate answer.

3) Ethnically speaking, please rate how similar/dissimilar you are from "Takeisha Jackson". Please circle the appropriate answer.

4) Ethnically speaking, please rate how similar/dissimilar you are from "Tyrone Jefferson". Please circle the appropriate answer.

5) Ethnically speaking, please rate how similar/dissimilar you are from "Guillermo Rodriguez". Please circle the appropriate answer.

6) Ethnically speaking, please rate how similar/dissimilar you are from "Consuelo Hernandez". Please circle the appropriate answer.

1

Very

Dissimilar
2

Moderately

Dissimilar
3

4

5

\begin{abstract}
Neither
\end{abstract}
Dissimilar nor Similar
Moderately

Similar
Very

Similar 


\section{VITA}

\section{ALEXANDER ALONSO}

January 27,1976

1998

2000

1999-2002

$1998-2000$

$1998-2002$

2002
Born, Hialeah, FL

B. A. in Psychology

Florida International University

Miami, FL

M.S. in Industrial/Organizational Psychology Florida International University

Miami, FL

Assistant Project Manager

US Air Force (AFSOR) Grant

Integrated Multi-Team Decision Making

Assistant Project Manager

STEM Project

On-the-job Training and the Role of Mentoring in Educational Settings

Project Manager

Linguistic Effects in Translated Organizational Measures

Intern

City of Miami

Human Resources Department

Testing and Validation Division 


\section{PUBLICATIONS \& PRESENTATIONS}

Van Rooy, D. L., Alonso, A., \& Fairchild, Z. (Revise \& Re-submit). In with the new, out with the old? Has the technological revolution eliminated the traditional job search process? International Journal of Selection and Assessment, 11 .

Society for Industrial/Organizational Psychology, Orlando, FL, April 2003 The role of locus of control on test-retest reliability estimates.

Society for Industrial/Organizational Psychology, Orlando, FL, April 2003 Teams leading teams: An experimental investigation of leadership in multi-team systems.

Society for Industrial/Organizational Psychology, Orlando, FL, April 2003 The importance of goal hierarchies and teamwork processes for multi-team effectiveness.

Society for Industrial/Organizational Psychology, Orlando, FL, April 2003 Diversity in action teams.

Academy of Management, Denver, CO, August 2002

Examining the influence of multiple forms of diversity on ieam outcomes over time.

Society for Industrial/Organizational Psychology, San Diego, CA, April 2001 Mediating roles of task and contextual performance on predictor validity: A metaanalysis.

Society for Industrial/Organizational Psychology, San Diego, CA, April 2001 The role of mentoring in on-the-job training.

Academy of Management, Toronto, ON, Canada, August 2000 Linguistic effects in translated organizational meas,ures: A study of bilinguals. 